João Pedro Aiex Naccache

\title{
Desenvolvimento de emulsões modelo para mimetizar propriedades físicas de emulsões de petróleo
}

Dissertação de Mestrado

Dissertação apresentada como requisito parcial para obtenção do grau de Mestre pelo Programa de Pós-Graduação em Engenharia Mecânica do Departamento de Engenharia Mecânica da PUC-Rio.

Orientador: Prof. Paulo Roberto de Souza Mendes 


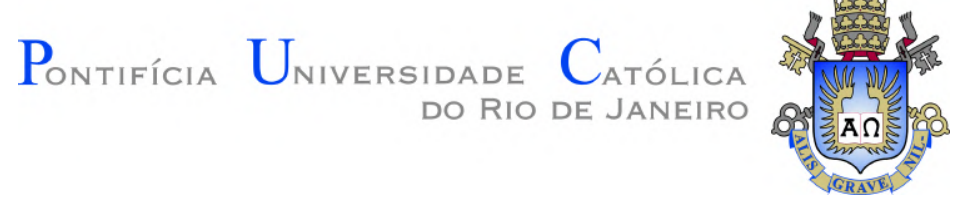

João Pedro Aiex Naccache

\begin{abstract}
Desenvolvimento de emulsões modelo para mimetizar propriedades físicas de emulsões de petróleo
\end{abstract}

Dissertação apresentada como requisito parcial para obtenção do grau de Mestre pelo Programa de Pós-Graduação em Engenharia Mecânica da PUC-Rio. Aprovada pela Comissão Examinadora abaixo.

Prof. Paulo Roberto de Souza Mendes

Orientador

Departamento de Engenharia Mecânica - PUC-Rio

Dr. Erick Fabrizio Quintella Andrade Coelho CENPES - Petrobras

Prof. Márcio da Silveira Carvalho

Departamento de Engenharia Mecânica - PUC-Rio 
Todos os direitos reservados. É proibida a reprodução total ou parcial do trabalho sem autorização da universidade, do autor e do orientador.

João Pedro Aiex Naccache

Graduou-se em Engenharia Química na Pontifícia Universidade Católica do Rio de Janeiro em 2017.

Ficha Catalográfica

Naccache, João Pedro A.

Desenvolvimento de emulsões modelo para mimetizar propriedades físicas de emulsões de petróleo / João Pedro Aiex Naccache; orientador: Paulo Roberto de Souza Mendes. - Rio de Janeiro : PUC-Rio, Departamento de Engenharia Mecânica, 2020.

114 f.: il. color.; $30 \mathrm{~cm}$

1. Dissertação (mestrado) - Pontifícia Universidade Católica do Rio de Janeiro, Departamento de Engenharia Mecânica.

Inclui bibliografia

1. Engenharia Mecânica - Teses

2. Emulsão; 3. Petróleo; 4. Propriedades fisicas; 5. Óleo modelo; 6. Emulsão modelo;

I. de Souza Mendes, Paulo Roberto. II. Pontifícia Universidade Católica do Rio de Janeiro. Departamento de Engenharia Mecânica. III. Título. 


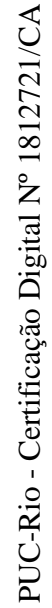

À minha família. 


\section{Agradecimentos}

Ao meu orientador, Paulo Roberto de Souza Mendes, pela toda confiança, contribuição e ensinamentos dados ao longo da execução deste trabalho.

À toda minha família, principalmente meus pais e irmã, por toda compreensão, apoio e carinho, sem vocês não estaria aqui hoje. Em especial à minha mãe, por ser minha inspiração e maior exemplo com toda sua dedicação e amor incondicionais.

Aos amigos do GReo, por todas contribuições, trocas de experiências e debates reflexivos que tornaram esse trabalho menos árduo, em particular ao Pedro, Elias, Camila, Lorena, Priscilla, Gustavo, Roberta, Bruno, Luzirene, Alexandre, Behbood.

Ao grupo Emulsificantes, Daniel, João Pedro Cunha, Patrícia, Tatiana, por toda troca de conhecimento e discussões sobre esse complexo mundo das emulsões. Em especial, à Eliana e Ricardo por todas as contribuições, conversas e ideias dadas ao longo deste trabalho, muito obrigado!

Aos meus amigos da vida, Fernanda, Hugo, João, Léo, Zeca, Daniel, Vitor, Ian, Matheus, por toda a ajuda e momentos ao lado de vocês.

À Petrobras, FAPERJ e à PUC-Rio, pelos auxílios concedidos, sem os quais este trabalho não poderia ter sido realizado. Além disso, o presente trabalho foi realizado com apoio da Coordenação de Aperfeiçoamento de Pessoal de Nível Superior - Brasil (CAPES) - Código de Financiamento 001. 


\section{Resumo}

Naccache, João Pedro A.; de Souza Mendes, Paulo Roberto. Desenvolvimento de emulsões modelo para mimetizar propriedades físicas de emulsões de petróleo. Rio de Janeiro, 2020. 114p. Dissertação de Mestrado - Departamento de Engenharia Mecânica, Pontifícia Universidade Católica do Rio de Janeiro.

Ao longo do tempo de vida de um poço de petróleo, a produção de óleo pode sofrer uma variação significativa. Sendo assim, esta que, anteriormente, era composta em sua maioria de petróleo pode acabar se tornando em uma mistura de água e óleo, gerando a ocorrência de emulsões no sistema. Contudo, a presença dessas emulsões torna-se um problema recorrente para a indústria de petróleo, uma vez que acarretam em um aumento de custos de transporte e processamento do óleo.

Com isso, a verificação da eficiência de separação primária de emulsões ocorre, normalmente, através da utilização de emulsões reais retiradas dos campos. Todavia, tais emulsões são fluidos que podem apresentar comportamentos tóxicos, voláteis e inflamáveis [1]. Somado a isso, a falta da confiabilidade necessária para a aferição da eficiência dessas tecnologias de separação uma vez que há uma extrema dificuldade de repetibilidade das emulsões sintetizadas a partir do óleo cru, induz à necessidade de utilização de fluidos modelos que possuam comportamentos similares ao petróleo.

O objetivo geral deste trabalho é, sobretudo, aprofundar o estudo das emulsões de petróleo e desenvolver um método para a síntese de fluidos de trabalho com características reológicas, de formação e de estabilidade semelhantes às de óleos e emulsões reais encontrados no campo. Assim, para o desenvolvimento deste trabalho, óleos modelo com características macroscópicas similares a dois diferentes petróleos (A e B) foram sintetizados. Verificou-se, então, que as emulsões modelo obtiveram um comportamento mais similar às emulsões formadas a partir do petróleo A. Contudo, tais sistemas apresentaram um fenômeno de shear-thinning no regime semi diluído, devido, sobretudo, a diferenças qualitativas na estrutura dos agentes tensoativos das emulsões de petróleo e os surfactantes comerciais utilizados em emulsões modelo.

\section{Palavras-chave}

Emulsão; Petróleo; Propriedades fisicas; Óleo modelo;

Emulsão modelo; 


\section{Abstract}

Naccache, João Pedro A.; de Souza Mendes, Paulo Roberto(Advisor). Development of model oil emulsions to mimetize petroleum emulsions' physical properties. Rio de Janeiro, 2020. 114p. MsC Thesis - Departamento de Engenharia Mecânica, Pontifícia Universidade Católica do Rio de Janeiro.

Over the life of an oil well, oil production can vary significantly. The production that initially mostly composed of petroleum eventually becomes a combination of water and oil, causing the occurrence of emulsions in the system. The presence of these emulsions becomes a recurring problem for the oil industry as they lead to increase in transportation and oil processing costs.

Verification of the primary separation efficiency of emulsions usually occurs with the use of emulsions taken from the field. However, such emulsions are fluids that may exhibit toxic, volatile and flammable behaviors [1]. In addition, the measurement of separation efficiency technologies is typically not reliable due to an extreme difficulty in obtaining repeatability of emulsions synthesized from crude oil, which induces the need to use model fluids whose behavior is similar to petroleum.

The general objective of this work is to deepen the study of petroleum emulsions and develop a method for the synthesis of working fluids with rheological characteristics, formation and stability similar to those of real oils and emulsions found in the field. Therefore, for the development of this work, model oils with macroscopic characteristics very close to two different crude oils (A and B) were synthetized. It was found that model emulsions possessed very similar behavior of A-oil emulsions. However, model emulsions showed shear thinning phenomenon in the semi-diluted regime, probably due to qualitative differences between the indigenous surfactants of real emulsions and commercial surfactants used in model emulsions.

\section{Keywords}

Emulsion; Petroleum; Physical properties; Model oil; $\quad$ Model emulsion; 


\section{Sumário}

$\begin{array}{ll}\text { Lista de Figuras } & 11\end{array}$

$\begin{array}{ll}\text { Lista de Tabelas } & 14\end{array}$

1 Introdução $\quad 15$

1.1 Motivação . . . . . . . . . . . . . . . . 16

1.2 Objetivos . . . . . . . . . . . . . . . 17

1.3 Organização do trabalho . . . . . . . . . . . . . 17

2 Revisão bibliográfica $\quad 18$

2.1 Petróleo e sua composição . . . . . . . . . . . . . . . . . 18

2.1.1 Propriedades do petróleo . . . . . . . . . . . . . . . . . . 20

2.2 Emulsão . . . . . . . . . . . . . . . . . . . . . . . 21

2.2.1 Emulsões de petróleo . . . . . . . . . . . . . . . . . . . 22

2.2.2 Estudo termodinâmico das emulsões . . . . . . . . . . . . . . . 23

2.2.2.1 A interface de Gibbs e outros fenômenos . . . . . . . . . . . . 23

2.2.2.2 Formação de emulsões e termodinâmica . . . . . . . . . . . 25

2.2.3 Forças de interação entre as gotas . . . . . . . . . . . . . . 26

2.2.3.1 Forças de van der Waals . . . . . . . . . . . . . . . . 26

2.2.3.2 Repulsão eletrostática . . . . . . . . . . . . . . . . . . 28

2.2.3.3 Teoria DLVO . . . . . . . . . . . . . . . . . . . 30

2.2.3.4 Repulsão estérica . . . . . . . . . . . . . . . . . . . . . . 31

2.2.3.5 Atração por depleção . . . . . . . . . . . . . . . . . . . 32

2.2.4 Desestabilização das emulsões . . . . . . . . . . . . . . . . . 33

2.2.4.1 Creaming e sedimentação . . . . . . . . . . . . . . . . . 34

2.2.4.2 Coalescência . . . . . . . . . . . . . . . 36

2.2.4.3 Floculação . . . . . . . . . . . . . . . . . . . . 37

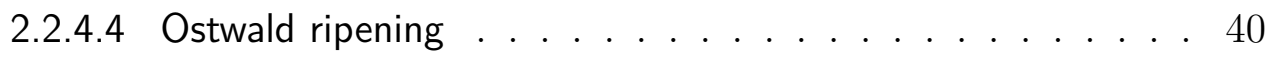

2.2.4.5 Inversão de fase . . . . . . . . . . . . . . . . . . . 40

2.2.4.6 Demais fatores que influenciam na desestabilização das emulsões . . . . . . . . . . . . . . . . 4 41

2.3 Mecanismos de estabilização de emulsões . . . . . . . . . . . . . . . 41

2.3.1 Efeito Gibbs-Marangoni . . . . . . . . . . . . . . . . . . . . . . 41

2.3.2 Outros métodos de estabilização de emulsões . . . . . . . . . . 43

2.4 Surfactantes . . . . . . . . . . . . . . . . . . . . 43

2.4.1 Tipos de surfactantes . . . . . . . . . . . . . . . . . . 45

2.4.1.1 Não-iônicos . . . . . . . . . . . . . . . . . . . 45

2.4.1.2 Aniônicos . . . . . . . . . . . . . . . . 46 
2.4.1.3 Catiônicos . . . . . . . . . . . . . . . . . 46

2.4.1.4 Anfóteros . . . . . . . . . . . . . . . . . 46

2.4.2 Concentração Micelar Crítica (CMC) . . . . . . . . . . . . . 47

2.4.3 Balanço Hidrofílico-Lipofílico (HLB) . . . . . . . . . . . . . 49

2.5 Reologia . . . . . . . . . . . . . . . . . . 51

2.5.1 Reologia de emulsões . . . . . . . . . . . . . . . . 53

2.5.1.1 Equação de Krieger-Dougherty . . . . . . . . . . . . . . . . 55

2.5.2 Aspectos relevantes na reologia das emulsões . . . . . . . . . . 57

2.6 Fluido modelo . . . . . . . . . . . . . . . . . . . . . . . . 61

2.7 Equipamentos de separação das emulsões . . . . . . . . . . . . . . 62

2.7.1 Separador gravitacional . . . . . . . . . . . . . . 62

2.7.2 Tratador eletrostático . . . . . . . . . . . . . . . . . 64

$3 \quad$ Materiais e métodos $\quad 66$

3.1 Materiais utilizados . . . . . . . . . . . . . . 66

3.2 Método experimental . . . . . . . . . . . . . . . 66

3.2.1 Pré Tratamento do Petróleo . . . . . . . . . . . . . . . . 66

3.2.2 Procedimentos Gerais do Petróleo . . . . . . . . . . . . . . . 68

3.2.2.1 Viscosidade . . . . . . . . . . . . . . . . . . 68

3.2.2.2 Densidade . . . . . . . . . . . . . . . . . . . 69

3.2.2.3 Tensão Interfacial . . . . . . . . . . . . . . . . . . . . . 69

3.2.3 Procedimentos geral das emulsões . . . . . . . . . . . . . 71

3.2.3.1 Processo de emulsificação . . . . . . . . . . . . . . . . 71

3.2.3.2 Síntese da emulsão real . . . . . . . . . . . . . . . . . . . 72

3.2.3.3 Síntese da emulsão modelo . . . . . . . . . . . . . . . . . . 74

3.2.4 Caracterização das emulsões . . . . . . . . . . . . . . . . . . 79

3.2.4.1 Caracterização Reológica . . . . . . . . . . . . . . . . . . . 79

3.2.4.2 Concentração efetiva . . . . . . . . . . . . . . . . . . . . . 79

3.2.4.3 Distribuição do Tamanho de Gotas (DTG) . . . . . . . . . . 80

4 Resultados e discussão $\quad 83$

4.1 Caracterização físico-química dos petróleos . . . . . . . . . . . . 83

4.1 .1 Composição dos petróleos . . . . . . . . . . . . . . . . . 83

4.1 .2 Massa específica . . . . . . . . . . . . . . . . . . 84

4.1 .3 Caracterização reológica . . . . . . . . . . . . . . . . . . . 84

4.1 .4 Tensão interfacial . . . . . . . . . . . . . . . . . . . . . . 85

4.2 Caracterização das emulsões de petróleo . . . . . . . . . . . . . 85

4.2.1 Concentração efetiva . . . . . . . . . . . . . . . . . . 85

4.2.2 Propriedades . . . . . . . . . . . . . . . . . . . 87

4.2.2.1 Viscosidade . . . . . . . . . . . . . . . . . 87

4.2.2.2 Distribuição de tamanho de gotas . . . . . . . . . . . . . . 89 
4.3 Caracterização de óleos modelo . . . . . . . . . . . . . . . . 92

4.4 Caracterização das emulsões modelo - A . . . . . . . . . . . . . . . 96

4.4.1 Concentração efetiva . . . . . . . . . . . . . . . . . . . . . 96

4.4 .2 Propriedades . . . . . . . . . . . . . . . . . . . 97

4.4.2.1 Viscosidade . . . . . . . . . . . . . . . . . . . . 97

4.4.2.2 Distribuição de tamanho de gotas . . . . . . . . . . . . . . 99

4.5 Caracterização das emulsões modelo - B . . . . . . . . . . . . . . . 101

4.5.1 Concentração efetiva . . . . . . . . . . . . . . . . . . . . . 101

4.5.2 Propriedades . . . . . . . . . . . . . . . . . . . . 103

4.5.2.1 Viscosidade . . . . . . . . . . . . . . . . . . 103

4.5.2.2 Distribuição de tamanho de gotas . . . . . . . . . . . . . . 105

5 Conclusão 107

5.1 Trabalhos futuros . . . . . . . . . . . . . . . . . 108

6 Referências bibliográficas 110 


\section{Lista de Figuras}

Figura 2.1 - (A) Classificação básica dos tipos de emulsões (B) Casos de combinações de dois tipos de emulsões . . . . . . . . . 21

Figura 2.2 - Representação da interface entre duas fases I e II.

A) Sistema ideal B) Sistema Real . . . . . . . . . . . . . 23

Figura 2.3 - Gráfico representativo da variação da energia de atração de Van der Waals com relação à distância (h). . . . . . . 27

Figura 2.4 - Representação da dupla camada elétrica. . . . . . . . . . 29

Figura 2.5 - Curva de energia de interação em função da distância na teoria DLVO. . . . . . . . . . . . . . . . . 31

Figura 2.6 - Processos de desestabilização de emulsões. . . . . . . . . 34

Figura 2.7 - Representação do processo de coalescência das gotas. . . . 36

Figura 2.8 - Representação do processo de deformação de duas gotas durante o fenômeno da floculação. Um filme líquido de espessura h pode ser formado. . . . . . . . . . . . . . 37

Figura 2.9 - Representação do Efeito de Gibbs-Marangoni sequencialmente. . . . . . . . . . . . . . 42

Figura 2.10 - Representação de uma molécula de surfactante. . . . . . 44

Figura 2.11 - Classificação dos surfactantes de acordo com suas moléculas: não iônicos, aniônicos, catiônicos e anfóteros. . 45

Figura 2.12 - Formação de micela reversa (emulsão A/O) . . . . . . . . . 47

Figura 2.13 - Tipos de micelas e suas representações. . . . . . . . . . . 48

Figura 2.14 - Propriedades fisico-químicas de soluções de dodecil sulfato de sódio a $25^{\circ} \mathrm{C} \ldots$. . . . . . . . . . . . . . . . . . . 49

Figura 2.15 - Escala representativa do valor de HLB . . . . . . . . . . . 50

Figura 2.16 - Reômetro DHR-3 da TA instruments . . . . . . . . . . . . 52

Figura 2.17 - Diferentes arranjos com frações de empacotamento máximo variados. . . . . . . . . . . . . . . . 56

Figura 2.18 - Comportamento da viscosidade com relação à fração de empacotamento. . . . . . . . . . . 56

Figura 2.19-Comportamento de shear-thinning e shear thickening em emulsões. . . . . . . . . . . . . . . 57

Figura 2.20 - Representação da desestruturação de agregados e floculação com aumento da taxa de cisalhamento. . . . . . 58 
Figura 2.21 - Representação do comportamento da viscosidade com tamanho de gotas.

Figura 2.22 - A) Representação do desvio das linhas de corrente em partículas com diferentes formas. B) Visualização de maior interação entre as partículas de formas diferentes, representada pelo "X"amarelo.

Figura 2.23 - Representação do comportamento da viscosidade em função da taxa de cisalhamento e forma das partículas. . . 61

Figura 2.24 - Esquema de um separador gravitacional horizontal trifásico. 64

Figura 2.25 - Imagem representativa de tratador eletrostático . . . . . . 65

Figura 3.1 - (a) Rampa de Temperatura do petróleo A.(b) Rampa de Temperatura do petróleo $B$.

Figura 3.2 - A) Reômetro DHR-3 da TA Instruments. B) Geometria Couette utilizada para confecção dos testes experimientais. 68

Figura 3.3 - Representação do processo de medição de tensão interfacial. 70

Figura 3.4 - Representação do processo de emulsificação das emulsões de petróleo . . . . . . . . . . . . . . 73

Figura 3.5 - Visualização do delimitador de altura para o frasco utilizado. 74

Figura 3.6 - Foto representativa do rotor (interno) e estator (externo) contidos no ULTRA-TURRAX ${ }^{\circledR}$. . . . . . . . . . . . . 75

Figura 3.7 - Foto representativa do novo elemento dispersor projetado para o processo de emulsificação das emulsões modelo. . . 75

Figura 3.8 - Desenho representativo da descentralização do misturador com relação ao frasco que contém a emulsão. . . . . . . . 76

Figura 3.9 - Foto do microscópio Nikon Eclipse LV100n polarizado. . . 80

Figura 3.10 - Fotos de antes e depois da análise feita pelo programa MATLAB® . . . . . . . . . . . . . . . . . 82

Figura 3.11 - Gráfico gerado da distribuição de tamanho de gotas de uma emulsão.

Figura 4.1 - O corte de água crítico para as emulsões do petróleo A se estabelece entre 32 e $37 \%$ de concentração com o protocolo utilizado. . . . . . . . . . . . . . . 86

Figura 4.2 - O corte de água crítico para as emulsões do petróleo B se estabelece entre 15 e $20 \%$ de concentração com o protocolo utilizado. . . . . . . . . . . . . . . 8

Figura 4.3 - Gráfico da equação viscosidade de Krieger-Dougherty baseado nos dados experimentais das emulsões do petróleo A. . . . . . . . . . . . . . . 88 
Figura 4.4- Gráfico da equação viscosidade de Krieger-Dougherty baseado nos dados experimentais das emulsões do petróleo B. . . . . . . . . . . . . . 88

Figura 4.5 - Diâmetro médio das gotas das emulsões do petróleo $A$ em diferentes concentrações efetivas. . . . . . . . . . . . 90

Figura 4.6 - Diâmetro médio das gotas das emulsões do petróleo $B$ em diferentes concentrações efetivas. . . . . . . . . . . . . 90

Figura 4.7 - Índice de polidispersidade das emulsões do petróleo A em diferentes concentrações efetivas. . . . . . . . . . . . . 91

Figura 4.8 - Índice de polidispersidade das emulsões do petróleo B em diferentes concentrações efetivas. . . . . . . . . . . . . 92

Figura 4.9 - Comparação da estrutura química de moléculas de Span e Tween, com variação de sufixo numérico. . . . . . . . . . . 94

Figura 4.10 - Gráfico representativo das emulsões modelo do petróleo A. 96

Figura 4.11 - (a) Curva de escoamento de emulsões de petróleo A reais e modelo com $5 \%$ de concentração efetiva (b) Curva de escoamento de emulsões de petróleo $A$ reais e modelo com 32\% de concentração efetiva. Para este caso, o comportamento shear-thinning pode ser observado. . . . . 98

Figura 4.12 - Comparação dos dados experimentais das emulsões do petróleo A com a Equação de viscosidade de Krieger-Dougherty. . . . . . . . . . . . . . . 99

Figura 4.13 - Comparação dos diâmetros médios das emulsões reais e modelo do petróleo A com relação (a) à concentração efetiva e (b) ao corte de água. . . . . . . . . . . . . . . 100

Figura 4.14 - Comparação dos índices de polidispersidade das emulsões reais e modelo do petróleo $A$ com relação (a) à concentração efetiva e (b) ao corte de água. . . . . . . . . . . 101

Figura 4.15 - Gráfico representativo das emulsões modelo do petróleo B. 102

Figura 4.16 - Curvas de escoamento de emulsões reais (B) e modelo com $15 \%$ de concentração efetiva. . . . . . . . . . . . . . 103

Figura 4.17-Comparação dos dados experimentais das emulsões modelo B com a Equação de viscosidade de Krieger-Dougherty. . . . . . . . . . . . . . . . . 104

Figura 4.18 - Comparação dos diâmetros médios das emulsões reais e modelo do petróleo $\mathrm{B}$ com relação (a) à concentração efetiva e (b) ao corte de água. . . . . . . . . . . . . . . 105

Figura 4.19 - Comparação dos índices de polidispersidade das emulsões reais e modelo do petróleo $B$ com relação (a) à concentração efetiva e (b) ao corte de água. . . . . . . . . 106 


\section{Lista de Tabelas}

Tabela 2.1 - Composição média do petróleo . . . . . . . . . . . . . . . 19

Tabela 2.2 - Composição química média do petróleo . . . . . . . . . . 20

Tabela 3.1 - Composição da água sintética . . . . . . . . . . . . . . . 71

Tabela 4.1 - Análise SARA do petróleo A . . . . . . . . . . . . . . . 83

Tabela 4.2 - Massa específica dos petróleos em diferentes temperaturas. 84

Tabela 4.3 - Média da viscosidade dos petróleos a $40^{\circ} \mathrm{C}$. . . . . . . . 84

Tabela 4.4 - Valores de tensão interfacial do sistema petróleo $A$ ou $B$ e água sintética em duas diferentes temperaturas: $25^{\circ} \mathrm{C}$ e $40^{\circ} \mathrm{C} \ldots \ldots \ldots \ldots \ldots$. . . . . . . . . . . 85

Tabela 4.5 - Viscosidade e densidade de diferentes óleos utilizados para a formação do óleo modelo. . . . . . . . . . . . . . . . . 93

Tabela 4.6 - Composições percentuais dos componentes em cada um dos óleos modelo. . . . . . . . . . . . . . . . . . . 95

Tabela 4.7 - Viscosidade, densidade e tensão interfacial (com a água sintética) dos petróleos e seus respectivos óleos modelos a $40^{\circ} \mathrm{C} \ldots \ldots \ldots \ldots \ldots$. . . . . . . . . . . 95 


\section{Introdução}

Emulsões são sistemas gerados a partir da mistura de dois líquidos imiscíveis entre si, no qual as gotas de um líquido ficam dispersas no outro. Tais sistemas são termodinamicamente instáveis uma vez que as fases aquosa e oleosa separadas possuem uma energia livre menor do que quando misturadas na forma de emulsão. Por causa disso, emulsões estão propensas a diminuir essa energia livre através da redução da área interfacial total [2], sempre com a tendência de se separarem ao longo do tempo e com uma taxa de desestabilização referente ao tamanho da barreira de energia cinética do sistema [3].

Por isso, essa disposição natural de separação das fases pode ser vista através da ocorrência de alguns fenômenos de desestabilização amplamente conhecidos na literatura, conforme será visto na seção (2.2). Esses fenômenos podem ocorrer de forma singular ou simultânea, o que acarreta em um elevado nível de complexidade para seus estudos. A ocorrência destes pode ser baseada em uma série de propriedades que são responsáveis pelo entendimento do sistema como um todo. Dentre essas propriedades, pode-se citar:

- Distribuição de tamanhos de gotas;

- Diferença de densidade e/ou de viscosidade entre as fases;

- Forças atrativas e repulsivas entre as fases;

- Tensão interfacial entre as fases;

- Solubilidade de uma fase na outra;

Uma forma de aumentar a estabilidade das emulsões é através da adição de elementos tensoativos, usualmente chamados de surfactantes. Tais substâncias são responsáveis por uma modificação nas tensões superficiais/interfaciais entre as fases líquidas sendo capazes de formar uma estrutura ao longo da interface [4]. Por causa da presença desses tensoativos, emulsões se formam de maneira mais fácil podendo haver a formação de um filme protetor capaz de impedir a quebra das mesmas [5]. Cabe ressaltar aqui que cada um desses agentes possui uma estrutura molecular e concentração micelar crítica que possibilitam uma maior capacidade de síntese e estabilidade dessas misturas bifásicas. 


\section{1 \\ Motivação}

No decorrer do tempo de exploração de um poço de petróleo, a produção de óleo dá lugar a uma mistura de água/óleo a medida que o envelhecimento do mesmo acontece. Essa mistura bifásica, ao ser exposta a uma série de esforços mecânicos, acarreta na geração de emulsões que podem permanecer no processo industrial em etapas como perfuração, produção, refino, transporte e processamento dos óleos brutos. Por outro lado, emulsões também podem ser utilizadas em técnicas de recuperação avançada de petróleo no deslocamento de óleo ao longo dos reservatórios $[6,7]$.

Sendo assim, baseado na premissa de aproveitamento máximo da quantidade de óleo extraído, o tratamento das emulsões vem se tornando um importante fator para a indústria petrolífera. Isso pode ser reforçado uma vez que mais de $50 \%$ de todo o petróleo recuperado é na forma de emulsões do tipo água em óleo (A/O) [1]. Dessa forma, a extração desse óleo se apresenta como um grande empecilho para a rentabilidade do processo, uma vez que custos de transporte e, principalmente, de processamento são maiores para o caso das emulsões [8]. Por isso, a presença de emulsões é indesejada na indústria do petróleo e deve ser evitada de alguma forma [9]. Em consequência, processos de separação primários são necessários a fim de que o máximo de óleo seja extraído da mistura água/óleo, evitando que esses fluidos cheguem as refinarias. Isso acontece, sobretudo, de acordo com os limites impostos para que um barril de petróleo possa ser comercializado, o que faz com que seu preço seja menor a medida que o mesmo apresente uma maior quantidade de água.

Dentre os processos de separação primária, pode-se destacar os separadores gravitacionais. Tais equipamentos geralmente são testados através do uso de emulsões reais de petróleo vindas diretamente dos campos de exploração. Contudo, a logística de transporte de grandes quantidades dessas emulsões dos campos até os laboratórios para a realização de testes experimentais é bastante complexa e pode ser extremamente custosa. Somados a isso, características físicas como toxicidade, volatilidade e inflamabilidade fazem com que seu uso acarrete na possibilidade de riscos ambientais e de segurança nos laboratórios $[1,10]$. Há relatos na literatura ainda de que a falta de repetibilidade dos experimentos com tais emulsões afeta diretamente o nível de confiança da eficiência dessas tecnologias de separação. Portanto, o desenvolvimento da pesquisa de fluidos modelo que simulem o comportamento do petróleo e suas emulsões é extremamente benéfico para o aperfeiçoamento de tais tecnologias de desestabilização/separação de fases. 


\section{2}

\section{Objetivos}

O objetivo principal deste trabalho consiste na possibilidade de desenvolvimento de um método para a síntese de fluidos modelo com propriedades físicas como características reológicas, de formação e estabilidade semelhantes as de óleos e emulsões reais encontrados em campo. Tal objetivo poderá ser alcançado através da mimetização de um fluido modelo que sintetize emulsões com valores de viscosidade $(\eta)$, distribuição de tamanho de gota (Dmedio e PDI) e estabilidade $\left(\phi_{\text {eff }}\right)$ similares as geradas a partir do petróleo cru. Através desses resultados, os testes de eficiência de tecnologias de transporte e separação, poderão se tornar mais rentáveis e, sobretudo, haverá a possibilidade de acontecer um aumento na confiabilidade do processo devido a uma melhor seleção dos instrumentos utilizados.

\section{3}

\section{Organização do trabalho}

A fim de que fosse possível uma melhor organização deste trabalho, o mesmo foi divido em cinco capítulos: Introdução, Revisão bibliográfica, Materiais e métodos experimentais, Resultados e discussão e Conclusão. Conforme exposto anteriormente, a motivação e os objetivos da pesquisa são descritos brevemente no capítulo 1 .

No capítulo 2 é apresentada a Revisão bibliográfica, enquanto no capítulo 3 encontra-se os materiais e métodos empregados na pesquisa.

Os resultados principais são apresentados e analisados no capítulo 4, enquanto no capítulo 5 há a conclusão do trabalho e propostas para trabalhos futuros. 


\section{2}

\section{Revisão bibliográfica}

\section{1}

\section{Petróleo e sua composição}

O petróleo é uma mistura majoritária de hidrocarbonetos que pode conter frações de outros compostos orgânicos. Tais frações podem possuir moléculas de oxigênio, enxofre, nitrogênio, níquel, vanádio, entre outros. Contudo, a presença desses últimos componentes representam características indesejáveis, bem como complicações nas operações de refino e produção do óleo.

Usualmente, como uma forma de simplificação, a composição do petróleo é classificada em quatro diferentes frações de hidrocarbonetos: saturados, aromáticos, resinas e asfaltenos.

Hidrocarbonetos saturados são aqueles formados por alcanos normais (n-parafinas), isoalcanos (isoparafinas) e cicloalcanos (naftenos) [11]. Cabe ressaltar que uma cadeia carbônica saturada apresenta apenas ligações simples, sendo os mesmos ligados a um átomo de hidrogênio. Apresenta por isso uma fórmula geral $C_{n} H_{2 n+2}$, com n sendo um número inteiro de até 45 átomos de carbono em parafinas normais e ramificadas [12]. Usualmente a presença de parafinas normais pode variar de 3 a 35\% na composição final do petróleo.

Por outro lado, os hidrocarbonetos aromáticos são aqueles compostos por anéis benzênicos, cuja fórmula geral é $C_{n} H_{2 n-6}$, possuindo ou não ramificações. Devido a presença de insaturações nas ligações entre os carbonos, possuem reatividade maior que os hidrocarbonetos saturados, podendo ser representados pelos naftenoaromáticos e os benzotiofenos [11]. Não apresentam propriedade emulsificante sobre o petróleo e possuem ação de solvência sobre os asfaltenos. É importante ressaltar também que compostos com três ou mais anéis podem representar de 15 a $50 \%$ das frações mais pesadas do petróleo bruto.

Asfaltenos têm como estrutura química uma parte polar composta de: anéis aromáticos policondensados, grupamentos funcionais, como carboxilas e carbonilas, e metais, como níquel e ferro. Já para a parte apolar das moléculas há a presença de cadeias alifáticas [13]. Asfaltenos puros são sólidos escuros, solúveis em solventes aromáticos mas insolúveis em parafínicos. Apresentam uma grande complexidade e maior peso molecular quando se comparados as 
moléculas de resinas, o que faz com que possuam uma maior dificuldade de análise devido a sua tendência de agregação. Promovem a formação de emulsões do tipo A/O em petróleos além de possuírem grande variedade de componentes, acarretando em diferenças no processo de separação de água devido a variações nos diversos tipos de petróleos existentes.

Resinas possuem uma composição molecular bastante similar à dos asfaltenos, conforme visto acima. Tais componentes apresentam características próximas a líquidos pesados ou sólidos pastosos com elevada solubilidade no petróleo. Atuam sobretudo como dispersantes dos agregados dos asfaltenos, não formando emulsões estáveis do petróleo com a água [13]. Por fim, é importante notar também que tanto asfaltenos quanto resinas são comumente encontrados em óleos pesados e viscosos.

Devido a grande variação da quantidade de cada um dos componentes anteriormente citados, a composição do petróleo pode ser diferente de acordo com a região com que o mesmo é extraído. A seguir, tem-se na Tabela 2.1, uma demonstração representativa do teor médio aproximado dos componentes acima citados na composição do petróleo.

\begin{tabular}{cc} 
Fração de Petróleo & Percentagem [\%] \\
\hline Parafinas normais & 14 \\
Parafinas ramificadas & 16 \\
Parafinas cíclicas & 30 \\
Aromáticos & 30 \\
Resinas e asfaltenos & 10 \\
\hline
\end{tabular}

Tabela 2.1: Composição média do petróleo [11]

É usual também a representação de uma relação dos componentes químicos presentes, em média, no petróleo, conforme visto na Tabela 2.2 abaixo. 


\begin{tabular}{cc} 
Elemento químico & Percentagem em peso [\%] \\
\hline Carbono & 83 a 87 \\
Hidrogênio & 11 a 14 \\
Enxofre & 0,06 a 8 \\
Nitrogênio & 0,11 a 0,17 \\
Oxigênio & 0,5 \\
Metais (Ex.: Fe, Ni, V) & 0,3 \\
\hline
\end{tabular}

Tabela 2.2: Composição química média do petróleo [12]

\subsection{1}

\section{Propriedades do petróleo}

O petróleo bruto possui uma série de propriedades físicas e químicas que são comumente conhecidas. O óleo puro é um recurso natural não renovável responsável por geração de energia e fabricação de diversos produtos. Apresenta propriedades inflamáveis com colorações e odores que variam de acordo com sua composição. Isso se deve pela presença de destilados leves ou pesados no petróleo, uma vez que colorações mais escuras indicam uma maior presença de compostos pesados no óleo.

Somando-se as diferenças que sejam visualmente perceptíveis, o petróleo também possui variações em características químicas de acordo com sua composição, como é o caso da densidade. Um conceito amplamente utilizado é a classificação baseada no grau API que pode ser calculado conforme a Equação (2-1) abaixo, na qual $d$ é o valor do densidade do óleo [12]. De acordo com sua definição, a medida que a densidade do petróleo diminui, seu grau API aumenta e, consequentemente, o valor comercial do óleo é maior. Esse último indicador se deve ao fato que petróleos com densidades inferiores são aqueles mais propensos a produzirem derivados como gasolina, diesel e GLP, que possuem maior valor agregado [14].

$$
{ }^{\circ} A P I=\frac{141,5}{d}-131,5
$$




\section{2}

\section{Emulsão}

Emulsões podem ser definidas como uma classe de sistemas dispersos heterogêneos de dois líquidos imiscíveis entre si (por exemplo, água e óleo) no qual uma das fases é dispersa na outra. Nesses sistemas, gotas da fase dispersa ficam esparsadas na fase contínua [15].

Tais sistemas podem ser de diferentes tipos, sendo os principais deles: óleo em água (O/A), água em óleo (A/O) e óleo em óleo (O/O). Para o último caso, tem-se uma mistura de óleos polares e não polares, sendo imiscíveis entre si [5]. Além disso, é possível que se encontrem emulsões que sejam uma combinação de dois tipos das citadas anteriormente como, por exemplo, uma emulsão de água em óleo em água (A/O/A), em que gotas de água estão dentro de gotas de óleo dispersas em uma fase contínua de água, conforme visto na Figura (2.1).

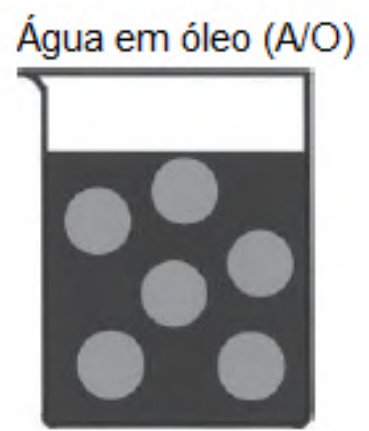

Água em óleo em água $(\mathrm{A} / \mathrm{O} / \mathrm{A})$

Óleo em água em óleo

B)
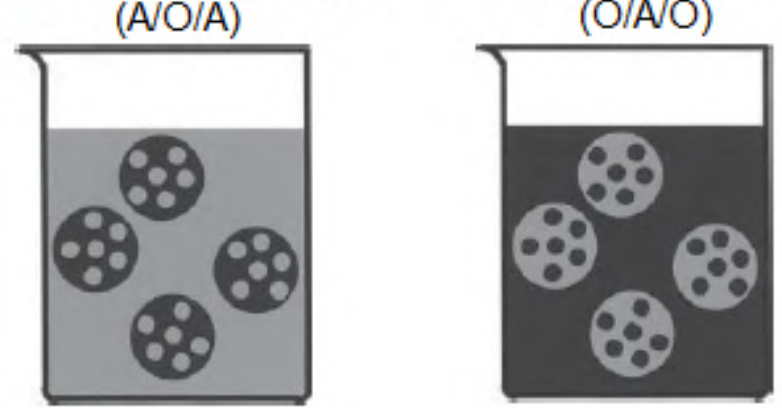

Figura 2.1: (A) Classificação básica dos tipos de emulsões (B) Casos de combinações de dois tipos de emulsões (Adaptado de [5])

Frequentemente, emulsões podem ser sintetizadas com o auxílio de um elemento denominado de emulsificante. Esse componente ajuda na formação e estabilização da emulsão sobretudo devido sua capacidade de atuar na interface 
dos fluidos utilizados, assunto este que será tratado posteriormente neste trabalho [15].

\subsection{1}

\section{Emulsões de petróleo}

Conforme visto na seção (2.1), os petróleos possuem em sua composição uma gama extensa de componentes. Contudo, espécies como ácidos carboxílicos e, sobretudo, asfaltenos e resinas são os principais responsáveis para a estabilização das emulsões de petróleo [16]. Dentre esses, os asfaltenos apresentam um papel de destaque na geração de emulsões, uma vez que podem exibir um comportamento de auto associação com a presença de grupos doadores e receptores em sua molécula. Essa propriedade é influenciada por fatores como concentração, polaridade do solvente, temperatura, pressão e ocorrência de resinas [17].

Portanto, essa característica de auto associação do asfalteno na interface líquido-líquido e a formação de uma multicamada são os principais responsáveis pela estabilização das emulsões devido a formação de um filme que impede a coalescência das gotas. É importante ressaltar que asfaltenos adsorvem irreversivelmente na interface óleo-água apesar de não serem necessariamente moléculas anfifílicas. Por isso, fatores como o pH da solução aquosa, presença de eletrólitos e a solubilidade podem afetar de maneira considerável a estabilidade das emulsões formadas [17].

Com relação a influência do pH do meio aquoso, tem-se que a protonação/desprotonação dos grupos - $\mathrm{COOH}$ e a ação de componentes básicos das moléculas de asfaltenos podem influenciar substancialmente a separação das fases. Sendo assim, a enormidade de grupamentos funcionais do asfalteno atuam na formação de um filme interfacial rígido em ph ácido $(<4,0)$, intermediário em $\mathrm{pH}$ neutro $(6,9-7,7)$ e fraco em pH básico (>8) [18].

Da mesma forma, a presença de eletrólitos pode contribuir para o efeito de "salting-out", que torna as moléculas de asfalteno menos solúveis na fase aquosa ocasionando no aumento na coalescências entre as gotas de água. Por fim, a solvatação dos asfaltenos pode ser responsável pela formação de um filme mais elástico na interface a medida que a afinidade do solvente com o próprio asfalteno diminui. Por isso, um comportamento de máxima estabilidade pode ser visto em emulsões quando a concentração de asfaltenos é próxima ao início da precipitação $[16,17]$. 


\subsection{2}

\section{Estudo termodinâmico das emulsões}

\subsubsection{1}

\section{A interface de Gibbs e outros fenômenos}

Um sistema de emulsões é composto, sobretudo, por duas fases de bulk e uma camada interfacial que se encontra entre elas. Frequentemente, essa camada interfacial é tratada como uma superfície plana, conforme pode ser visto na Figura (2.2). Contudo, essa aproximação é bastante simplória, sobretudo, se há a presença de um filme adsorvente no sistema com determinada espessura, o que torna possível uma influência sobre estruturas vizinhas a ele. Sendo assim, a presença dessa região de composição variada e espessura relevante não pode ser negligenciada a nível de dimensões moleculares [19].

O processo de formação do filme adsorvente contido no sistema se baseia em termos de concentrações de excesso de superfície. Sendo $n_{i}^{\sigma}$ a quantidade do componente $i$ na fase superficial $\sigma$ em excesso do que seria apenas com a presença de duas fases de bulk (I e II) estendidas até a superfície SS de composição constante, a concentração de excesso da superfície do componente $i$ é dada pela Equação (2-2) [19].

$$
\Gamma_{i}=\frac{n_{i}^{\sigma}}{A}
$$

Onde A é a área interfacial. Cabe ressaltar que o valor de $\Gamma$ pode ser tanto positivo quanto negativo e depende da região escolhida para ser a representativa da superfície SS.

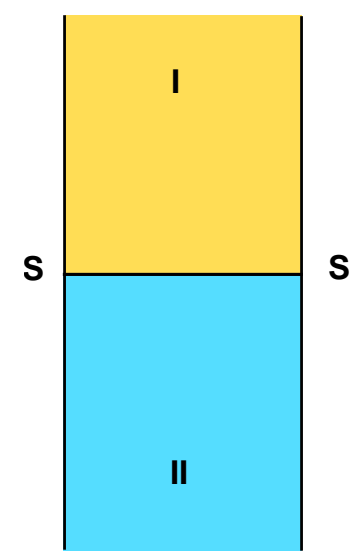

A)

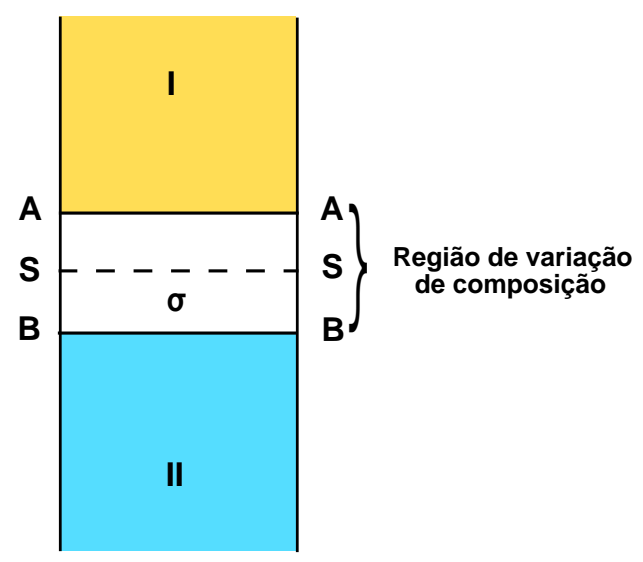

B)

Figura 2.2: Representação da interface entre duas fases I e II.

A) Sistema ideal B) Sistema Real 
Um dos modelos mais utilizados para descrever o comportamento termodinâmico desse tipo de sistema é a convenção de Gibbs, na qual as fases são separadas por uma camada infinitesimal, a chamada superfície de Gibbs. Através da utilização desse modelo, é possível a definição da tensão superficial ou interfacial $(\gamma)$ e da energia livre de Gibbs. Essa última é uma grandeza termodinâmica que busca medir a totalidade da energia atrelada a um sistema termodinâmico disponível para execução de trabalho. A derivação dessa energia $\left(d G^{\sigma}\right)$ representa a espontaneidade dos processos e pode ser expressa pela Equação de Gibbs-Duhem (2-3) [5]:

$$
d G^{\sigma}=-S^{\sigma} d T+A d \gamma+\sum n_{i} d \mu_{i}
$$

Na qual $S^{\sigma} \mathrm{dT}$ é um termo de entropia, $A d \gamma$ um termo interfacial e $\sum n_{i} d \mu_{i}$ é um termo de composição, sendo n o número de moles do componente i com potencial químico $\mu_{i}[20]$.

Levando-se em consideração temperatura e composição constantes, a Equação (2-3) se reduz a:

$$
\begin{gathered}
d G^{\sigma}=A d \gamma \\
\gamma=\left(\frac{\partial G^{\sigma}}{\partial A}\right)_{T, n_{i}}
\end{gathered}
$$

Para uma interface estável, a tensão interfacial $(\gamma)$ apresenta um valor positivo, fazendo com que a área interfacial aumente quando a energia livre de Gibbs cresce. É importante notar que, levando-se em conta interfaces curvas como gotas, sabe-se que a tensão interfacial pode ser bastante similar quando se comparada a superfícies planas. A exceção à esse efeito se apresenta em gotas com tamanhos inferiores a $10 \mathrm{~nm}$, fazendo com que o raio de curvatura deva ser considerado [5].

Outro parâmetro físico que também pode ser considerado a partir de superfícies curvas e afeta consideravelmente a estabilidade das emulsões formadas é a pressão de Laplace (p) [21]. Ela é expressa como sendo a diferença de pressão entre os lados convexo e côncavo da superfície curva, sendo dada pela Equação (2-6).

$$
\Delta p=\gamma\left(\frac{1}{r_{1}}+\frac{1}{r_{2}}\right)
$$

Onde $r_{1}$ e $r_{2}$ são os dois principais raios de curvaturas. Para uma partícula perfeitamente esférica $\left(r_{1}=r_{2}=\mathrm{r}\right)$, a Equação anterior é reduzida a:

$$
\Delta p=\frac{2 \gamma}{r}
$$


Sendo assim, uma gota esférica com um raio menor será responsável por uma pressão de Laplace maior. Assim, para o caso de duas gotas com mesma tensão superficial que estejam conectadas, a menor gota apresentará uma pressão interna maior. Isso, afetará sua estabilidade, acarretando em seu colapso e transferindo seu conteúdo para a gota maior que se encontra em sua vizinhança.

\subsubsection{2}

\section{Formação de emulsões e termodinâmica}

Ao longo do processo de formação das emulsões, a energia livre de Gibbs pode variar substancialmente, conforme visto através do exemplo abaixo. Considere um sistema no qual uma gota de um fluido 2 é representado por uma gota de área $A_{1}$ imerso em um líquido 1 . Em seguida, essa gota é dividida em grande número de gotas menores com área superficial $A_{2}$, sendo $A_{2}>A_{1}$. Essa modificação no sistema acarreta em uma variação na energia livre de Gibbs uma vez que, primeiramente, a energia superficial $(\Delta A \gamma)$, sendo $\Delta A=A_{2}-A_{1}$, representa um valor positivo. Em um segundo momento, a entropia expressa por $T \Delta S$ aumenta devido a um maior número de gotas. Todas essas variações podem ser analisadas de acordo com a segunda lei da Termodinâmica expressa abaixo:

$$
\Delta G=\Delta A \gamma-T \Delta S
$$

Usualmente, sabe-se que $\Delta A \gamma>T \Delta S$, o que significa que $\Delta G$ é positivo. Isso se deve ao fato de que a medida que $\gamma$ é positivo, a energia para expansão da interface se torna maior e mais positiva, fazendo com que esse termo não possa ser compensado pelo termo entrópico. Por causa disso, a formação das emulsões não é espontânea e o sistema é termodinamicamente instável, necessitando energia para a geração de gotas. Por conseguinte, a falta de um mecanismo estabilizante possivelmente acarretará a separação de fases da emulsão [5].

Baseando-se no exemplo proposto, é possível concluir também que a medida que ocorre a diminuição do tamanho da gota formado, maior é a quantidade de energia ou de estabilizante necessária. A explicação para isso pode ser baseada pela pressão de Laplace, que foi definida na subseção acima. Para a formação de emulsões com gotas menores, as mesmas devem ser mais deformadas o que acarreta em um aumento de $\Delta p$. Assim, a tensão é maior neste tipo de gota, o que induz a necessidade de uma agitação mais vigorosa e maiores quantidades de energia aplicada. 


\subsection{3}

\section{Forças de interação entre as gotas}

As forças de interação entre as gotas devem ser consideradas quando a separação entre elas é menor que 100 nm [22]. As mais comuns são encontradas ao longo desta seção.

\subsubsection{1}

\section{Forças de van der Waals}

As forças de van der Waals se originam do movimento de elétrons carregados negativamente ao redor do núcleo atômico carregado positivamente [22]. Essa força de atração entre átomos e moléculas é usualmente classificada de acordo com três diferentes tipos:

- dipolo-dipolo (Keesom)

- dipolo-induzido por dipolo (interações Debye)

- dispersão (interações de London)

É importante ressaltar que, devido a diferentes orientações dos dipolos e suas magnitudes vetoriais, as duas primeiras forças de atração tendem a se cancelar. Sendo assim, as interações de dispersão de London são bastante importantes na interação entre as gotas já que surgem das flutuações de carga [5]. Isso se deve a movimentação dos elétrons ao redor do núcleo criando um dipolo temporário que poderá interagir com os átomos ou moléculas adjacentes. A energia de interação entre dois átomos ou moléculas $\left(G_{A}\right)$ é de curto alcance, sendo expressa pela Equação (2-9) abaixo.

Sendo $\beta$

$$
G_{A}=-\frac{\beta}{r^{6}}
$$

a constante de dispersão de London que é determinada pela polarizabilidade do átomo ou molécula e $r$ a distância de separação dos mesmos.

Ao longo do tempo, estudos foram feitos a fim de que fosse possível ter um conhecimento maior sobre a energia de interação entre dois átomos ou moléculas em corpos macroscópicos, como é o caso de emulsões. Um desses estudos foi o de Hamaker [23], que se baseia na adição das forças intermoleculares. Assim, a interação entre duas partículas é calculada simplesmente somando as interações de todas as moléculas em uma partícula com todas as moléculas de outra partícula [24], acarretando em uma grande atração de van der Waals. Para isso, apresentou uma Equação (2-10) que exprime a magnitude da atração de van der Waals $\left(G_{A}\right)$ entre duas esferas 
de raios $r_{1}$ e $r_{2}$, separadas por uma distância $h$, com $h>>r$ para pequenas aproximações entre elas:

$$
G_{A}=-\frac{A_{12}}{6 h} \frac{r_{1} r_{2}}{r_{1}+r_{2}}
$$

Para duas esferas com raios iguais a $r$, temos:

$$
G_{A}=-\frac{A_{12} r}{12 h}
$$

onde A é a constante efetiva de Hamaker,

$$
A=\left(A_{11}^{1 / 2}-A_{22}^{1 / 2}\right)^{2}
$$

sendo $A_{11}$ e $A_{22}$ as constantes Hamaker das gotas e do meio de dispersão, respectivamente. Cabe ressaltar que essa constante de Hamaker depende nas propriedades dielétricas das duas partículas que interagem e o meio [22]. Além disso, tal constante pode ser expressa através do número de átomos ou moléculas por unidade de volume $(q)$ e da constante de dispersão de London $(\beta)$, conforme visto na Equação (2-13).

$$
A=\pi^{2} q^{2} \beta
$$

Um gráfico representativo da variação da energia de atração de van der Waals com relação a distância (h) entre duas gotas de uma emulsão é mostrado na Figura (2.3). Por meio da análise deste gráfico é possível supor que a medida que a distância entre as gotas diminuem, há um aumento repentino de $G_{A}$.

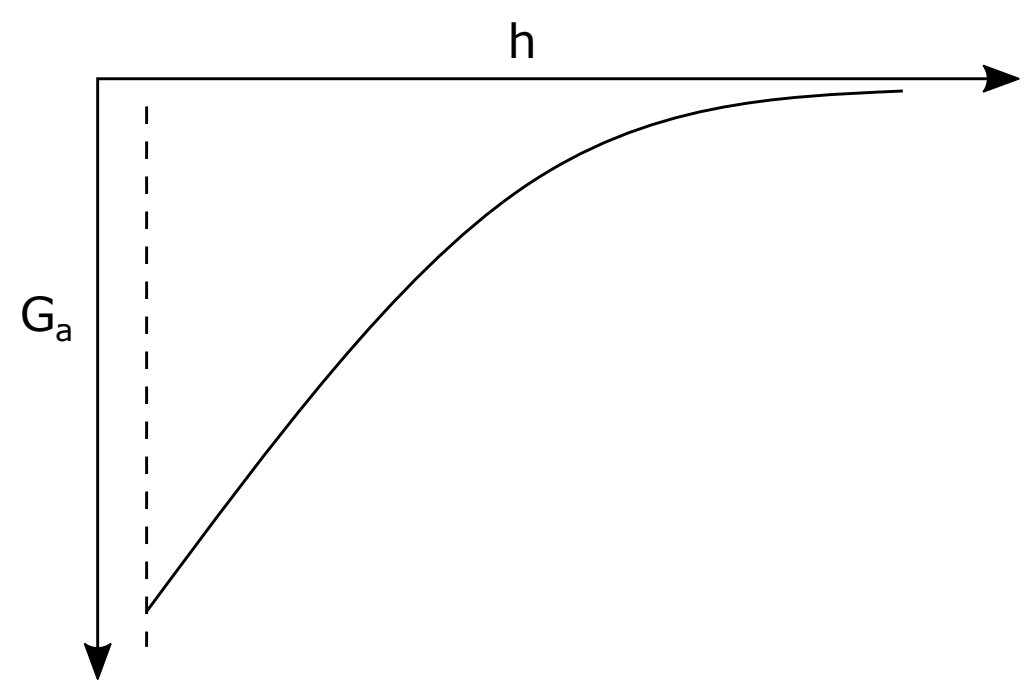

Figura 2.3: Gráfico representativo da variação da energia de atração de Van der Waals com relação à distância (h) [25].

Portanto, a fim de que essa força de atração seja neutralizada e, consequentemente, não aconteça a formação de grandes agregados, faz-se necessário a presença de forças repulsivas, que podem ser classificadas em [5]: 
- Eletrostática que ocorre devido à criação de uma camada dupla elétrica.

- Estérica que ocorre devido à presença de surfactante adsorvido ou camadas poliméricas.

\subsubsection{2}

\section{Repulsão eletrostática}

A repulsão eletrostática em soluções eletrolíticas é causada pela formação de uma dupla camada elétrica, criada a partir de uma distribuição desigual de íon ao redor de uma partícula carregada. Assim, a carga na superfície de uma partícula é balanceada por uma quantidade equivalente de cargas opostas contidas na solução [24]. Por isso, a formação da dupla camada é baseada em uma estrutura estabelecida por duas camadas com seguintes características [5]:

- Primeira camada: formada pela carga superficial (positiva ou negativa), derivada dos íons adsorvidos na partícula devido a interações químicas. Para o caso de emulsões, essa camada é composta de surfactantes iônicos.

- Segunda camada: é composta de íons atraídos pela carga superficial dos surfactantes adsorvidos. Ela é formada, sobretudo, de íons livres que se movem no fluido sob a influência de atração elétrica e movimento térmico. Esse efeito ocorre principalmente em colóides na escala de micrômetros e nanômetros.

O conceito da camada elétrica dupla foi desenvolvido por Chapman e Gouy e, posteriormente, aperfeiçoada por Stern [19]. Por causa disso, a primeira delas é conhecida como camada de Stern e a camada difusa é conhecida como camada de Gouy-Chapman, formando assim a dupla camada elétrica conforme visto na Figura (2.4). Analisando-se a Figura a seguir, é possível perceber que os primeiros íons da dupla camada difusa de Gouy-Chapman não estão na superfície, mas a alguma distância $d$ da mesma. Esta distância geralmente é definida como o raio do íon. 


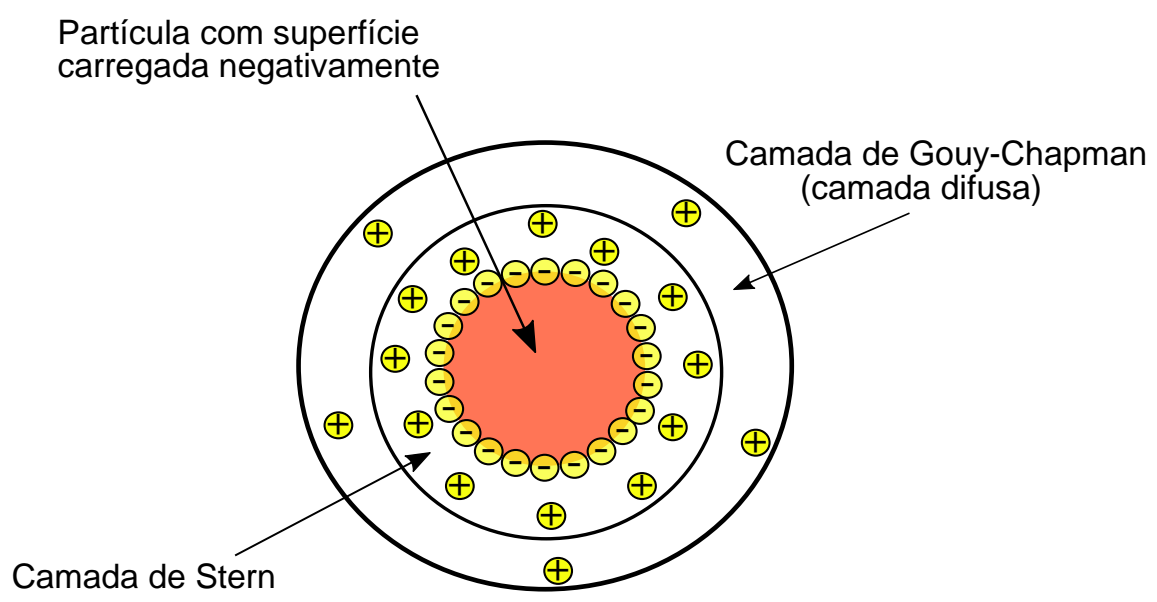

Figura 2.4: Representação da dupla camada elétrica.

Um outro conceito importante a ser citado aqui é do potencial elétrico, que representa a capacidade que um corpo energizado tem de atrair ou repelir outras cargas elétricas. O potencial Stern, $\Psi_{\sigma}$, é aquele que acontece entre as camadas de Stern e difusa, uma vez que a interação entre duas partículas carregadas acontece devido a sobreposição da camada de Gouy-Chapman $[22,24]$. Assim, quando a distância de separação entre as gotas de emulsão se torna menor do que o dobro da extensão de camada dupla, o potencial no plano médio entre as superfícies não é igual a zero, representando uma força de repulsão entre as gotas. Por outro lado, quando essa distância é maior do que dobro da extensão de camada dupla esse potencial é igual a zero [26].

A interação repulsiva eletrostática $\left(G_{e l}\right)$ para duas gotas com cargas idênticas, um potencial eletrostático de superfície pequeno e um raio grande quando se comparado a distância que as separa, é dada pela seguinte expressão $[22]:$

$$
G_{e l}=2 \pi R \varepsilon_{r} \varepsilon_{o} \Psi_{o}^{2} \ln [1+\exp (-\kappa h)]
$$

sendo $\varepsilon_{r}$ a permissividade relativa, $\varepsilon_{o}$ a permissividade do espaço livre, $\Psi_{o}$ é o potencial de superfície, $\kappa$ é o parâmetro de Debye-Huckel. Cabe notar também que a extensão da camada dupla pode ser dada por:

$$
\frac{1}{\kappa}=\frac{\varepsilon_{r} \varepsilon_{o} k T}{2 n_{o} Z_{i}^{2} e^{2}}
$$

sendo $k$ a constante de Boltzmann, $T$ a temperatura absoluta, $n_{o}$ o número de íons por unidade de volume de cada tipo presente na solução por unidade de volume, $Z_{i}$ a valência dos íons e $e$ a carga elétrica [5]. Conclui-se, portanto, que a interação devido a dupla camada elétrica decai exponencialmente com a separação das superfícies, sendo a extensão de 
decaimento igual ao comprimento de Debye. Somado a isso, pode-se ressaltar também que o comprimento de Debye e, consequentemente, o alcance da força de repulsão da camada dupla diminui com o aumento da concentração de sal e da valência dos íons presentes em solução [22].

\subsubsection{3}

\section{Teoria DLVO}

A conhecida teoria da estabilidade dos coloides proposta por Deryaguin, Landau, Verwey e Overbeek (teoria DLVO) leva em consideração uma combinação de atração de van der Waals e repulsão de dupla camada $[5,22,26,27]$. Sendo assim, a energia total $\left(G_{T}\right)$ é dada por:

$$
G_{T}=G_{e l}+G_{A}
$$

Uma representação esquemática da curva de força (energia) em função da distância, de acordo com a teoria DLVO, é dada na Figura (2.5). Através da análise gráfica, é possível perceber que esta curva pode ser dividida em algumas seções principais:

- Separação: acontece quando a atração entre as gotas é fraca, havendo a presença de uma grande barreira energética de repulsão entre elas.

- Floculação fraca: decorre quando a atração entre as gotas é moderadamente forte com a existência de uma grande barreira energética de repulsão.

- Floculação forte: ocorre quando a atração entre as gotas é extremamente forte havendo uma barreira energética de repulsão pequena. Além disso, a repulsão de curto alcance é bastante representativa [3].

- Coalescência: exibe comportamento similar a floculação forte apresentando a inexistência de repulsão de curto alcance entre as gotas. 


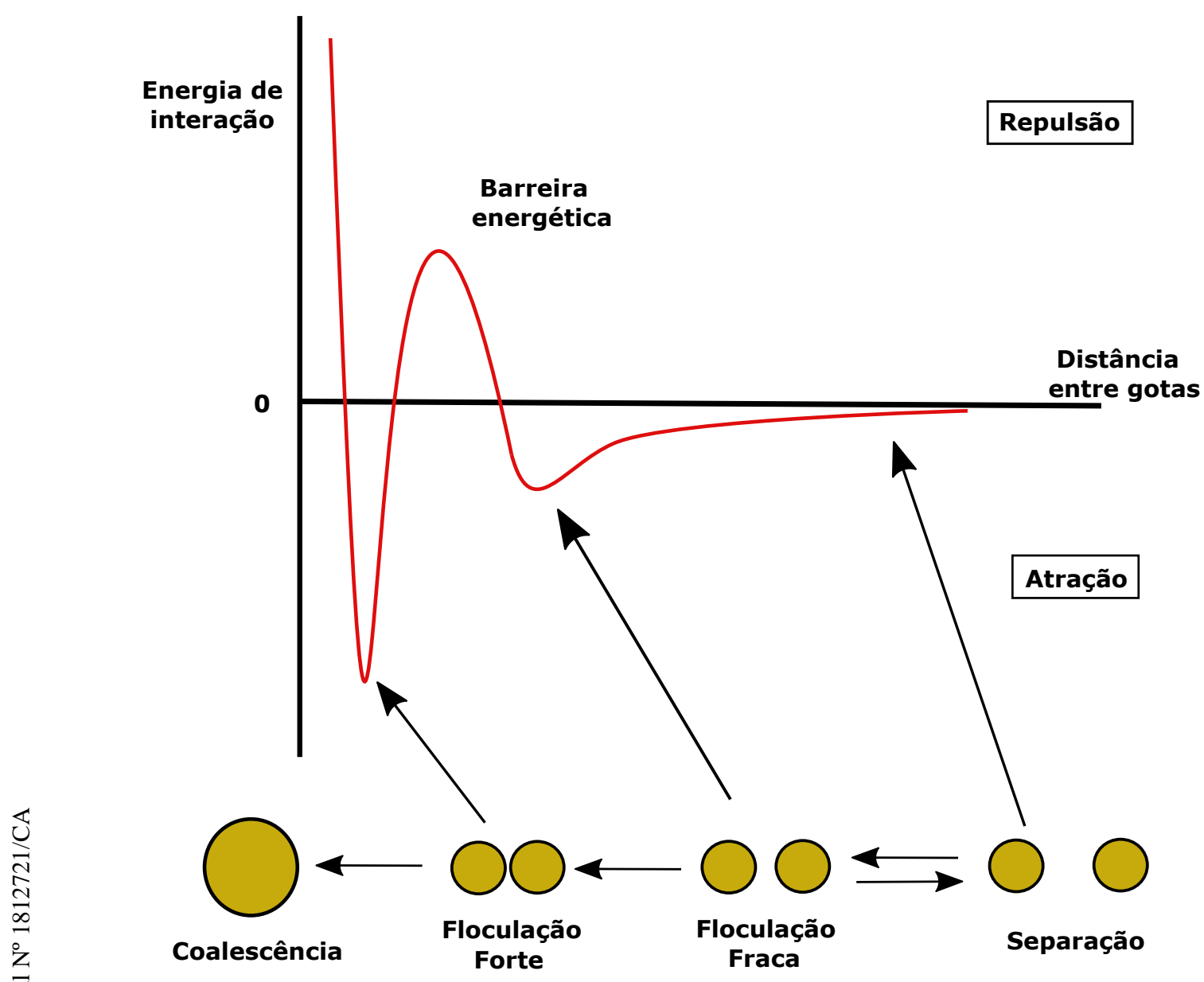

Figura 2.5: Curva de energia de interação em função da distância na teoria DLVO. (Adaptado de [3])

\subsubsection{4}

\section{Repulsão estérica}

O segundo tipo de forças de repulsão mais conhecido é a chamada repulsão estérica. Ela é produzida através da adesão de macromoléculas, como surfactantes não iônicos e polímeros, as superfícies das partículas [5]. Sendo assim, uma aproximação das partículas torna-se improvável devido ao arranjo físico estrutural dessas macromoléculas, ocasionando um repelimento entre elas. Como um exemplo, para emulsões do tipo A/O, longos grupos alquil se estendem para a fase oleosa a partir de surfactantes que constituem o filme interfacial, gerando uma barreira estérica nas gotas geradas [28].

Levando-se em consideração moléculas poliméricas, seu uso pode ser baseado através da possibilidade de emprego de um polímero de ancoragem ao longo da própria cadeia polimérica. Sendo assim, um dos polímeros contidos na 
cadeia tem forte afinidade pela superfície da partícula e serve para ancorarem de todo conjunto. Já o outro é mais compatível com o meio de dispersão e tem pouca afinidade com a superfície. Portanto, ele é estendido para o meio de dispersão e fornece uma barreira estérica [29], o que ocasiona no fenômeno de repulsão estérica entre as partículas.

Com isso, em determinadas condições, quando um polímero está firmemente ancorado à superfície e esta é, relativamente extensa, espera-se uma repulsão estérica [22]. Essa repulsão depende, principalmente, da densidade de adsorção do polímero, da afinidade com relação a superfície, da estrutura molecular do polímero e dos solventes envolvidos. Portanto, a pressão, $P(D)$, entre duas superfícies revestidas de polímero pode ser expressa por:

$$
P(D)=\frac{k T}{s^{3}}\left[\left(\frac{D *}{D}\right)^{9 / 4}-\left(\frac{D}{D *}\right)^{3 / 4}\right]
$$

No qual a separação D é menor que $D *$ (que representa o dobro da cadeia polimérica) e $s$ é a distância linear entre as cadeias ancoradas na superfície. Por outro lado, para o caso de duas esferas com raios maiores que as suas separações, essa relação é modificada para a Equação (2-18) [22]:

$$
\frac{F(D)}{R}=-\pi \int_{D *}^{D} P\left(D^{\prime}\right) d D^{\prime}
$$

\subsubsection{5}

\section{Atração por depleção}

As gotas de emulsões usualmente estão dispersas em sistemas que contém espécies que não foram adsorvidas em suas interfaces e possuem tamanhos muito reduzidos, como é o caso de polímeros, micelas e microemulsões. Por isso, tais espécies são responsáveis por afetar a atração entre as gotas através do processo denominado de atração por depleção [30].

A presença de polímeros não adsorvidos ocorre quando duas partículas podem ser atraídas pela exclusão de macromoléculas entre as superfícies [31] através da formação, ao redor de cada uma das partículas, de uma região de solvente com baixa concentração de polímero, denominada de volume excluído. Essa sobreposição inicial das regiões de volume excluído causa a expulsão da solução de polímero para uma região de maior concentração, o que facilita a aproximação das partículas.

De acordo com o modelo de Asakura e Oosawa [31], a força de atração por depleção por unidade de área para duas superfícies infinitas e paralelas quando $\mathrm{h}<\mathrm{d}$ é igual a (Equação 2-19), sendo $d$ o diâmetro dos menores coloides e $\phi$ a fração volumétrica dos mesmo. Para o caso de $\mathrm{h}>\mathrm{d}$, temos que essa força de depleção é nula [30]. 


$$
f_{\text {dep }}(h)=-\frac{6 \phi}{d^{3}}(d-h)
$$

Por fim, a presença desta força atrativa pode ainda acarretar na possibilidade de formação de uma floculação de depleção já que há um desequilíbrio na pressão osmótica compressiva que atua na superfície da partícula quando uma outra se aproxima [31,32]. Com isso, se o sistema possuir uma repulsão suficientemente forte para impedir cineticamente a aproximação das partículas, a macromolécula retornará à sua posição na região de menor concentração e o efeito será estabilizante, sendo a força de depleção repulsória. Por outro lado, a instabilidade gerada pela pressão osmótica acarretará em uma maior proximidade desses elementos.

\subsection{4}

\section{Desestabilização das emulsões}

A compreensão de estabilização ou desestabilização das emulsões pode ser baseado em conceitos cinéticos [4] e temporais, uma vez que essa estabilidade pode ser relativa a algumas frações de segundos ou até mesmo em anos. Todavia, o processo de desestabilização das emulsões acontece baseado em alguns fatores relevantes para o estudo do comportamento das mesmas. Dentre eles, pode-se citar, por exemplo, a diferença de densidade/viscosidade entre as gotas de emulsão e o meio na qual estão inseridas assim como a distribuição do tamanho de gotas das mesmas, as forças atrativas/repulsivas entre elas e a tensão interfacial.

Os processos de desestabilização de emulsões mais conhecidos na literatura são listados e vistos abaixo através da Figura (2.6):

- Creaming ou sedimentação

- Coalescência

- Floculação

- Ostwald ripening

- Inversão de fase 


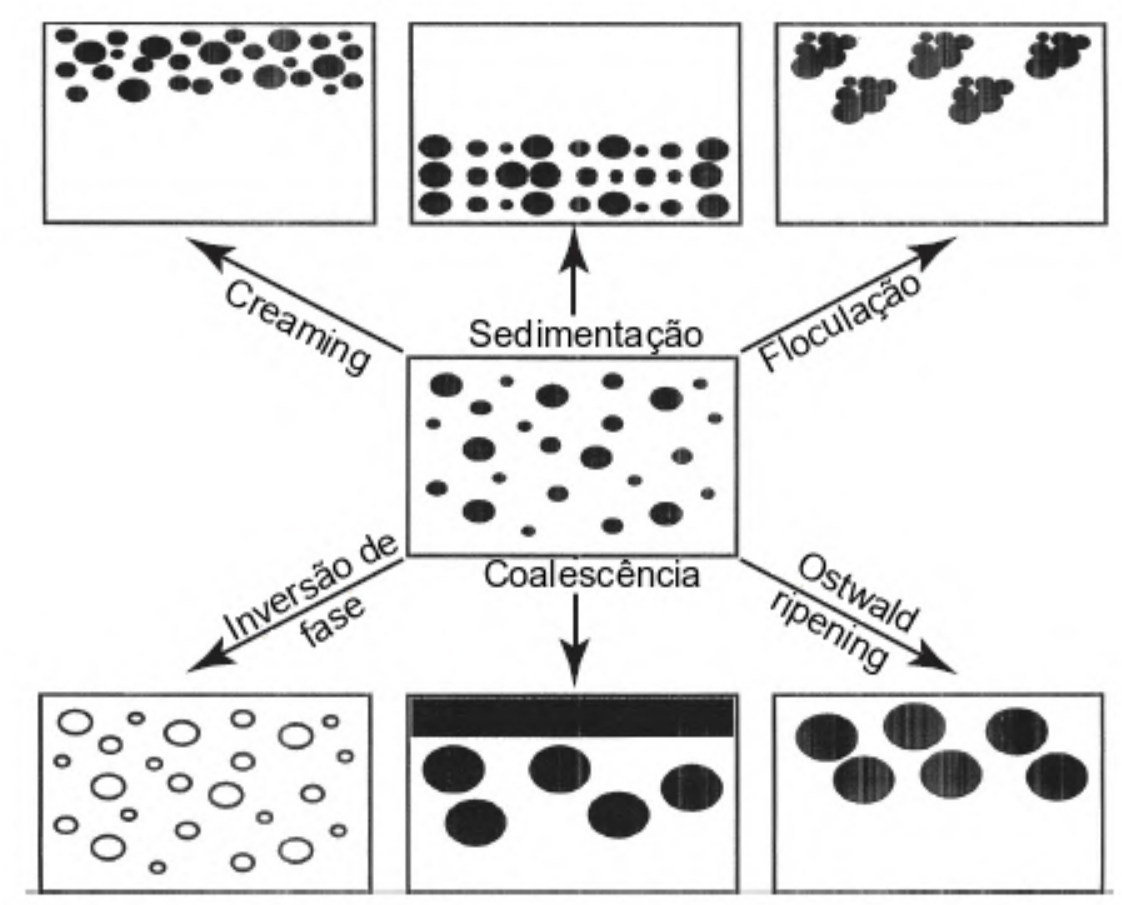

Figura 2.6: Processos de desestabilização de emulsões. (Adaptado de [5])

\subsubsection{1}

\section{Creaming e sedimentação}

Os processos de creaming e sedimentação são aqueles que ocorrem com a presença de forças externas ao sistema como, por exemplo, a força gravitacional e centrífuga. É importante ressaltar que eles são baseados na diferença de densidade do meio contínuo e da fase dispersa. Por causa disso, um gradiente de concentração de gotas maiores pode ser formado ao longo do reservatório em que a emulsão gerada se encontra, originando-se dois fluidos com características distintas.

O fenômeno de creaming ocorre quando a densidade da fase dispersa é menor do que a do meio, gerando a formação de uma camada de emulsão sobre uma das fases. Já o fenômeno de sedimentação, acontece quando a densidade da fase dispersa é maior do que a do meio, se estabelecendo uma camada de emulsão sob uma das fases, conforme visto na Figura (2.6).

Pode-se destacar que, usualmente, observa-se o processo de creaming em emulsões $\mathrm{O} / \mathrm{A}$, enquanto o fenômeno de sedimentação é mais propenso a acontecer em emulsões A/O [3,4].

Cálculos da taxa de creaming e sedimentação Um importante parâmetro que rege os processos de creaming e sedimentação é a Lei de Stokes (Equação 
2-20) para emulsões muito diluídas $(\phi<0,01)$. Essa equação faz o balanço entre forças hidrodinâmicas e gravitacionais, mostrando o motivo pelo qual gotas agregadas em uma emulsão realizam o processo de creaming mais rápido do que gotas individuais, assim como porque sólidos coagulados em uma suspensão sedimentam mais rápido do que partículas simples [5]. Vale ressaltar que, para gotas grandes (d>100 nm), a distribuição vertical das gotas é dominada, sobretudo, pela força gravitacional. Por outro lado, em gotas menores de 100 nm, essa distribuição é baseada no movimento Browniano [3].

Portanto, de acordo com a diferença de densidade dos fluidos, a força gravitacional apresenta uma maior significância inicialmente no sistema, fazendo com que a velocidade de sedimentação aumente com o tempo. No entanto, o crescimento da velocidade da partícula causa um aumento de uma força que tende a desacelerá-la. Assim, em um determinado momento há um equilíbrio de forças e atinge-se uma velocidade terminal. Dessa maneira, a velocidade terminal de uma gota esférica isolada de raio $(r)$ movendo-se em um fluido de densidade $\left(\rho_{0}\right)$ e viscosidade Newtoniana da fase contínua $\left(\eta_{0}\right)$ é dada por:

$$
v_{s}=\frac{2 r^{2}\left(\rho_{0}-\rho\right) g}{9 \eta_{0}}
$$

Cabe ressaltar que a Equação anterior assume que as partículas são neutras e esféricas. Por causa disso, partículas carregadas apresentam um obstáculo para a Lei de Stokes, uma vez que os contraíons menores sedimentam em uma taxa inferior àquela vista para partículas coloidais grandes. Isso acaba gerando um potencial elétrico que tende a acelerar os contraíons e retardar as partículas. Contudo, em concentrações altas de eletrólitos, o potencial elétrico é dissipado rapidamente e esse efeito desaparece [5].

Já para o caso de emulsões semi-diluídas $(0,1<\phi<0,2)$ a interação hidrodinâmica não pode ser negligenciada. Essas interações diminuem a velocidade vertical das gotas de acordo com a Equação (2-21) a seguir:

$$
v=v_{s}(1-k \phi)
$$

sendo $k$ uma constante que considera as interações hidrodinâmicas entre as partículas da ordem de 6,5. Esse número representa uma redução na velocidade de sedimentação/creaming de aproximadamente $65 \%$ devido a essas interações. Isso se deve pois em um recipiente com paredes, cada movimento para cima de uma gota deve estar acompanhado por um movimento para baixo de um determinado volume de fase contínua [4].

Por fim, para emulsões concentradas $(\phi>0,2)$, a taxa de sedimentação/creaming aumenta de complexidade se baseando na fração 
volumétrica, conforme visto na Equação (2-22) [4]. A velocidade diminui com o aumento da concentração até que se aproxima de zero quando a fração volumétrica chega um valor crítico: a fração máxima de empacotamento $\left(\phi_{m}\right)$.

$$
v=v_{s}(1-\phi) /\left(1+\phi^{1 / 3}\right) \exp [5 \phi / 3(1-\phi)]
$$

Prevenção de creaming e sedimentação Através da análise da Equação (2-20), é possível prevenir a possibilidade de ocorrência desses dois fenômenos. O meio mais fácil para isso é igualando a densidade da fase contínua e da fase dispersa, uma vez que isso acarreta em uma velocidade terminal igual a zero.

Outra alternativa é a diminuição do tamanho das gotas, já que isso resultaria em uma redução drástica na velocidade terminal, reduzindo em muito a ocorrência dos fenômenos. Além disso, a utilização de espessantes que alterem a viscosidade da fase contínua ou a utilização de óleos que aumentem essa propriedade, possibilitaria em uma menor mobilidade das gotas devido ao aumento das forças hidrodinâmicas.

\subsubsection{2}

\section{Coalescência}

Um segundo fenômeno bastante conhecido para a desestabilização das emulsões é o processo de coalescência. Ela ocorre quando a força motriz entre as superfícies das gotas é tamanha que o filme de fase contínua que as separa diminui até seu rompimento total provocando a fusão das mesmas [5]. Esse processo pode ser visto na Figura (2.7), sendo usualmente irreversível e com chances de ocorrer quando duas gotas grandes de emulsão se aproximam a distâncias menores que $1 \mu \mathrm{m}[4]$.

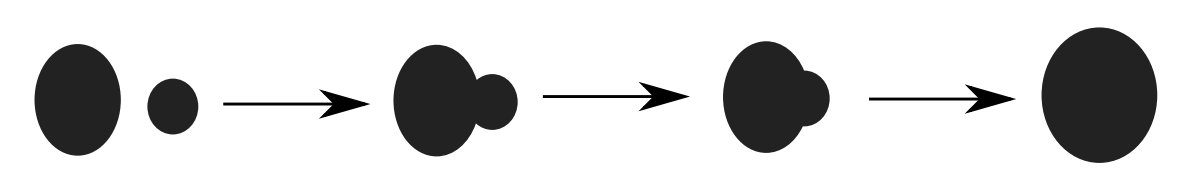

Figura 2.7: Representação do processo de coalescência das gotas.

Prevenção da coalescência Uma forma de prevenir a coalescência das gotas pode ser dada através de um aumento na repulsão estérica/eletrostática entre 
elas. Através disso, as gotas não estariam propensas a estarem próximas umas as outras e, com isso, o fenômeno de coalescência dificilmente ocorreria.

\subsubsection{3}

\section{Floculação}

Um outro fenômeno bastante comum para o caso das emulsões é a floculação. Esta ocorre quando há a agregação das gotas em unidades maiores sem com que haja uma alteração no tamanho das mesmas e a fusão entre elas [3]. Sendo assim, gotas floculadas permanecem separadas por um filme de fase contínua, de acordo com a Figura (2.8).

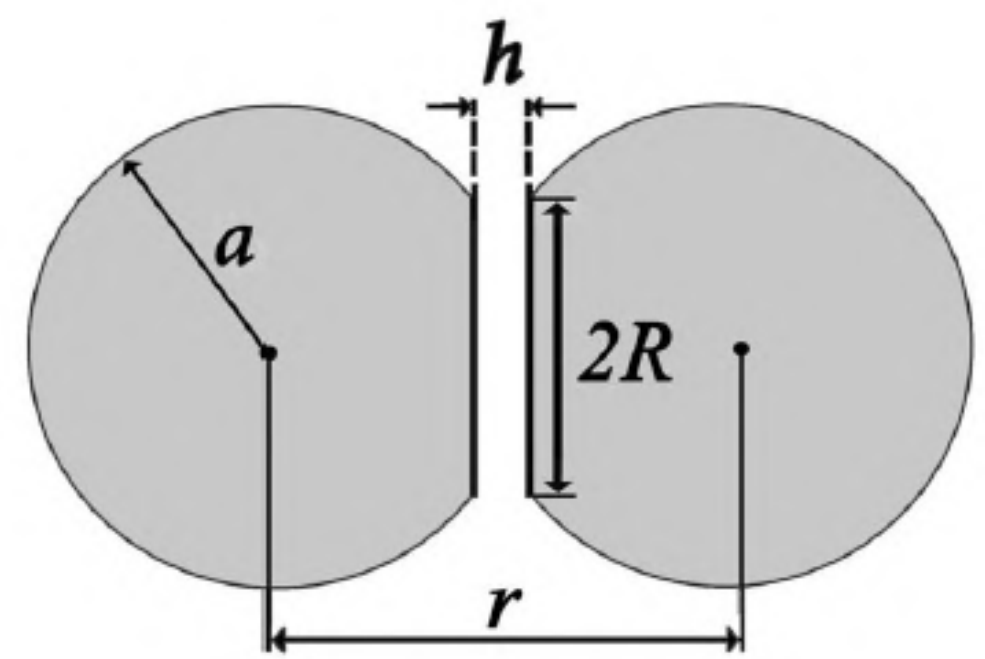

Figura 2.8: Representação do processo de deformação de duas gotas durante o fenômeno da floculação. Um filme líquido de espessura h pode ser formado. [30]

É importante ressaltar que o processo pode ser reversível, ocasionando novamente uma separação das gotas agregadas, ou irreversível, dependendo da força de interação entre elas [4]. Por isso, partículas que apresentam uma repulsão forte entre si não possuem a tendência de formação de agregados. Por outro lado, uma interação fraca entre elas pode acarretar na geração de grandes clusters uma vez que essas partículas estão mais propensas à colisão.

Sintetizando, então, o processo de floculação acontece quando não há uma força repulsiva suficiente para manter as gotas separadas em distâncias nas quais a atração de van der Waals é fraca [5], o que faz com que a magnitude do processo dependa da energia de atração envolvida.

Um exemplo típico é a interação DLVO, vista na seção (2.2.3.3), que sugere que a estabilidade contra agregação em uma emulsão, por exemplo, 
depende do equilíbrio entre a atração de van der Waals e a repulsão eletrostática [30]. Essa energia de atração diverge proporcionalmente a $1 / h \mathrm{em}$ pequenas separações e decai proporcionalmente a $1 / h^{6}$ a distâncias maiores. Por outro lado, a repulsão eletrostática é finita em pequenas distâncias e decai exponencialmente. Portanto, a energia geral da interação é dominada em pequenas e grandes separações pelo termo atrativo, enquanto a região intermediária pode ser repulsiva devido à contribuição eletrostática [30]. Esse comportamento pode ser visto na Figura (2.5) na seção (2.2.3.3).

É importante notar que as duas forças supracitadas não representam todas as interações que podem influenciar no acontecimento do fenômeno de floculação. Além dessas, repulsão estérica, atração por depleção, forças oscilatórias de superfícies e interações hidrofóbicas e de hidratação também são responsáveis por reger o comportamento das interação das gotas de uma emulsão.

À vista disso, somando-se aos fatores energéticos e de interação, a polidispersidade das gotas da emulsão também pode influenciar substancialmente a decorrência da floculação. Isso se deve à diferença de velocidade de sedimentação das gotas, uma vez que, em sistemas polidispersos, estas se aproximam de maneira mais habitual quando se comparada aos sistemas monodispersos. Além disso, a frequência de encontro das gotas das emulsões e o tempo de contato das mesmas são também fatores que podem ser fundamentais para que o processo de floculação aconteça [4].

Cinética da floculação A floculação pode ser dividida em duas etapas principais: transporte e fixação, uma vez que elas só acontecem quando as partículas colidem e se aderem umas as outras. A maioria das interações coloidais são de curto alcance, representando pouca influência sobre o transporte das partículas [24]. Porém, essas interações são as principais responsáveis pela etapa de fixação.

Tal regime de transporte pode ser divido em duas partes principais: o movimento Browniano e a sedimentação diferencial [24]. O primeiro é uma movimentação aleatória das gotas causada pelas colisões destas com átomos e outras gotas. Já a segunda é causada pela diferença na velocidade de sedimentação/creaming de gotas com tamanhos distintos, conforme já supracitado.

Por outro lado, na literatura, é muito mais notório a preocupação com as forças de superfície que governam a etapa de fixação do que com a cinética da floculação em si, visto que esta última abrange o processo completo. Tal estudo é bastante relevante uma vez que analisa e acompanha como as propriedades 
da emulsão se modificam até uma possível etapa de desestabilização da mesma. Juntamente com o processo de floculação e geração de pequenos agregados, é possível também a formação de uma estrutura gelificada. Em emulsões diluídas e com elevada polidispersidade, por exemplo, a floculação causa um aumento na taxa de sedimentação/creaming, uma vez que a velocidade vertical dos agregados é superior a de gotas individuais. Por outro lado, em emulsões extremamente concentradas, esses fenômenos são retardados por causa da formação de uma robusta rede de agregados [33,34]. Isso se baseia no fato de que as forças de interação não são influenciadas pela concentração, fazendo com que um aumento da concentração acarrete em um aumento no número de gotas agregadas.

Por fim, é importante ressaltar que a maioria dos estudos a respeito da cinética da floculação é baseada em sistemas monodispersos, o que simplifica a visão geral do processo. Juntamente a isso, estudos acerca da cinética da coalescência das gotas também podem ser realizados, devido à intensa correlação entre os dois processos.

Prevenção da floculação A prevenção para o processo de floculação pode ocorrer de diferentes formas. No caso de emulsões estericamente estabilizadas, quatro principais características são necessários:

- Cobertura completa das gotas pelas moléculas estabilizadoras.

- Forte ancoragem das cadeias à interface. Isso requer cadeias insolúveis no meio e solúveis na fase dispersa.

- Camadas espessas adsorvidas; a espessura da camada adsorvida deve estar na região de 5-10 nm.

- A cadeia estabilizadora deve ser mantida em boas condições de solvente, sob todas as condições de modificações de temperatura no armazenamento.

Cabe ressaltar que todas as propriedades expostas acima facilitam o surgimento/fortalecimento de forças repulsivas entre as gotas, fazendo com que elas se afastem cada vez mais impedindo a formação de agregados nas emulsões. 


\subsubsection{4}

\section{Ostwald ripening}

O fenômeno de Ostwald ripening tem como característica principal ser fundamentado na diferença de solubilidade entre gotas com tamanhos variados. Sendo assim, a polidispersidade do tamanho das gotas de uma emulsão é essencial para a entendimento de como ocorre o processo. Gotas menores possuem elevadas solubilidades quando comparadas com gotas maiores devido, sobretudo, ao efeito de curvatura e a pressão de Laplace. Assim, gotas menores tendem a se dissipar no bulk ao longo do tempo, sendo o material dissolvido nas de maior tamanho. Isso acarreta então em um maior crescimento das gotas maiores enquanto as espécies menores tendem a desaparecer. Do ponto de vista da estabilidade da dispersão, esse processo é quase sempre indesejável, porque espécies maiores terão taxas de sedimentação ou creaming elevadas [3,5].

Assim, de acordo com a Equação de Kelvin (2-23), a solubilidade de uma substância na forma de partículas esféricas aumenta com a diminuição do tamanho das mesmas [4].

$$
c(r)=c(\infty) \exp \left(\frac{2 \gamma V_{m}}{r R T}\right)
$$

onde $c(r)$ é a solubilidade em fase aquosa do óleo contido em uma gota de raio $r, c(\infty)$ é a solubilidade em um sistema com uma interface plana, $\gamma$ é a tensão interfacial entre duas fases e $V_{m}$ é volume molar de óleo (expresso em $\left.m^{3} m^{-1}\right), R$ a constante de gases e $T$ a temperatura absoluta.

Prevenção da Ostwald ripening Uma forma de prevenir a ocorrência do fenômeno de Ostwald ripening se baseia na adsorção de surfactantes ou polímeros na interface das gotas, o que dificultaria a taxa de incorporação de novas moléculas. Uma outra forma de se fazer isso seria a adição de componentes que reduziriam a taxa de difusão de moléculas no interior de outras espécies dispersas. Uma exemplo para isso seria adicionar uma pequena quantidade de óleo altamente insolúvel nas gotas de óleo dispersas em emulsões O/A, o que reduziria a taxa de difusão das moléculas de óleo originais [5].

\subsubsection{5}

\section{Inversão de fase}

Inversão de fase é o acontecimento no qual ocorre uma troca entre as fases dispersas e contínua de uma emulsão devido a algumas condições de tempo e espaço. Um exemplo claro desse processo é a conversão de emulsões O/A para 
outras do tipo A/O, passando assim por uma etapa de transição entre as duas emulsões.

\subsubsection{6}

\section{Demais fatores que influenciam na desestabilização das emulsões}

Conforme visto na seção (2.2) através da Lei de Stokes, um outro fator responsável por aumentar a velocidade de sedimentação das gotas e, com isso, ocasionar uma desestabilização das emulsões é o tamanho de gotas. Quanto menor o tamanho das gotas de emulsão, mais difícil será o processo de separação de água da fase oleosa.

Além disso, a viscosidade do meio se mostra um fator importante que influencia na estabilidade das emulsões. Quanto maior a viscosidade do meio em que as gotas se encontram dispersas, menor é a velocidade de sedimentação da gotas e mais difícil será separar a água da fase oleosa. Somado a isso, a temperatura também acaba sendo relevante no processo uma vez que um aumento na mesma ocasiona a diminuição da viscosidade do meio em função da redução das forças interativas intermoleculares.

\section{3}

\section{Mecanismos de estabilização de emulsões}

Conforme visto anteriormente, fatores termodinâmicos são extremamente relevantes quanto a estabilidade, ou não, de emulsões. Por outro lado, a presença de tensoativos, que serão vistos na seção (2.4), facilitam a formação e estabilização das emulsões sob o ponto de vista cinético. Como um exemplo, na indústria do petróleo, tensoativos naturais como asfaltenos e ácidos naftênicos são responsáveis por reduzir o efeito da coalescência, pois conseguem migrar efetivamente para interface, diminuindo a tensão interfacial entre as fases e promovendo assim a formação de uma película rígida e bem estruturada [11].

Sendo assim, alguns mecanismos associados a efeitos como o de Gibbs-Marangoni, queda de tensão interfacial e a formação de filme de interface [19] são responsáveis pela estabilização de emulsões sintetizadas.

\subsection{1}

\section{Efeito Gibbs-Marangoni}

A medida que há um aumento na concentração da fase dispersa nas emulsões, a importância do filme líquido responsável pela separação das gotas entre si também cresce, fazendo-o fundamental para a determinação da estabilidade do sistema. 
Ao longo do processo de emulsificação, acontece uma expansão da área superficial (A) acarretando em uma distribuição desigual de surfactante ao longo das regiões que foram expandidas da interface. Sendo assim, essa região possui uma menor adsorção de surfactante quando se comparada àquelas que não sofreram expansão (B). Consequentemente a isto, há também uma rápida difusão das moléculas de surfactantes ocupando a recém criada interface a fim de que o equilíbrio dinâmico seja restabelecido (C). Esse processo pode ser visto na Figura (2.9) e pode ser denominado de Efeito Marangoni ou Gibbs Marangoni.

Em síntese, esse fenômeno causa um aumento local da tensão superficial, assim como maior resistência a outras expansões e uma contração imediata da superfície. Isso provoca a geração de um gradiente de tensão superficial, sendo o transporte de líquido do bulk devido a esse gradiente [5].
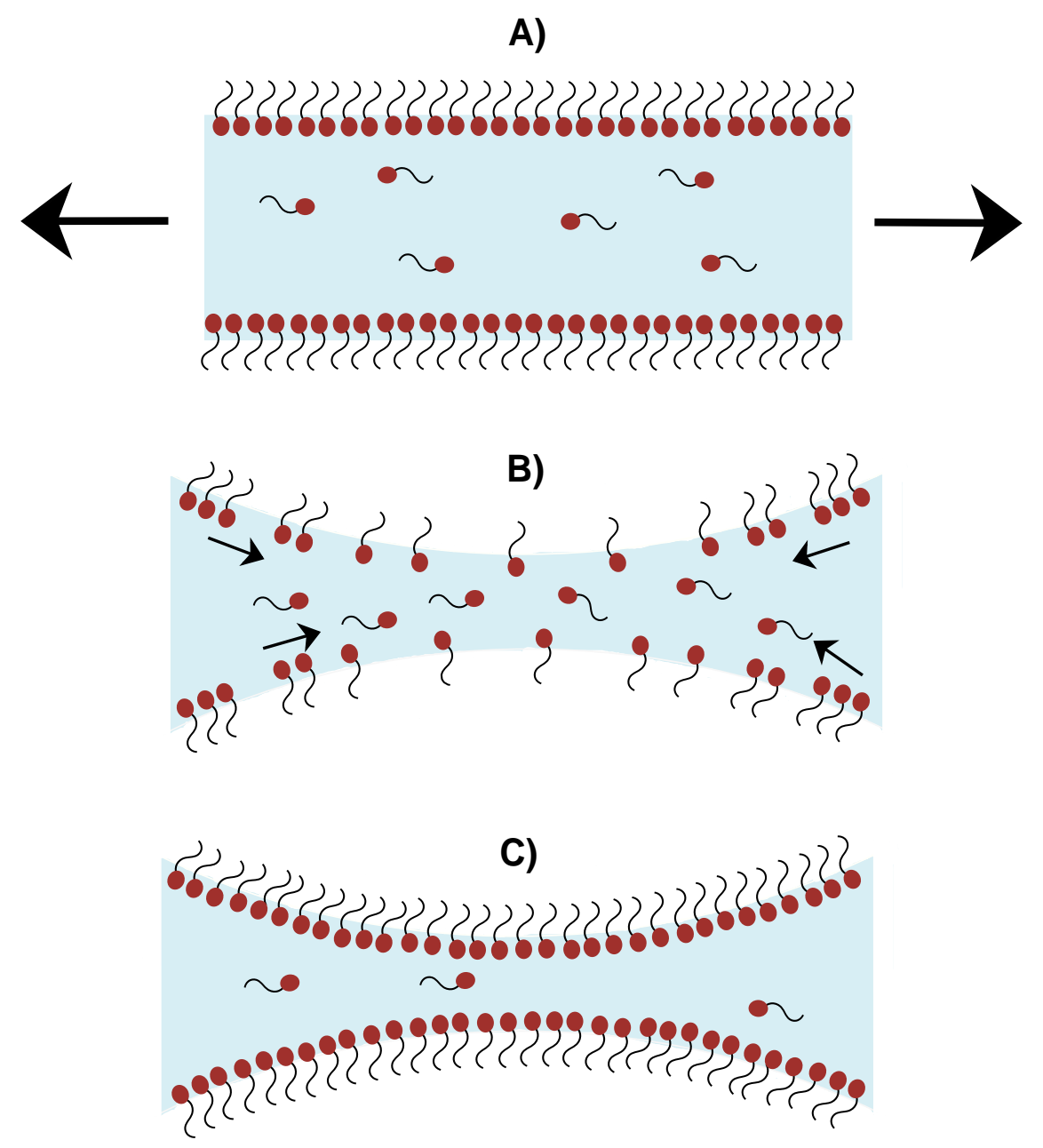

Figura 2.9: Representação do Efeito de Gibbs-Marangoni sequencialmente. 
É importante ressaltar que o efeito Gibbs Marangoni acontece somente até o restabelecimento do equilíbrio da adsorção de surfactantes no filme, uma vez que isto visa impedir a ruptura de filme. Por causa disso também, esse processo varia de acordo com a espessura do filme formado.

\subsection{2}

\section{Outros métodos de estabilização de emulsões}

Somando-se ao efeito de Gibbs-Marangoni, outros fatores também podem contribuir para o processo de estabilização das emulsões [19]:

- Formação de filme interfacial mecânico e elástico: o estabelecimento de uma camada rígida e bem estruturada de filme ao redor das gotas do sistema é fundamental para a melhoria da estabilidade das emulsões, evitando que alguns efeitos ocorram. Por isso, a camada de surfactantes é fundamental na estruturação do filme ao redor das gotas, o que a torna capaz de resistir a algumas deformações.

- Queda de tensão interfacial facilitando a formação de gotas.

- Repulsão da dupla camada elétrica: a presença de camadas elétricas similares serve como um componente que previne as colisões e, consequentemente, a coalescência das gotas.

- Distribuição de tamanho de gotas estreita: gotas maiores são menos instáveis do que as menores por causa da pequena razão área/volume assim emulsões com uma distribuição de tamanho de gotas uniforme apresentam maior estabilidade.

- Alta viscosidade da fase contínua o que diminui a ocorrência de eventos como creaming e coalescência.

\section{4}

\section{Surfactantes}

Conforme já dito ao longo deste trabalho, surfactantes são substâncias que possuem um papel essencial quanto as atividades superficiais ou interfaciais em sistemas dos quais eles estão contidos. Essas substâncias são materiais que diminuem a tensão superficial de líquidos ou a tensão interfacial de um sistema com duas fases devido a adsorção na superfície ou interface [5,35]. Tais compostos são formados por moléculas que possuem uma região hidrofílica, com afinidade a fase aquosa, e outra hidrofóbica, que apresenta pouca ou nenhuma afinidade com a mesma fase. A maioria desses surfactantes possuem moléculas com a "cabeça" hidrofílica (polar) e a cauda hidrofóbica (apolar), conforme visto na Figura (2.10). 


\section{Região hidrofílica (polar)}

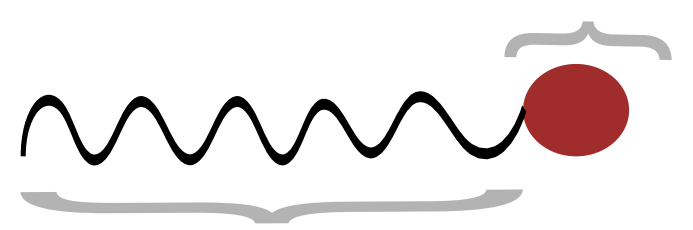

Região hidrofóbica (apolar)

Figura 2.10: Representação de uma molécula de surfactante.

Devido a essa estrutura anfifílica, as moléculas de surfactantes podem, portanto, ficar absorvidas na interface das duas fases imiscíveis do sistema. Para o caso mais simples de uma fase aquosa e outra oleosa, tem-se que a parte hidrofóbica da molécula (cauda) fica exposta ao óleo, enquanto a parte hidrofílica (cabeça) fica em contato com água.

De acordo com essa capacidade anfifílica, a explicação de como ocorre o funcionamento dos surfactantes se deve ao fato que a medida que dois líquidos imiscíveis são colocados em contato, as moléculas na interface são submetidas a um desequilíbrio de forças coesivas, que são forças intermoleculares que causam a tendência dos líquidos a resistirem a separação, e adesivas, que são forças atrativas entre moléculas diferentes causadas por forças mecânicas ou eletrostáticas. O desequilíbrio dessas forças acarreta, então, em um acúmulo de energia livre na interface, chamada de energia livre de superfície. Essa energia livre dividida por uma unidade de área é comumente conhecida como tensão interfacial. Assim, através da modificação drástica dessa energia de superfície é que ocorre a atuação dos surfactantes, fazendo-se com que a tensão superficial seja reduzida drasticamente [36].

Esses tensoativos podem ser classificados em diferentes tipos principais, de acordo com a carga de sua porção hidrofílica, sendo eles: não-iônico, aniônico, catiônico e anfóteros. 


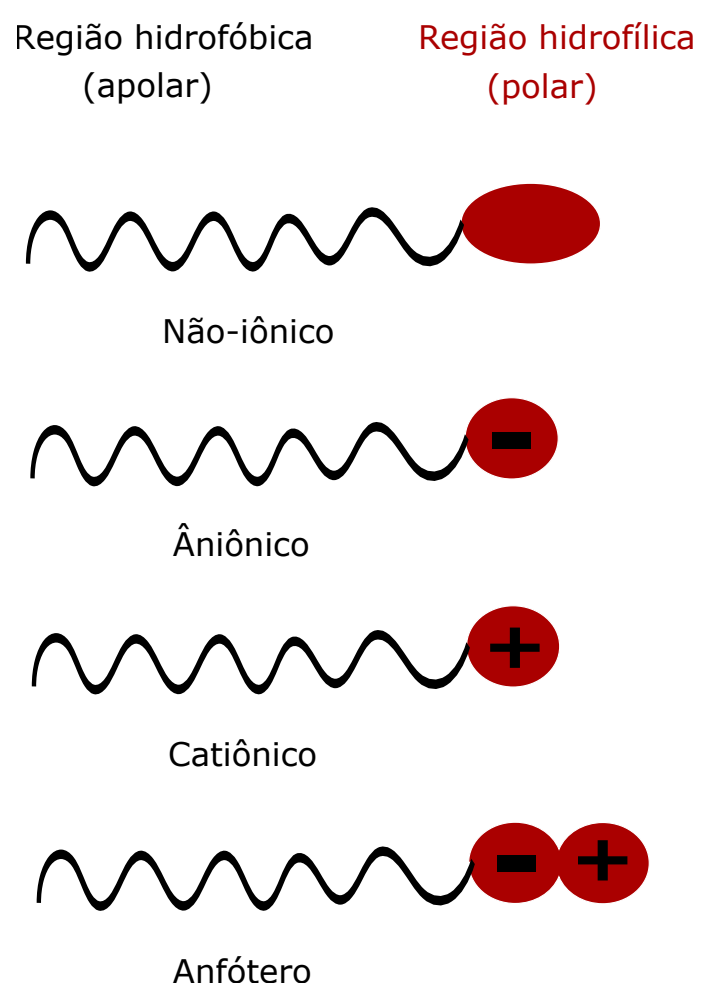

Figura 2.11: Classificação dos surfactantes de acordo com suas moléculas: não iônicos, aniônicos, catiônicos e anfóteros.

\subsection{1}

Tipos de surfactantes

\subsubsection{1}

\section{Não-iônicos}

Surfactantes não-iônicos não possuem carga em sua cabeça hidrofílica, sendo amplamente utilizados para a síntese de emulsões. Além disso, seu uso é bastante comum para a remoção de sujeira orgânica devido a capacidade de alguns deles possuírem uma baixa produção de espumas.

Além desta característica, esse tipo de surfactante possui uma propriedade denominada ponto de névoa, que representa a temperatura na qual começa a acontecerr uma separação de fases na mistura, uma vez que os surfactantes se separam da solução. Sabe-se, contudo, que abaixo desse valor a capacidade de detergência dos surfactantes é maior, enquanto acima deste esta diminui drasticamente. Essa propriedade varia conforme a razão entre as partes hidrofóbica e hidrofílica da molécula do surfactante [35].

Alguns exemplos de surfactantes não-iônicos podem ser o etoxilatos, alkoxilatos, entre outros. 


\subsubsection{2}

\section{Aniônicos}

Surfactantes aniônicos são aqueles que apresentam uma carga negativa em sua cabeça hidrofílica [5]. Em temperaturas mais elevadas, apresentam efeitos hidrofóbicos quando dissolvidos em água enquanto em temperaturas baixas manifestam certa insolubilidade. Normalmente, são utilizados em produtos de limpeza uma vez que sua carga negativa é a responsável para suspensão das partículas de sujeira, o que facilita o processo de limpeza devido a formação de micelas. Além disso, são amplamente utilizados como aditivos de combustíveis, preventor de corrosão e desemulsificante [35].

Alguns exemplos de surfactantes aniônicos podem ser sulfatos, sulfonatos, gluconatos, entre outros.

\subsubsection{3}

\section{Catiônicos}

Os surfactantes catiônicos possuem uma carga positiva em sua cabeça hidrofílica sendo comumente encontrados em desinfetantes, funcionando como agentes antimicrobianos.

Tais surfactantes não são utilizados juntamente com o tipo aniônico em um único sistema de emulsão, já que as cargas opostas dos dois acarretaria em uma queda da efetividade de ambos. Alguns exemplos de surfactantes aniônicos incluem cloretos de alquil amônio [35].

\subsubsection{4 \\ Anfóteros}

Por último, tem-se os surfactantes anfóteros que possuem uma carga negativa e outra positiva em sua cabeça hidrofílica. Por causa desse contraste de cargas, o pH do sistema se torna o principal responsável pela mudança de comportamento dessas substâncias. Em soluções com baixo pH, os tensoativos ficam carregados positivamente e se comportaram de maneira similar a um surfactante catiônico. Por outro lado, em altos valores de $\mathrm{pH}$, o comportamento é similar aos surfactantes aniônicos [37].

Tais surfactantes são ainda pouco conhecidos mas já comumente utilizados em produtos de higiene pessoal como shampoos e cosméticos. Alguns exemplos de surfactantes anfóteros podem ser betaínas e óxidos aminos. 


\section{4 .2}

\section{Concentração Micelar Crítica (CMC)}

O aumento da quantidade de surfactante em uma solução aquosa acarreta em uma maior migração das moléculas para a interface, reduzindo substancialmente a tensão interfacial. Assim, em um determinado ponto, a interface se torna saturada atingindo uma concentração máxima de surfactante. É nessa concentração de início de formação das micelas que se estabelece a chamada Concentração Micelar Crítica (CMC). A partir desse ponto, surfactantes ficam diluídos na fase contínua, tendendo a se agregarem de uma forma que minimiza a área de contato desses grupos com a fase contínua, iniciando-se o processo de surgimento das micelas, expresso na Figura (2.12) [38]. Por causa disso, é importante notar também que a CMC é o ponto no qual o aumento da quantidade de surfactante não impacta diretamente a interface já formada.

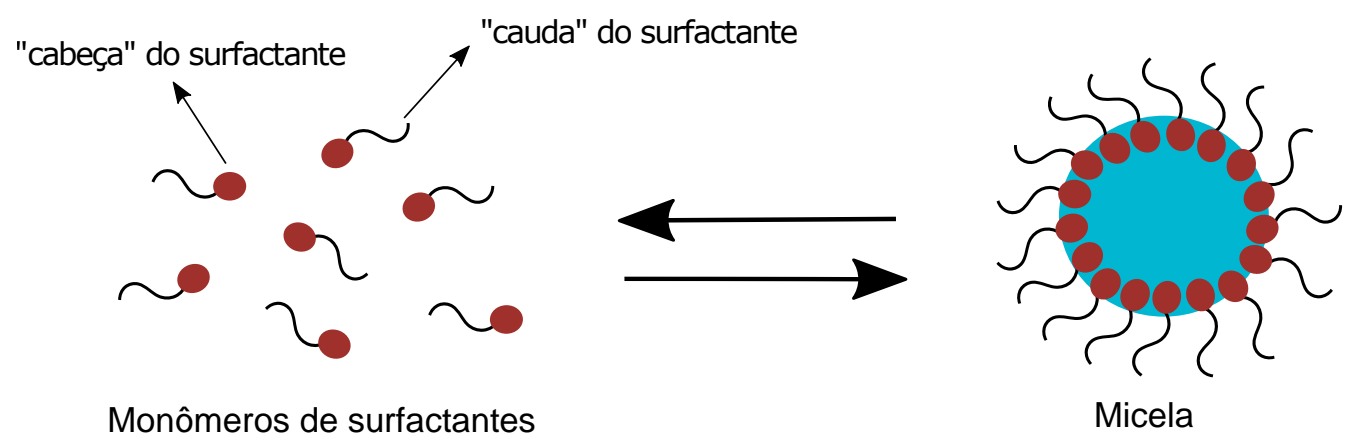

Figura 2.12: Formação de micela reversa (emulsão A/O).

Essas micelas podem apresentar diferentes configurações, conforme pode ser visto na Figura (2.13) abaixo. Cabe ressaltar que um fator de empacotamento $(C p p)$ pode ser associado a cada uma dessas estruturas, no qual $L$ representa o comprimento da cadeia, $A$ a área da seção transversal da cabeça polar e $V$ o volume da cadeia hidrofóbica [39]. 


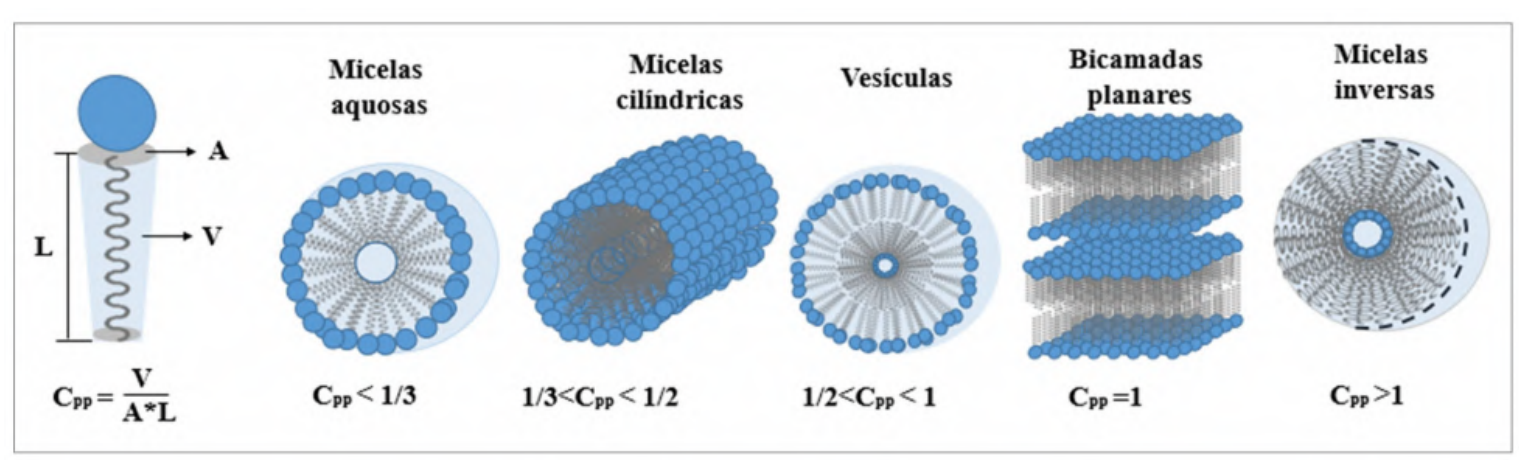

Figura 2.13: Tipos de micelas e suas representações [39].

A mais comum dessas estruturas, encontrada em fases aquosas, é a micela esférica, cuja superfície é composta de diversas cabeças polares que isolam as cadeias lineares apolares em seu interior. Esses agregados são formados por 30 a 100 moléculas de surfactantes, o que representa uma grande variação do tamanho do agregado dependendo do tipo de surfactante [40]. Analogamente, micelas esféricas inversas podem ser formadas em fases contínuas oleosas.

$\mathrm{Na}$ literatura, um grande número de estudos apontam que a $\mathrm{CMC}$ é influenciada de acordo com a estrutura molecular (tamanho da cadeia carbônica), concentração de eletrólitos, pH e temperatura. Além disso, a variação de entropia do sistema pode facilitar a formação das micelas e induzir numa alteração da CMC. Como etapa preliminar, esse processo é favorecido por um aumento na entropia: as moléculas de água próximas à cadeia hidrocarbônica são mais ordenadas do que as moléculas do bulk, causando consequentemente redução de entropia. Contudo, esse efeito é pequeno em comparação ao ganho de entropia das moléculas de água no entorno, já que todas as cadeias de hidrocarbonetos encontram-se escondidas dentro das micelas. Através da formação de agregados, as cadeias hidrofóbicas se tornam menos próximas das moléculas de água e a entropia aumenta [11].

Alguns parâmetros apresentam comportamentos fortemente associados ao atingimento da CMC. O primeiro deles é a tensão superficial, uma vez que o aumento da concentração de surfactantes faz com que haja uma queda substancial da mesma. Ao atingir esse valor, a tensão superficial torna-se praticamente constante com o surgimento de micelas em solução. Esse comportamento é similar àquele que ocorre com a pressão osmótica após a CMC, conforme visto na Figura (2.14). Por outro lado, para a turbidez verifica-se que há um crescimento linear a medida que aumenta-se a concentração de surfactante, sobretudo após o ponto de CMC. Já para a condutividade molar, uma queda brusca da curva pode ser observada após 
este ponto [19].

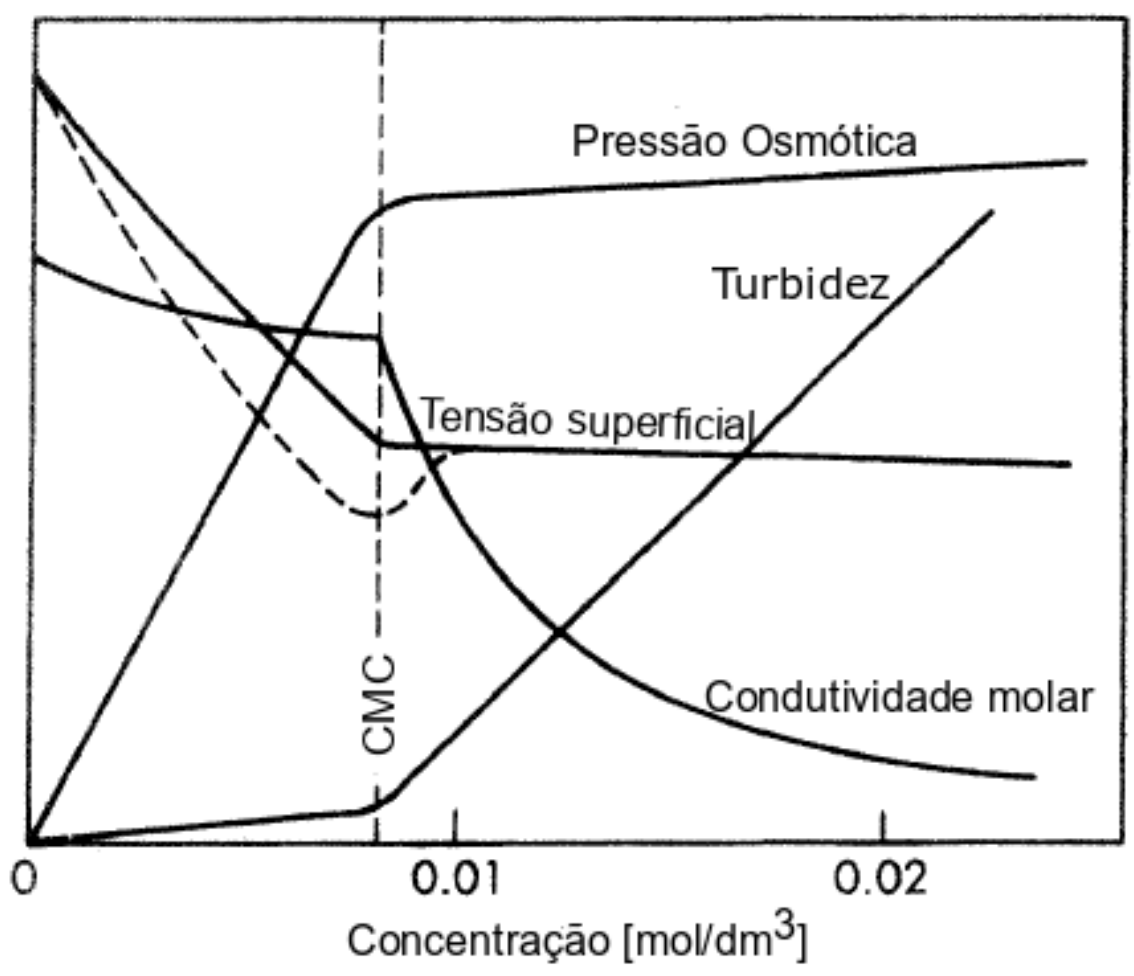

Figura 2.14: Propriedades fisico-químicas de soluções de dodecil sulfato de sódio a $25^{\circ} \mathrm{C}$ (Adaptado de [19]).

\subsection{3}

\section{Balanço Hidrofílico-Lipofílico (HLB)}

A síntese de diferentes tipos de emulsões pode ser realizada através da escolha correta do surfactante a ser utilizado ou, até mesmo, da mistura destes. Essa seleção é extremamente importante uma vez que isso acarretará na estabilidade e possibilidade, ou não, de inversão de fases das emulsões sintetizadas. Para essa escolha, dois conceitos básicos podem ser citados visando a geração das emulsões: a regra de ouro de Bancroft e o conceito da escala de HLB.

Resumidamente, a regra de Bancroft afirma que a fase contínua de uma emulsão será a fase na qual o emulsificante é preferencialmente solúvel. Por causa disso, Bancroft definiu que "um certo colóide hidrofílico tende a fazer com que a água seja a fase contínua enquanto um colóide hidrofóbico tende a fazer com que a fase aquosa seja a fase dispersa" [38]. Portanto, devido a sua diversidade, surfactantes podem ser dissolvidos mais facilmente tanto em fases aquosas quanto em fases oleosas [41]. 
Um outro importante conceito denominado de Balanço Hidrofílico-Lipofílico (HLB) é amplamente utilizado e estudado na literatura. Tal compreensão se apoia na observação de que o valor de HLB é baseado no balanço de tamanho e força dos grupos hidrofílicos e lipofílicos de uma mesma molécula de surfactante. Esses valores variam entre 0 e 20, representando numericamente o equilíbrio do tamanho da parte polar (hidrofílica) em relação a parte apolar (lipofílica) da molécula [25]. Sendo assim, um maior valor de HLB representa surfactantes que possuem uma maior afinidade com a fase aquosa, enquanto valores menores são aqueles que caracterizam tensoativos lipofílicos. Com isso, surfactantes com baixos valores de HLB (3-6) tendem a estabilizar emulsões de água em óleo, enquanto aqueles com altos valores de HLB (8-18) tendem a formar emulsões de óleo em água, conforme visto na Figura (2.15).

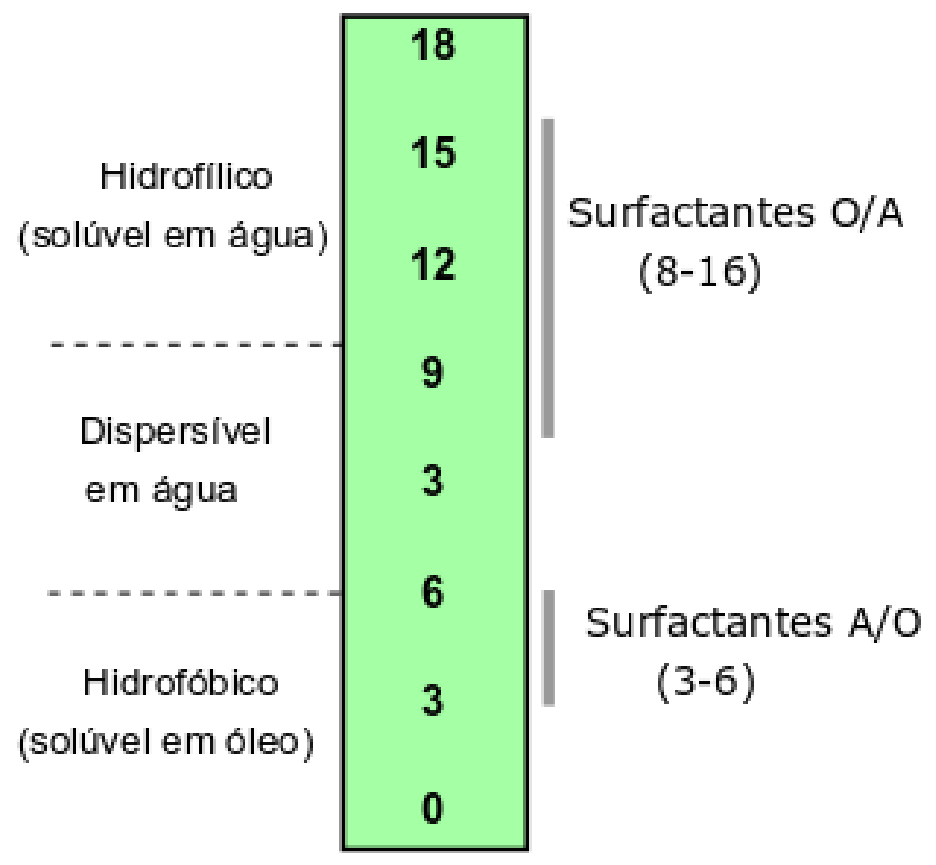

Figura 2.15: Escala representativa do valor de HLB

Com relação a misturas de dois surfactantes diferentes, observou-se que a combinação de surfactantes com HLB baixos e altos proporcionam emulsões mais estáveis do que aquelas sintetizadas a partir de um único surfactante, ainda que o valor do HLB seja equivalente ao da mistura gerada [42], o que faz com que esse último procedimento seja mais comumente utilizado. Para o cálculo desse HLB da mistura, tem-se a Equação (2-24).

$$
H L B_{m}=x_{1} H L B_{1}+x_{2} H L B_{2}
$$


no qual $H L B_{m}$ é o HLB da mistura, $x_{1}$ e $x_{2}$ são as frações volumétricas de cada um dos surfactantes, respectivamente.

Entretanto, o valor de $H L B_{m}$ não retrata o HLB característico que representa a composição da interface. Isso se deve as diferenças de mobilidades e solubilidades dos diferentes tipos de surfactantes em cada uma das fases, sem contar com a viscosidade dessas duas fases utilizadas. Sendo assim, a difusão dos surfactantes para a interface acontece de forma diferente para cada tipo de molécula, o que faz com que a composição do filme interfacial não seja correspondente à composição global de surfactantes no sistema [43]. Portanto, em misturas torna-se extremamente difícil a determinação da composição da camada de adsorção interfacial dos surfactantes.

Por fim, é importante destacar também que o valor de HLB pode mudar de acordo com o óleo utilizado para a síntese dos diferentes tipos de emulsões.

\section{5}

\section{Reologia}

Reologia é a ciência usada para a avaliar a deformação de materiais e seus escoamentos, através do estudo de como estes materiais respondem a uma determinada solicitação. Como um exemplo, têm-se que líquidos e gases ideias sofrem deformações que são irreversíveis, já que a energia utilizada no processo pode ser dissipada na forma de dois tipos de escoamentos: extensional e cisalhante.

Em síntese, escoamento de cisalhamento é aquele que ocorre quando as partículas adjacentes se movem uma em relação as outras devido a uma deformação, enquanto no extensional os elementos do fluidos escoam a favor ou contra umas as outras [11].

Uma propriedade de fundamental importância no estudo reológico dos materiais é a viscosidade que pode ser definida como a habilidade do fluido em resistir a mudanças no arranjo das moléculas quando submetido a uma tensão de cisalhamento. Sendo assim, um fluido é definido como Newtoniano quando a relação entre a tensão de cisalhamento e o gradiente local da velocidade é linear representando, nesse caso, a própria viscosidade do fluido. Isso é expresso pela Equação (2-25).

$$
\tau_{y x}=\mu \frac{d u}{d y}
$$

onde $\tau_{y x}$ é tensão de cisalhamento na direção $x, \frac{d u}{d y}$ é a taxa de cisalhamento e $\mu$ é a viscosidade, respectivamente.

Quando o comportamento do fluido não obedece a Lei de Newton da Viscosidade, estes são então denominados de Não-Newtonianos, sendo 
divididos em dois grandes grupos: puramente viscosos, que não apresentam elasticidade, e fluidos viscoelásticos, que apresentam propriedades viscosas e elásticas. Para ambos os casos, modelos obtidos empiricamente regem o comportamento da viscosidade através da taxa de cisalhamento.

A fim de que sejam medidas as principais características dos fluidos, equipamentos que simulem escoamentos são utilizados, sendo o principal deles o reômetro (Figura 2.16). Nele, é possível medir a relação entre a tensão e deformação ou taxa de deformação para diferentes tipos de fluidos, o que torna possível a caracterização dos mesmos.

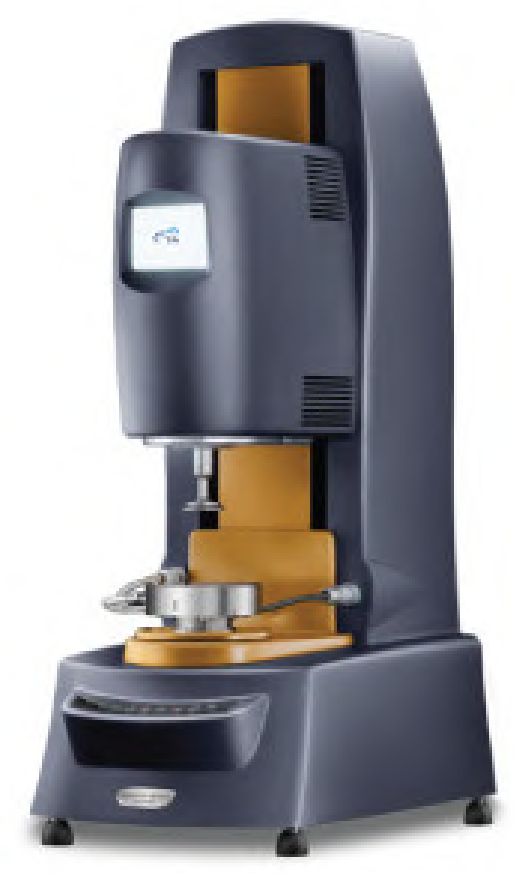

Figura 2.16: Reômetro DHR-3 da TA instruments

Essa medição acontece com a utilização de diferentes geometrias utilizadas para que o reômetro possa cisalhar a amostra a ser analisada. Dentre essas geometrias pode-se citar majoritariamente cilindros concêntricos, cone e placa e discos paralelos, sendo cada um delas escolhidas de acordo com a faixa de viscosidade do fluido a ser utilizado. Cabe ressaltar que problemas de deslizamentos ao longo dos testes experimentais podem acontecer com certa frequência, sendo evitados com o uso de superfícies ranhuradas em ambos os três casos dispostos anteriormente. 


\subsection{1 \\ Reologia de emulsões}

Através da adição de uma fase dispersa coloidal, a viscosidade do sistema aumenta quando se comparada a um valor inicial visto que partículas atuam como obstáculos para o escoamento do fluido [44]. A presença dessa fase dispersa acarreta em distorções nas linhas de corrente do escoamento na vizinhança dessas partículas. Essa modificação do escoamento causa, então, um aumento na dissipação local de energia e, consequentemente, um aumento na tensão cisalhante local para que o escoamento seja mantido. Por causa disso, a viscosidade do sistema cresce [45].

A reologia das emulsões pode ser influenciada por uma série de fatores, dentre eles: diâmetro médio da gota, distribuição de tamanho de gotas, fração volumétrica de fase dispersa, viscosidade da fase contínua, natureza da camada interfacial e forças de interação entre as gotas [4]. Somado a esses, um outro fator que pode interferir significativamente na viscosidade das emulsões é o fenômeno de floculação, uma vez que o comportamento reológico do sistema é alterado significativamente.

Dentre as propriedades citadas acima, a mais importante delas é a fração volumétrica da fase dispersa, representado por $\phi$. Dessa forma, a medida que há um aumento no valor de $\phi$, a distância entre as partículas é menor, o que acarreta em uma distorção das linhas de corrente entorno do escoamento de uma partícula adjacente e altera substancialmente a viscosidade do sistema como um todo. Sendo assim, há uma relação proporcional do valor de $\phi$ com a viscosidade do sistema disperso.

A fração volumétrica da fase dispersa ainda permite uma classificação das emulsões em quatro diferentes níveis [46, 47]:

- Emulsões diluídas: devido a pequena quantidade de gotas, as distorções nas linhas de corrente da fase contínua ao redor de uma gota não influenciam outras, sendo o regime dominado por movimentos Brownianos;

- Emulsões semi-diluídas: devido a um maior número de gotas, os campos de velocidade das gotas vizinhas são afetados, sendo o regime dominado por interações hidrodinâmicas;

- Emulsões concentradas: o limite superior dessa faixa é o limite de empacotamento máximo de uma suspensão de esferas rígidas e indeformáveis com a mesma distribuição de tamanho de partículas, sendo as interações dominadas por colisões de gotas; 
- Emulsões altamente concentradas: as gotas podem ser deformadas e comprimidas, sendo possível atingir níveis de concentrações acima do limite para suspensões de esferas rígidas. As interações são dominadas por atritos entre as superfícies das gotas e escoamentos internos.

De acordo com [48], em emulsões O/A bem diluídas $(\phi<0,01)$, a viscosidade $\eta$ será expressa utilizando-se da Equação de Einstein (2-26).

$$
\eta=\eta_{0}(1+[\eta] \phi)
$$

na qual $\eta_{0}$ representa a viscosidade da fase contínua, $\phi$ é a fração volumétrica da fase dispersa e $[\eta]$ é a viscosidade intrínseca. Esta última é uma medida de como a forma da partícula influencia nas perturbações das linhas de corrente. Para o caso das gotas serem consideradas esferas rígidas, esse valor é igual a 2,5 [25].

Desse modo, à medida que há um aumento da fração volumétrica, a complexidade do sistema cresce, o que faz com que a viscosidade relativa torne-se dependente dos coeficientes de Einstein, conforme visto na Equação $(2-27)$.

$$
\eta=\eta_{0}\left(1+k_{1} \phi+k_{2} \phi^{2}+k_{3} \phi^{3}+\ldots\right)
$$

no qual $k_{1}$ é o coeficiente de Einstein (equivalente a 2,5 para esferas rígidas), $k_{2}$ é o coeficiente que quantifica a interação hidrodinâmica entre as gotas, usualmente apresentando valor de 6,2 e é suficiente para descrever emulsões com até $\phi=0,2$. Por isso, acima desse valor o coeficiente $k_{3}$ é necessário $[25,48]$.

Particularmente para o caso quando a viscosidade das gotas dispersas é comparável ou inferior à do meio contínuo, emulsões com viscosidade $\eta_{i}$ para fase dispersa e $\eta_{o}$ para a fase contínua podem ser governadas pela Equação $(2-28)$.

$$
\eta_{r}=1+2,5\left(\frac{\eta_{i}+0,4 \eta_{o}}{\eta_{i}+\eta_{o}}\right) \phi
$$

Quando $\eta_{i}>>\eta_{o}$ as gotas se comportam como esferas rígidas, ficando a Equação (2-28) similar a Equação de Einstein (2-26). Por outro lado, quando $\eta_{i}<<\eta_{o}$ o termo entre parêntesis se resume ao valor de 1. É importante notar que esse estudo leva em consideração a deformação de gotas, fato este que não ocorre em casos com a presença de surfactantes na interface, devido a gotas se comportarem como esferas rígidas. Assim, emulsões que possuem um filme elástico que previne a deformação das gotas apresentam uma diminuição da viscosidade com $\phi$ quando se comparada àquelas cuja deformação é levada em consideração [48]. 
Um terceiro fator que afeta a reologia das emulsões é a distribuição do tamanho de gotas, sobretudo em emulsões com valores de $\phi$ elevados. Assim, quando $\phi>0,6, \eta_{r}$ que representa a viscosidade relativa sendo a razão entre a viscosidade da emulsão $(\eta)$ e da fase contínua $\left(\eta_{0}\right)$, é inversamente proporcional ao diâmetro médio das gotas [48]. Sendo assim, em emulsões altamente concentradas a deformação das gotas e a elasticidade das mesmas influenciam significativamente na viscosidade.

\subsubsection{1}

\section{Equação de Krieger-Dougherty}

Em regimes semi-diluídos e em boa parte do regime concentrado, emulsões se aproximam de dispersões de esferas rígidas. Para esses casos, a viscosidade dessas emulsões pode ser relacionada ao modelo de esferas rígidas de Krieger-Dougherty que é utilizado em taxas de cisalhamentos altas ou baixas [44]. Sendo assim, a viscosidade relativa vai ser expressa pela Equação $(2-29)$ :

$$
\eta_{r}=\left[1-\frac{\phi}{\phi_{m}}\right]^{-[\eta] \phi_{m}}
$$

No qual a viscosidade intrínseca $[\eta]$ segue com valor de 2,5 para esferas rígidas, conforme visto anteriormente, e $\phi_{m}$ é a fração máxima de empacotamento. Esse último conceito é função da distribuição do tamanho de gotas e da deformabilidade das mesmas. Ele é equivalente a 0,64 para empacotamentos aleatórios e 0,74 para empacotamentos hexagonais de esferas monodispersas, conforme visto na Figura (2.17). Contudo, de acordo com a polidispersidade das emulsões, valores maiores de $\phi_{m}$ podem ser encontrados a partir da extrapolação do gráfico de $\eta^{-0,5}$ versus $\phi_{m}$ no qual o valor de $\eta$ tende ao infinito [48]. 


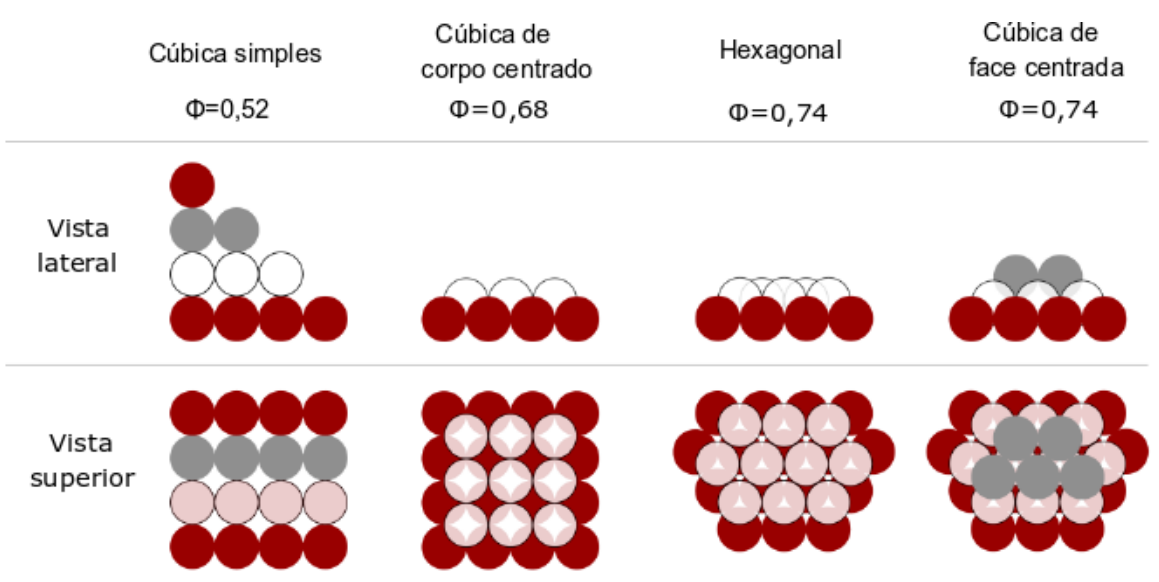

Figura 2.17: Diferentes arranjos com frações de empacotamento máximo variados. (Adaptado de [44])

Em síntese, para valores baixos de $\phi$, as interações entre as partículas são fracas fazendo com que o escoamento seja regido ainda pela comportamento Newtoniano da fase contínua. Com o aumento do valor de $\phi$, a colisão entre as partículas é cada vez maior acarretando um aumento na viscosidade, conforme visto na Figura (2.18) abaixo.

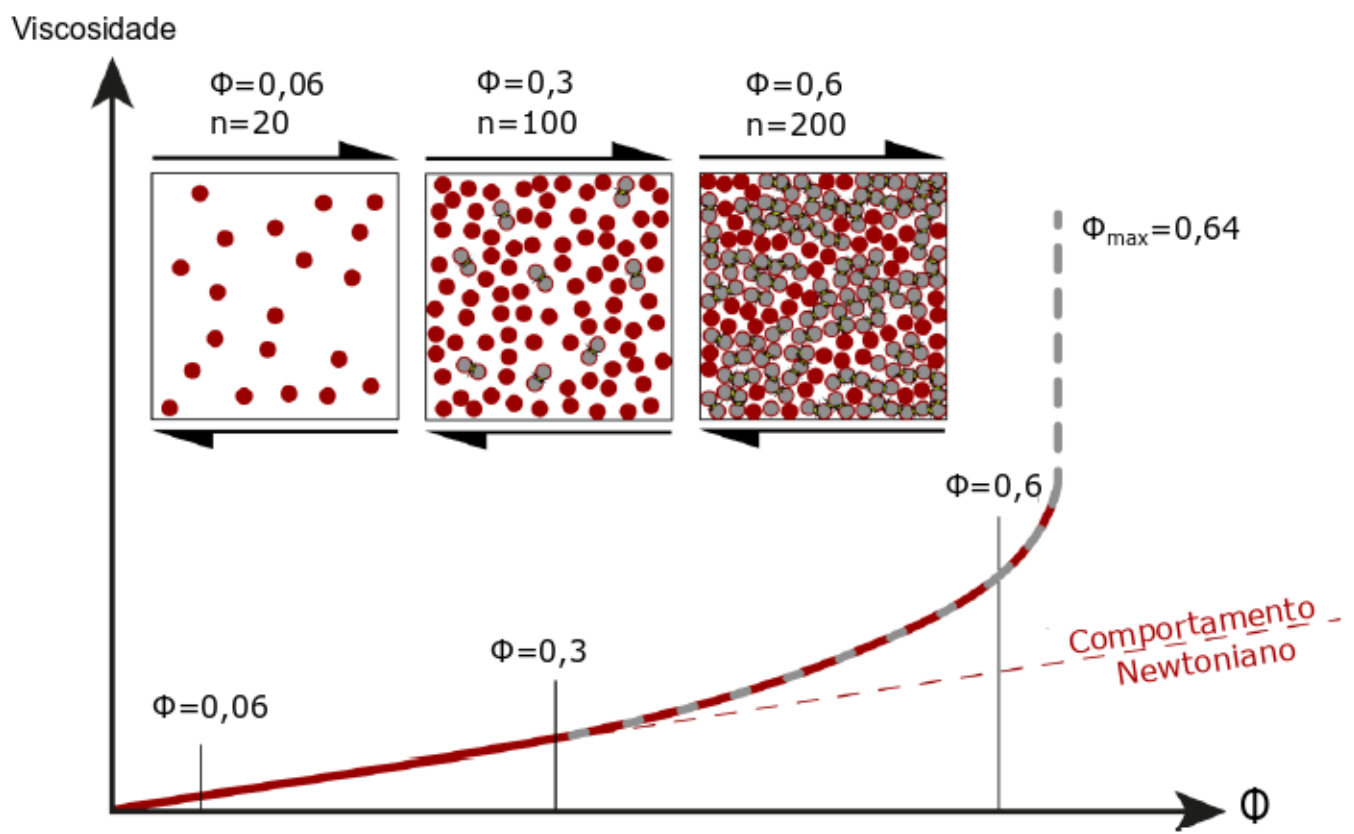

Figura 2.18: Comportamento da viscosidade com relação à fração de empacotamento. (Adaptado de [44]) 


\subsection{2}

\section{Aspectos relevantes na reologia das emulsões}

Além do equacionamento de modelagem do comportamento da reologia das emulsões mostrado anteriormente, há também uma série de fatores que regem o comportamento do escoamento desses sistemas.

- Shear Thinning: Para valores elevados de $\phi$, o comportamento Newtoniano descrito na seção anterior não permanece. Quando $\phi>$ 0,1, têm-se o início a ocorrência de shear thinning, uma vez que a interação entre as partículas se torna relevante, assim como a deformação das mesmas. Sendo assim, a observação do efeito de shear thinning é usualmente possível em partículas não esféricas e gotas deformáveis no regime diluído uma vez que, no regime semi diluído, partículas tendem a uma menor deformação e, portanto, uma redução no alinhamento às linhas de corrente. Por outro lado, no regime concentrado, restrições geométricas de empacotamento tendem a impor alguma orientação às gotas mesmo na ausência de cisalhamento [49].

De outra forma, em alguns sistemas, taxas maiores de cisalhamentos podem acarretar na formação de clusters causando a ocorrência de shear thickening, conforme pode ser visto na Figura (2.19) abaixo. A transição entre esses dois fenômenos reológicos é controlada por fatores como a distribuição do tamanho de gotas e a forma das mesmas.

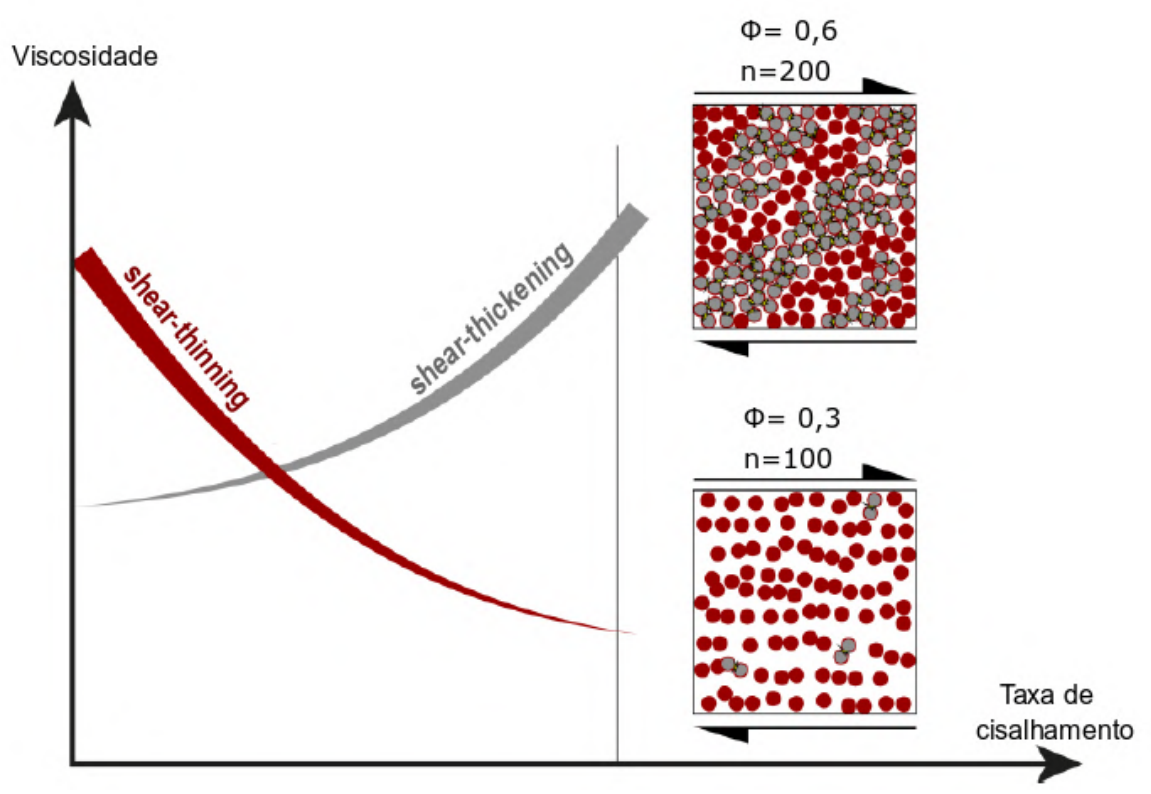

Figura 2.19: Comportamento de shear-thinning e shear thickening em emulsões. (Adaptado de [44]) 
Um fator que também causa o comportamento shear thinning em emulsões concentradas é a magnitude da floculação gerada devido a uma menor distância entre as gotas contidas no sistema. Assim, como visto anteriormente na seção (2.2.4.3), floculações fortes e fracas podem acontecer. Contudo, um aumento na taxa de cisalhamento pode ocasionar em uma quebra das estruturas criadas apenas pelas floculações mais fracas, conforme pode ser visto na Figura (2.20).

\section{Viscosidade}

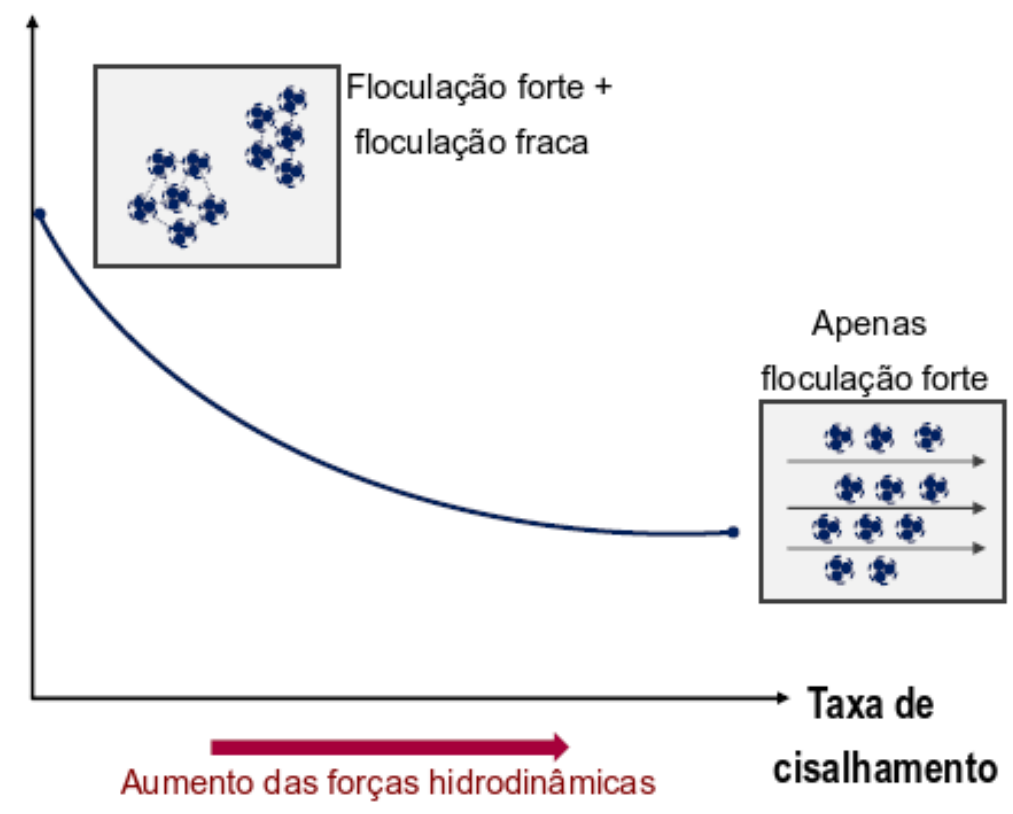

Figura 2.20: Representação da desestruturação de agregados e floculação com aumento da taxa de cisalhamento.

Por isso, a mudança no comportamento na viscosidade pode ser explicada a medida em que, em baixas taxas de cisalhamentos, há a formação de agregados cuja rotação causa mais dissipação de energia do que um mesmo número de gotas isoladas, fazendo com que a viscosidade da emulsão seja mais alta. Com o aumento da taxa de cisalhamento, esses agregados podem ser fragmentados à medida que forças hidrodinâmicas apresentem uma magnitude suficiente para quebrá-los, alinhando-os com as linhas de escoamento. Em consequência disso, a viscosidade do sistema cai substancialmente.

\section{- Tamanho das gotas:}

Com relação ao tamanho das partículas, sabe-se que gotas maiores apresentam uma menor rigidez e, consequentemente, maior capacidade de deformabilidade. Isso pode ser expresso através da razão $(\sigma / R)$ entre o 
tamanho da camada de surfactante e o raio da gota, já que gotas grandes apresentam valores reduzidos deste parâmetro quando se comparado àquelas menores [50].

Além disso, sabe-se que para dada fração volumétrica de fase dispersa, uma diminuição no tamanho das gotas resulta em uma menor distância média de separação e, portanto, em um aumento na interação hidrodinâmica e na viscosidade. Sendo assim, essa última propriedade cresce conforme o tamanho de gotas diminui. Com isso, em taxas de cisalhamentos maiores, a diferença de viscosidade entre partículas de tamanhos diferentes é diminuída devido ao alinhamento na direção de fluxo, fenômeno este representado na Figura 2.21 [44].

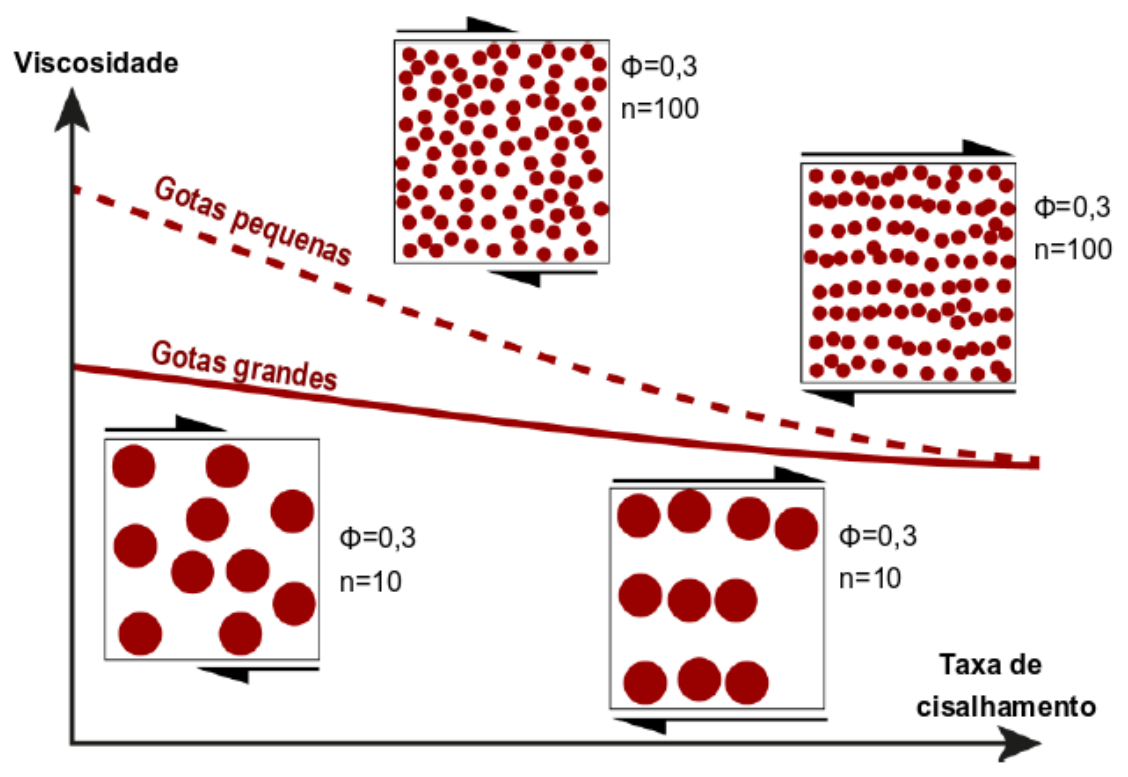

Figura 2.21: Representação do comportamento da viscosidade com tamanho de gotas. (Adaptado de [44])

O tamanho de gotas das partículas é também um parâmetro fundamental para um outro conceito que é a polidispersidade dos sistemas. Em sistemas concentrados que possuam uma polidispersidade maior das gotas, ou seja, com partículas grandes e pequenas, há um valor $\phi_{m}$ maior, o que acarreta em uma redução da viscosidade em uma determinada concentração de acordo com a equação de Krieger e Dougherty. Assim, quanto maior a polidispersidade do sistema, menor será a viscosidade medida. Cabe ressaltar que esse comportamento acontece somente quando a polidispersidade das gotas for bimodal $[44,51]$.

- Forma das partículas: Um outro importante fator que afeta a reologia das emulsões é a forma da partícula. A medida que irregularidades são 
encontradas na superfície das partículas, a viscosidade aumenta uma vez que há um maior desvio nas linhas de escoamento ao redor da partícula. Além disso, essa maior irregularidade na superfície acarreta também em uma maior interação entre as partículas, o que faz com que aconteçam modificações nos valores absolutos da viscosidade, como pode ser visto na Figura (2.22).
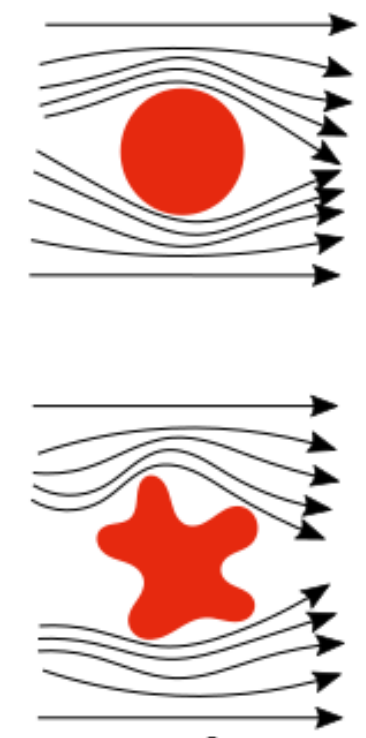

A)
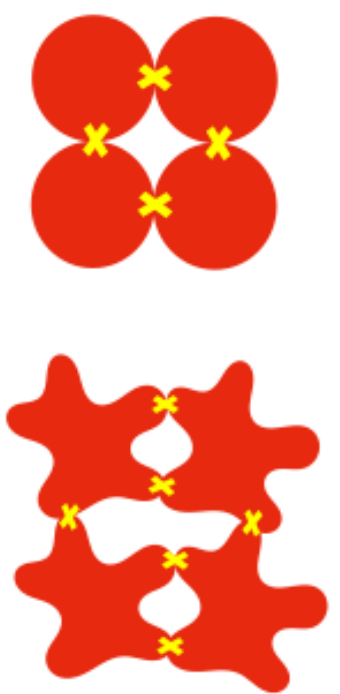

B)

Figura 2.22: A) Representação do desvio das linhas de corrente em partículas com diferentes formas. B) Visualização de maior interação entre as partículas de formas diferentes, representada pelo "X"amarelo.

Sendo assim, partículas elipsóides, em baixas taxas de cisalhamento, apresentam maior viscosidade por perturbarem de maneira mais concisa as linhas de corrente. Por outro lado, em altas taxas de cisalhamento, esse comportamento se inverte uma vez que tais partículas possuem uma maior capacidade de adaptação a direção do escoamento, reduzindo a viscosidade quando se comparada àquelas com formato esférico. Esse fenômeno pode ser visto na Figura (2.23). 


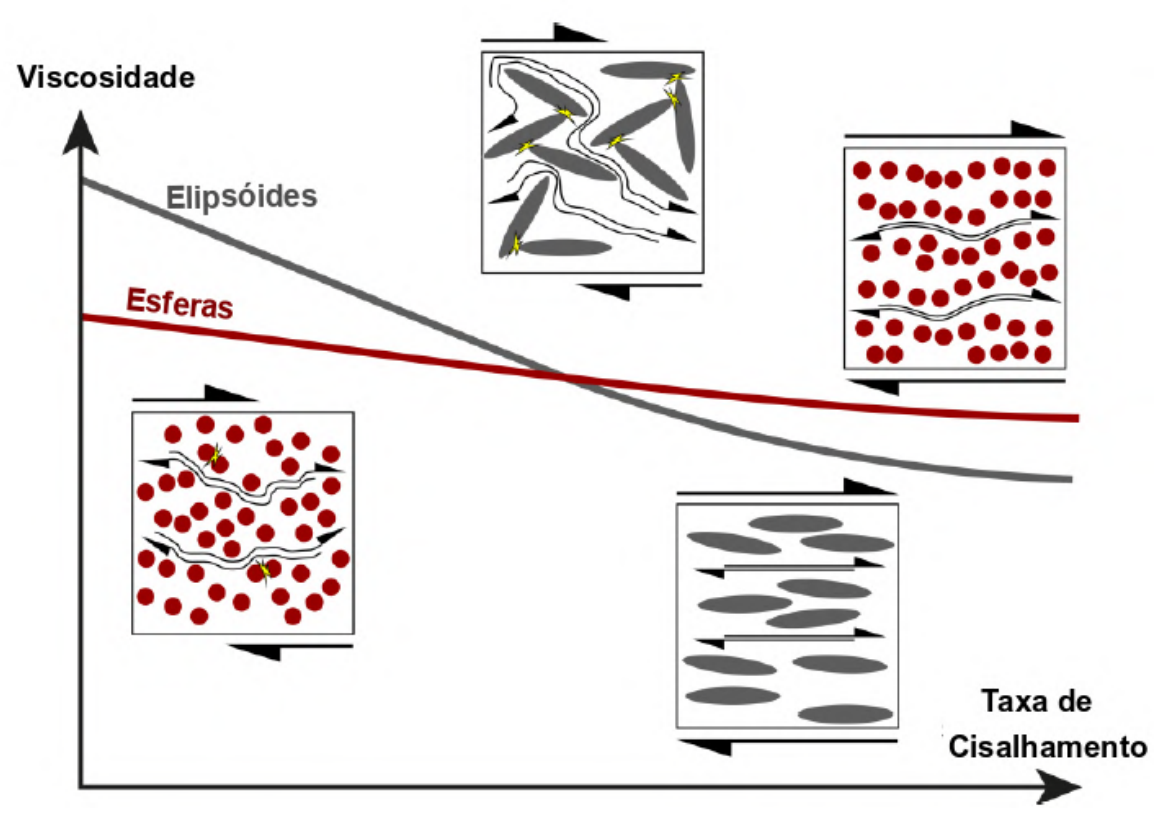

Figura 2.23: Representação do comportamento da viscosidade em função da taxa de cisalhamento e forma das partículas. (Adaptado de [44])

\section{6}

\section{Fluido modelo}

Fluido modelo, conhecido também como fluido de referência, são fluidos que são sintetizados com o objetivo de possuir características semelhantes a outros fluidos em determinadas condições. Tais fluidos de referência são mais baratos, não prejudiciais ao meio ambiente e possuem composição conhecida [9]. Assim, na literatura é comum o uso desses modelos voltados para o desenvolvimento de pesquisas biológicas e médicas, como é o caso da síntese de sangue artificial.

Para a indústria de petróleo, óleos crus e emulsões são fluidos de extrema dificuldade de trabalho. Isso é devido a uma grande variação na composição e propriedades físicas dos óleos crus, sem contar com o fato desse óleo ser tóxico, volátil e inflamável. Por causa disso, utilizar fluidos de referência com diferentes composições ao invés de óleos reais diminui o impacto ambiental e aumenta a segurança do laboratório [1]. Um exemplo para isso, assim como para a realização deste trabalho, pode ser visto em Rodionova et al. [1] que sintetizou um fluido modelo para mimetizar as propriedades do óleo pesado do Mar do Norte.

Rodionova et al. [1] explicita também que um dos componentes majoritários de fluidos modelos são os óleos minerais ou sintéticos. Tais óleos apresentam baixa capacidade em produzir emulsões que possuam grande 
estabilidade, tornando-se necessário o uso de surfactantes específicos. Esses tensoativos seriam responsáveis por simularem o comportamento exercido por resinas e asfaltenos em emulsões de petróleo, uma vez que são essas moléculas que permanecem na interface ajudando na estabilização desses sistemas.

Deste modo, é cada vez mais frequente o uso de fluidos modelo para a síntese de emulsões que representem aquelas obtidas com o petróleo durante o processo de envelhecimento do poço. O emprego dessas emulsões modelo torna-se essencial para observar a estabilidade e formação/separação das mesmas, o que é de grande importância para o desenvolvimento e otimização de equipamentos que utilizem emulsões de petróleo, como será visto na seção a seguir.

\section{7}

\section{Equipamentos de separação das emulsões}

A separação de fases das emulsões pode ser realizada através da utilização de uma série de métodos. Processos físicos, químicos e eletroquímicos são os mais comumente aplicados, sendo alguns deles vistos abaixo.

\subsection{1}

\section{Separador gravitacional}

Dentre esses métodos, processos físicos são usualmente empregados na separação das fases oleosas e aquosas, já que apresentam menores custos, não modificam as propriedades físicas do óleo e possuem uma operação que praticamente não agride o meio ambiente [52]. O principal representante desses processos físicos é o separador gravitacional.

Esse equipamento possui as vantagens descritas acima mas também apresenta um contraponto referente ao seu extenso tamanho. Cabe ressaltar que esse problema é mais relevante em plantas industriais offshore, uma vez que há a limitação do espaço físico nas plataformas [52].

Sendo assim, o separador gravitacional é o equipamento no qual a separação dos fluidos ocorre devido a imiscibilidade entre eles, a diferença de densidade e a ação do campo gravitacional terrestre. Ele é formado por um vaso cilíndrico que contém um isolamento térmico assim como um sistema de pressurização capaz de manter um fluxo adequado para que ocorra a separação das fases.

O processo de separação por ação gravitacional para o caso das emulsões pode ser realizado tanto por batelada quanto de maneira contínua [53]. Ao longo dele, há a ocorrência de dois fenômenos principais simultaneamente: sedimentação/creaming e coalescência [52]. Primeiramente, o processo de 
separação gravitacional se baseia na sedimentação das gotas maiores até a formação de uma fase altamente empacotada, o que possibilitará uma coalescência entre elas e a formação de uma zona de água livre. Além disso, devido a uma menor velocidade terminal, gotas menores de água podem permanecer dispersas na fase oleosa assim como moléculas de óleo podem estar presentes na fase aquosa resultante, o que torna necessário um tratamento posterior do óleo a ser obtido e da água a ser descartada.

Separadores gravitacionais são dimensionados a fim de fornecer o tempo de retenção necessário para que haja a liberação da água livre. A partir de testes em batelada, estudos pilotos de fluxo ou informações catalogadas esse tempo de residência pode ser determinado [54]. Desta forma, o dimensionamento dos equipamentos são baseados a partir de duas informações principais, cujos valores devem estar abaixo dos permitidos pelas agências reguladoras:

- Quantidade de água contida no óleo.

- Teor de óleo contido na água (ou salmoura).

Cabe notar que tais equipamentos podem ser de dois tipos: horizontais e verticais. O primeiro caso é utilizado em petróleos leves e médios com ${ }^{\circ} \mathrm{API}$ superiores a 19, enquanto os separadores verticais são indicados para petróleos pesados. Em ambos os tipos, o fluxo líquido de entrada é direcionado para baixo da interface óleo/água através de um defletor localizado no início do separador. Isso é feito uma vez que a medida que o óleo sobe, por ser menos denso que fase aquosa, acontece o surgimento de um fluxo em contracorrente da água dispersa no mesmo, o que acarreta na coalescência das gotas e geração de uma zona de água livre [55]. É importante ressaltar que esses equipamentos são comumente utilizados para a separação de misturas trifásicas ao longo do processo de separações de fases (Figura 2.24). 


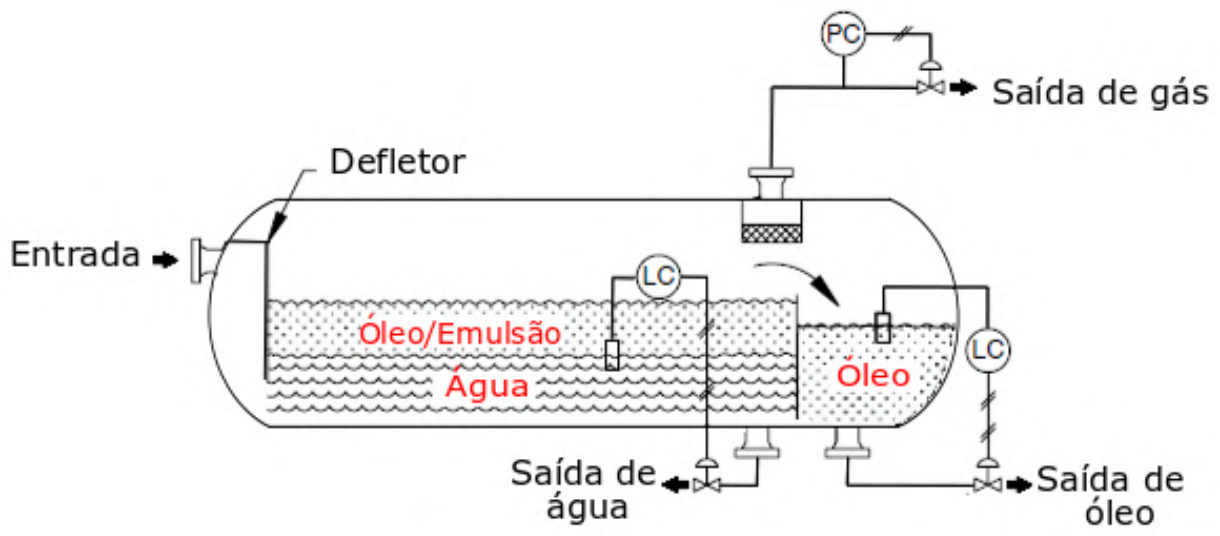

Figura 2.24: Esquema de um separador gravitacional horizontal trifásico (Adaptado de [55]).

\subsection{2}

\section{Tratador eletrostático}

Posteriormente ao separador gravitacional, há a presença do tratador eletrostático que visa retirar uma quantidade de água que ainda permanece no óleo obtido da primeira tecnologia. Neste equipamento a separação de fases se dá sobretudo devido a eletrocoalescência. Nele, gotas são submetidas a um campo elétrico criado entre dois eletrodos. Sob esse campo elétrico e, devido ao sal contido na água, há a formação de dipolos induzidos e alongamento das gotas de água. Sendo assim, a colisão entre as gotas ocorre por causa da atração de cargas contrárias gerando gotas maiores e a separação das fases. Esse equipamento é formado por um vaso cilíndrico contendo isolamento térmico, zona de pressurização e grades de eletrodos responsáveis pela ocorrência dos processo, podendo ser empregado para a desidratação ou dessalgação do petróleo. 


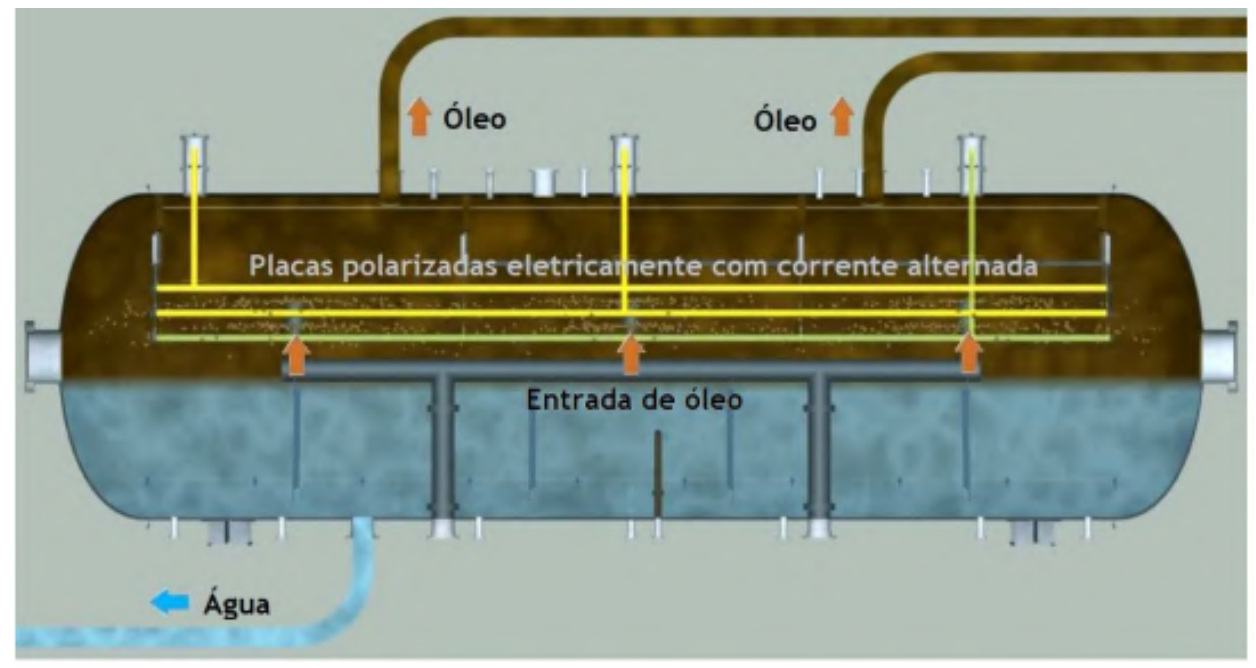

Figura 2.25: Imagem representativa de tratador eletrostático (Adaptado de [56]). 
3

\section{Materiais e métodos}

\section{1}

\section{Materiais utilizados}

Petróleos dos campos A e B foram fornecidos pela Petrobrás a fim de que fossem caracterizados em termos de viscosidade, densidade e tensão interfacial, conforme será visto posteriormente. Óleo mineral Primol 352, produzido pela Exxon Mobil, vaselina líquida, da LabSynth e surfactantes não iônicos como SPAN 85 (Trioleato de sorbitano; HLB 1,8; ideal para emulsões A/O) e TWEEN 85 (Trioleato de polioxietileno sorbitano; HLB 11,0; ideal para emulsões $\mathrm{O} / \mathrm{A}$ ) foram utilizados para a síntese das emulsões modelo. Ambos os surfactantes foram produzidos pela Sigma-Aldrich. Além disso, uma lista de sais foram utilizados para o preparo da água sintética, juntamente com água obtida através do processo de osmose reversa. Todos estes sais estão listados na seção (3.2.3.1).

\section{2 \\ Método experimental}

\subsection{1}

\section{Pré Tratamento do Petróleo}

Devido a volatilidade de alguns componentes presentes no petróleo, um pré tratamento do óleo é realizado visando um homogeneização da amostra como um todo. Nessa etapa, acontece a evaporação de frações mais voláteis e a substituição das memórias térmicas/mecânicas dos petróleos, alterando-se algumas características do óleo inicial.

Em petróleos parafínicos, como é o caso dos utilizados ao longo deste trabalho, existe uma temperatura inicial na qual começa a acontecer o aparecimento de cristais de parafina (TIAC). A formação desses cristais se baseia no histórico de temperaturas e esforços mecânicos sobre o qual o material foi exposto ao ser resfriado durante a etapa de extração do óleo. Por isso, processos de aquecimento são realizados visando a dissolução dos cristais de parafina e, sobretudo, o monitoramento das memórias térmicas e mecânicas do petróleo a ser utilizado nos testes experimentais. 
Por esses motivos, a etapa de pré tratamento dos petróleos deve ser baseada nos valores de TIAC obtidos através de rampas de temperatura dos fluidos, já que estas possibilitam a comparação entre a curva de viscosidade do óleo em resfriamento e um comportamento do tipo Arrhenius. Isso possibilita a utilização de uma taxa de aquecimento que não modifique de forma drástica as propriedades do óleo. Por isso, utilizou-se o reômetro AR-G2 da TA instruments, sendo a viscosidade dos petróleos obtidas em função da temperatura para uma taxa de resfriamento $\dot{T}_{c}=0,5^{\circ} \mathrm{C}$ e de cisalhamento $\dot{\gamma}=1[1 / \mathrm{s}]$. Para a execução dos testes, utilizou-se a geometria de placas paralelas ranhuradas com diâmetro de $60 \mathrm{~mm}$ como forma de minimizar efeitos de deslizamento.
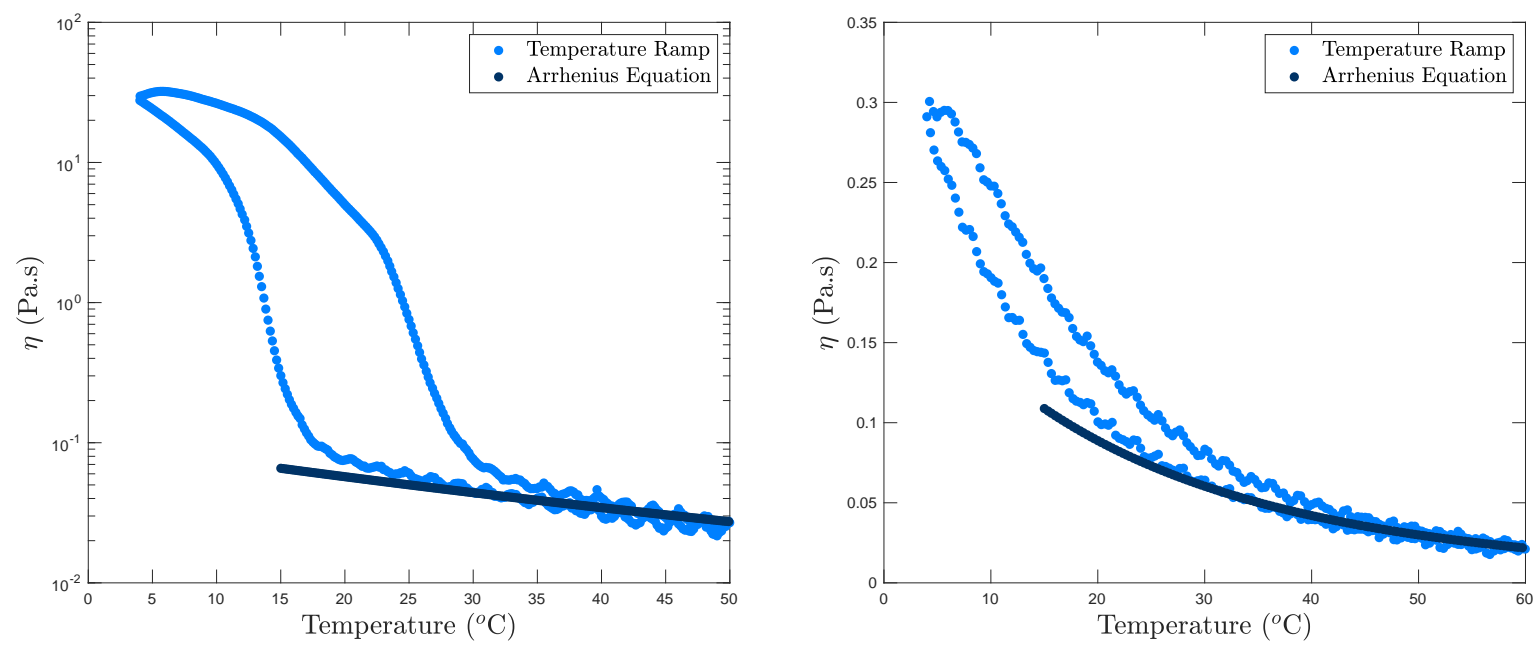

Figura 3.1: (a) Rampa de Temperatura do petróleo A.(b) Rampa de Temperatura do petróleo B.

A partir dos testes de temperatura de ambos os petróleos é possível perceber que o desvio significativo da rampa de resfriamento com relação à curva prevista pela equação de Arrhenius se dá em torno de $25^{\circ} \mathrm{C}$, o que define essa temperatura como o ponto TIAC (Figura 3.1). Cabe ressaltar também que, para o petróleo B, é possível notar uma presença menos marcada da formação de redes cristalinas de parafina.

Portanto, definiu-se o seguinte protocolo como pré tratamento dos petróleos:

- Pesar 200g de petróleo em um frasco padrão de $250 \mathrm{ml}$.

- Deixar o frasco destampado em banho-maria a $60{ }^{\circ} \mathrm{C}$ em uma placa aquecedora durante 60 minutos.

- Tampar o frasco e deixar o fluido resfriando à temperatura ambiente. 
Observa-se, portanto, que a temperatura escolhida encontra-se em uma faixa acima daquela obtida para o valor do TIAC, possibilitando a evaporação das frações voláteis e a uniformização das amostras a serem estudadas. É importante ressaltar que não foi necessário um procedimento para resfriamento do petróleo em uma taxa controlada, uma vez que os testes experimentais seriam realizados em temperaturas superiores $\left(40{ }^{\circ} \mathrm{C}\right)$ àquela obtida com a TIAC, o que impediria que a nova memória térmica/mecânica afetasse os resultados.

\subsection{2}

\section{Procedimentos Gerais do Petróleo}

\subsubsection{1}

\section{Viscosidade}

Para obtenção do comportamento reométrico dos petróleos utilizou-se o reômetro DHR-3, da empresa TA Instruments. Curvas de escoamento de $\dot{\gamma}=$ 1 1/s até $\dot{\gamma}=10001 / \mathrm{s}$ foram realizadas no reômetro DHR-3, utilizando a geometria de cilindros concêntricos DIN de superfícies lisas com diâmetro do estator $D_{E}=15,2 \mathrm{~mm}$ e do rotor de $D_{R}=14 \mathrm{~mm}$. Tais equipamentos podem ser vistos na Figura (3.2) a seguir.

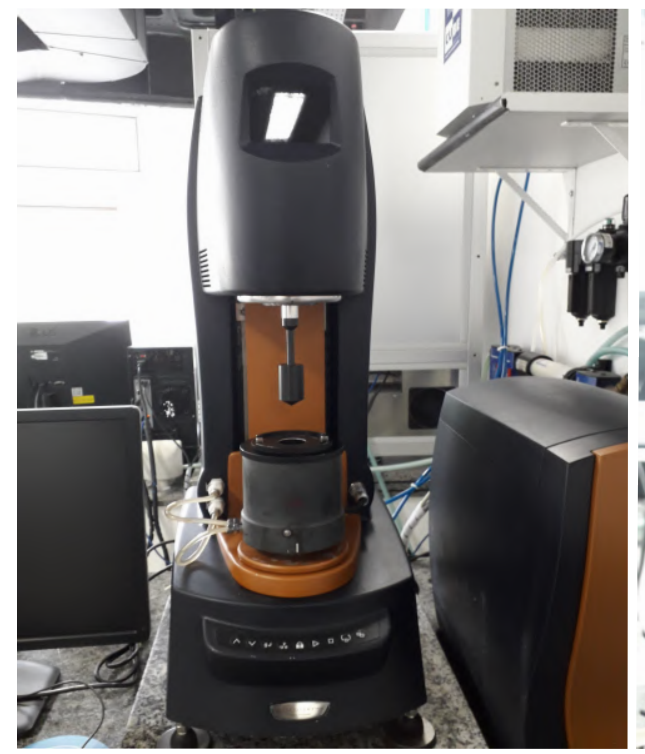

A)

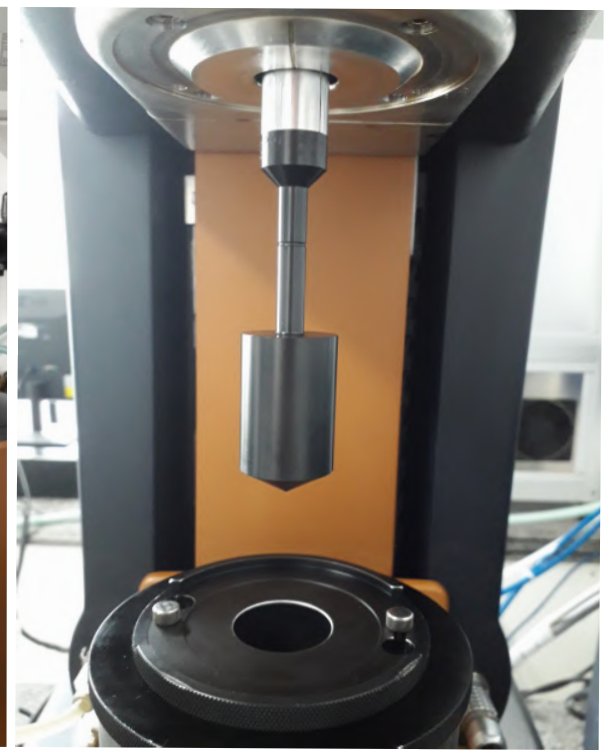

B)

Figura 3.2: A) Reômetro DHR-3 da TA Instruments. B) Geometria Couette utilizada para confecção dos testes experimientais.

A fim de que houvesse um equilíbrio térmico do sistema com a 
temperatura de interesse estabelecida $\left(40^{\circ} \mathrm{C}\right)$, o fluido permanece em repouso no reômetro durante 30 minutos. Sendo assim, é possível garantir que, ao iniciar a obtenção dos dados experimentais, o fluido já se encontre na temperatura estipulada.

\subsubsection{2}

\section{Densidade}

As medidas da massa específica dos petróleos em diferentes temperaturas foram realizadas de duas maneiras distintas. No Laboratório de Caracterização de Fluidos (LCF) da PUC-Rio, utilizou-se um picnômetro, de acordo com a norma ISO 1042. Já no Laboratório de Físico-química de Surfactantes (LaSurf), as medidas foram realizadas utilizando o equipamento DMA $4500 \mathrm{M}$, da empresa AntonPaar.

\subsubsection{3}

\section{Tensão Interfacial}

A tensão interfacial foi medida no Laboratório de Caracterização de Fluidos (LCF) da PUC-Rio com a utilização de um tensiômetro Lauda, uma geometria de placa de Wilhelmy e um multímetro Fluke 8846A. A geometria acoplada ao transdutor de força do tensiômetro transmite sinais elétricos ao multímetro possibilitando a obtenção dos dados experimentais. É importante frisar também que as medidas realizadas através da placa de Wilhelmy são estáticas, o que se apresenta como ideal de acordo com a tamanha mobilidade dos surfactantes contidos no petróleo e óleos modelo.

Primeiramente, é necessário uma calibração no transdutor de força do tensiômetro uma vez que este será responsável pela medição da força exercida na interface. Sendo assim, acopla-se a placa ao tensiômetro e zera-se a tensão. Posteriormente a isso, um peso de calibração é utilizado a fim de aferição se a tensão medida pelo multímetro é de $0,122 \mathrm{~V}$ (peso + placa), o que garante o ajuste do equipamento e possibilita o início dos testes experimentais. Todo esse procedimento garante que o empuxo seja considerado para o cálculo de resultados mais precisos e que representem apenas a força causada pela tensão interfacial.

O procedimento para medição da tensão interfacial (Figura 3.3) começa com a adição de uma determinada quantidade de água em um béquer localizado dentro da camisa metálica por onde circula a água do banho térmico do tensiômetro. Assim, dispõe-se a placa de Wilhelmy verticalmente até que a aresta inferior encoste levemente na interface, formando um menisco nas superfícies da placa e gerando uma força detectada pelo transdutor. Com o 
resultado obtido através deste teste, é possível verificar se a calibração do equipamento foi bem realizada tendo em vista que o valor da tensão superficial da água é conhecida na literatura.

Feito isso, o segundo passo consiste em descer a geometria de maneira com que ela fique abaixo da superfície da água, adicionando-se a fase mais leve até uma total submersão da placa. Posteriormente a isso, posiciona-se a geometria de forma com que a aresta inferior fique na interface entre as duas fases através da formação de um menisco, processo este que permanece até que o regime permanente seja estabelecido (cerca de 20 minutos). Feito isso, obtém-se os resultados experimentais através dos valores expressos no multímetro e há uma análise dos dados gerados.

a)

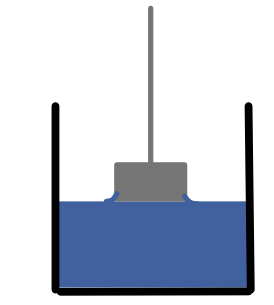

Medir a Tensão superficial da fase pesada (água 72 $\mathrm{mN} / \mathrm{m}$ a $25^{\circ} \mathrm{C}$ ).

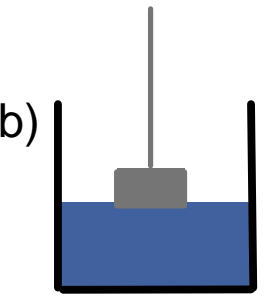

Descer um pouco abaixo da interface.

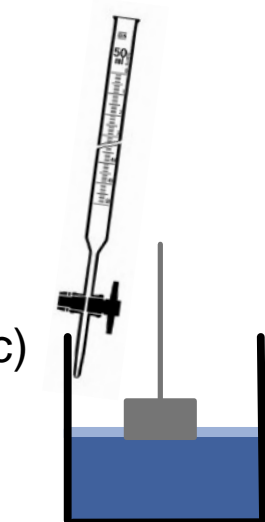

Adicionar cuidadosamente a fase mais leve.

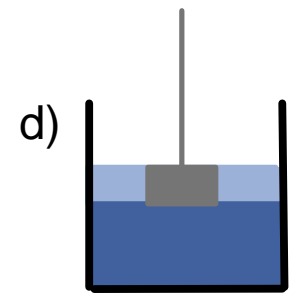

Adicionar fluido até que a placa fique totalmente submersa.

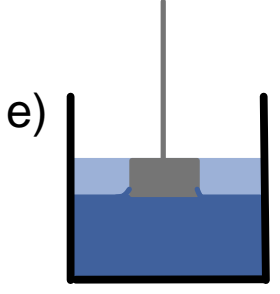

Subir a placa até o surgimento do menisco Deve - se pegar o valor maior da tensão interfacial.

Figura 3.3: Representação do processo de medição de tensão interfacial. 


\subsection{3}

\section{Procedimentos geral das emulsões}

\subsubsection{1}

\section{Processo de emulsificação}

Emulsões são produzidas nesse estudo através de processos de emulsificação de óleos e água sintetizada no laboratório, em diferentes cortes, visando simular o envelhecimento do poço.

A fim de que fosse possível simular emulsões que correspondessem fielmente às geradas no campo, decidiu-se pela utilização de uma água sintética caracterizada por possuir concentrações salinas semelhantes as da água do mar. Com isso, o foco principal seria no desenvolvimento de protocolos experimentais robustos e estudos de caso que possibilitassem a obtenção de um fluido modelo que fosse compatível com o petróleo, sem levar em conta variações na composição química da água utilizada.

Iniciando-se pelo processo de síntese da água sintética, concluiu-se que o uso de uma água contendo apenas $\mathrm{NaCl}$ poderia ser considerado uma aproximação bastante simplória da água do mar. Por isso, propôs-se então a utilização de outra formulação de água, baseada na norma ASTM D1141 - 98, que define o procedimento padrão para preparação de água do mar sintética.

\begin{tabular}{ccc} 
& Composição do Sal & Concentração $[\mathrm{g} / \mathrm{L}]$ \\
\hline $\mathrm{CaCl}$ & 61,99 \\
$\mathrm{CaCl}_{2} \cdot 2 \mathrm{H}_{2} \mathrm{O}$ & 10.0 \\
\multirow{2}{*}{ Água Sintética } & $\mathrm{MgCl}_{2} \cdot 6 \mathrm{H}_{2} \mathrm{O}$ & 6.3 \\
& $\mathrm{KCl}$ & 0.6 \\
& $\mathrm{NaCl}$ & 86.6 \\
$\mathrm{Na}_{2} \mathrm{SO}_{4}$ & 1.3 \\
\hline
\end{tabular}

Tabela 3.1: Composição da água sintética

Os componentes da água sintética, assim como os do fluido modelo a ser preparado e o próprio petróleo, foram pesados em uma balança analítica FA2104N da marca Bioprecisa dentro de uma vidraria específica para esta finalidade.

É importante frisar que, apesar de as emulsões serem sintetizadas com base em concentrações volumétricas, os métodos de medição de massa são muito mais precisos do que aqueles de medição de volume, uma vez que 
levam em consideração um maior número de casas decimais. Sendo assim, as concentrações volumétricas são calculadas para medidas mássicas através da massa específica de cada componente presente no sistema. Para cada um dos componentes utilizados, uma massa específica era associada visando o processo de pesagem desse componente.

Cabe ressaltar que as massas específicas dos componentes utilizados nas emulsões foram medidas de acordo com os procedimentos descritos na seção $(3.2 .2 .2)$.

\subsubsection{2}

\section{Síntese da emulsão real}

Primeiramente, é importante notar que o protocolo utilizado para o processo de formação das emulsões de petróleo foi fornecido pela Petrobras e é bastante simplório quando se comparado aos processos de emulsificação que ocorrem no campo. Ao longo do processo de extração dos fluidos do poço, a passagem dos mesmos por diversos esforços mecânicos como dutos, válvulas e bombas pode ter como consequência a formação das emulsões. Somado a isso, há ainda uma grande variação de temperatura que acontece no decorrer deste trajeto do poço até a plataforma, substituindo-se altas temperaturas iniciais por aquelas próximas a $4{ }^{\circ} \mathrm{C}$ que se encontram o leito dos oceanos e, por fim, pela temperatura ambiente da plataforma. Por causa desses fatores, a repetição desse processo complexo é praticamente impossível de ser realizado em nível laboratorial.

Portanto, o procedimento para emulsificação utilizado em laboratório é baseado no uso de um homogenizador ULTRA-TURRAX ® da IKA. O cisalhamento da amostra é realizado com o uso de uma rotação de 8000 rpm durante 5 minutos, podendo ser associada uma taxa de cisalhamento. Uma vez que o escoamento acontece no gap entre o rotor e o estator, é uma boa aproximação afirmar que:

$$
\dot{\gamma}=\frac{V}{h}, \quad h=\text { gap } \quad \text { e } \quad V=r \cdot \omega
$$

A velocidade linear na parede é dada por

$$
V=\left(D_{\text {estator }} / 2+h\right) \times R P M \times 0.10472
$$

Sabendo que $D_{\text {rotor }}=18 \mathrm{~mm}$ e $h=0.5 \mathrm{~mm}$ :

$$
\dot{\gamma}=\frac{7958.7}{0.5} \rightarrow \dot{\gamma}=15917[1 / s]
$$

O frasco que contém a emulsão é colocado em um banho maria a $40{ }^{\circ} \mathrm{C}$, 
uma vez que essa é uma temperatura intermediária do processo de transporte dos fluidos e que se encontra acima da temperatura de TIAC em ambos os petróleos. Além disso, a escolha da temperatura de interesse se baseia ainda na especificação técnica ET-3010.90-1223-941-PCI-001, que se fundamenta em informar a respeito de módulos de produção dos FPSOs padronizados utilizados no pré-sal, expondo a presença de um separador de água livre que atua a $40{ }^{\circ} \mathrm{C}$. Como essa tecnologia é a de nosso interesse, o argumento de escolha desta temperatura se fortalece ainda mais.

Com isso, essa temperatura $40{ }^{\circ} \mathrm{C}$ foi estabelecia como sendo representativa para o processo como um todo. Para que os fluidos a atinjam, é necessário ajustar o termostato da placa aquecedora para $41^{\circ} \mathrm{C}$ devido as perdas de calor do processo de aquecimento. Um tempo de 40 minutos foi escolhido por ser o ideal para garantir o equilíbrio térmico do sistema enquanto uma rotação de 500 rpm na placa agitadora é imposta visando a movimentação do fluido responsável pelo banho maria. Sendo assim, é possível que a amostra fique homogeneamente na temperatura desejada. Assim, após esse tempo, o homogenizador ULTRA-TURRAX ${ }^{\circledR}$ da IKA é ligado realizando o processo de emulsificação, conforme visto na Figura (3.4).

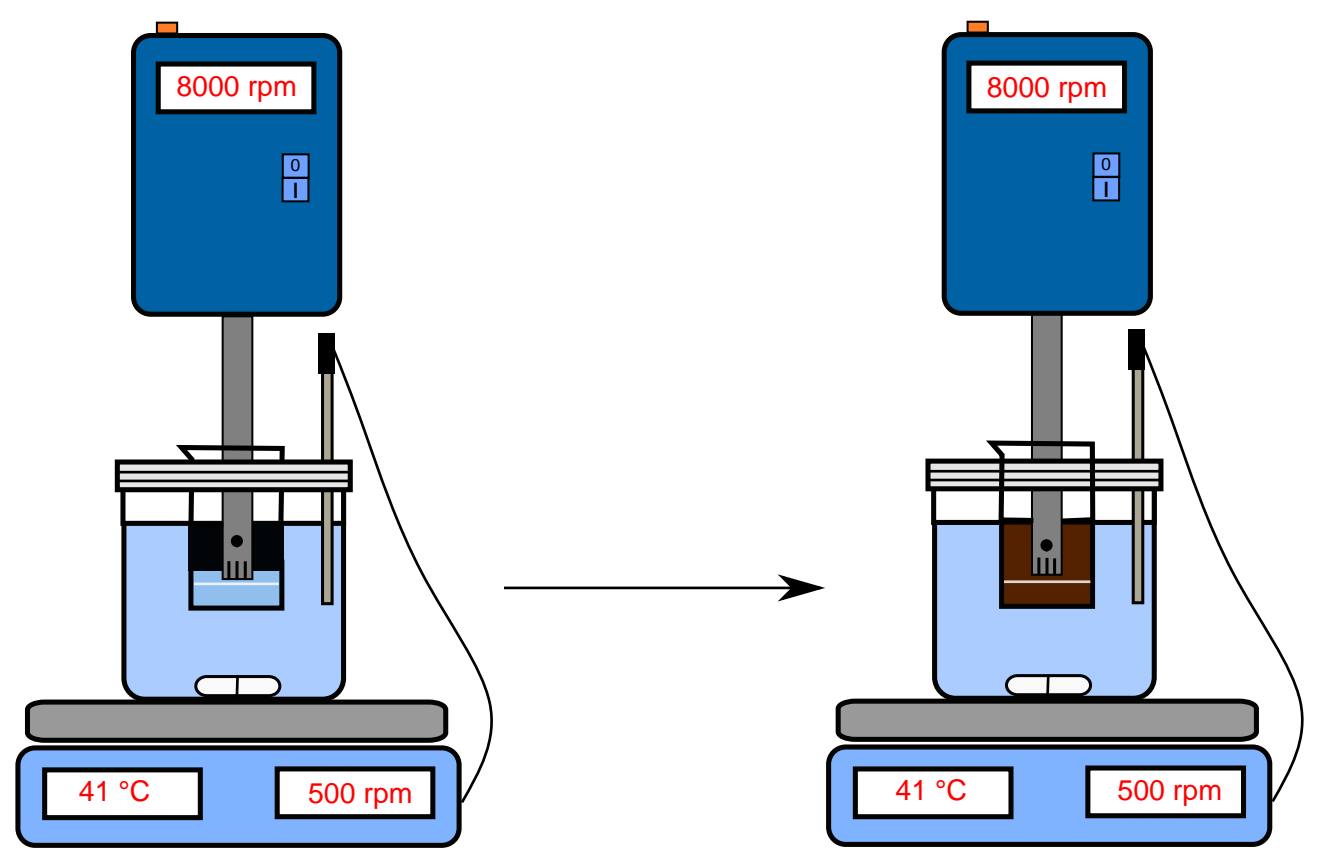

Figura 3.4: Representação do processo de emulsificação das emulsões de petróleo 
Cabe ressaltar que, tendo em vista uma uniformidade no protocolo experimental, os frascos utilizados possuíam um linha representativa que delimita a altura do misturador do fundo do frasco, podendo garantir a repetibilidade do processo em todos os testes experimentais (Figura 3.5).

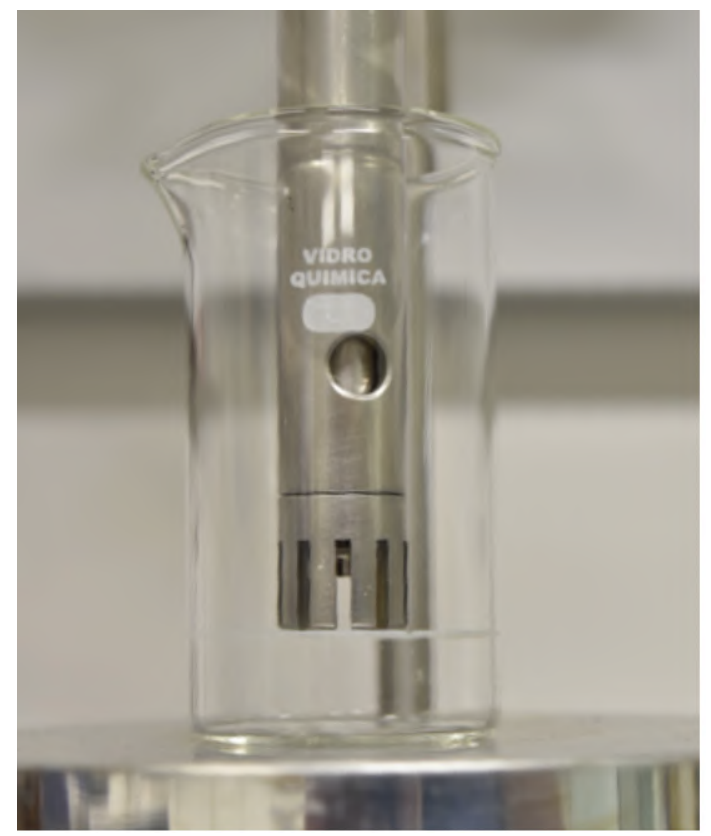

Figura 3.5: Visualização do delimitador de altura para o frasco utilizado.

\subsubsection{3}

\section{Síntese da emulsão modelo}

Devido as diferenças encontradas nos sistemas reais e modelo, que serão explicitadas posteriormente, o protocolo de emulsificação das emulsões reais se mostrou insatisfatório para a síntese das emulsões modelo após uma série de testes realizados. Tais testes resultaram em cortes de água e tamanhos de gotas de emulsões bastante distintos daqueles obtidos para emulsões de petróleo. Isso acontece, sobretudo, devido a uma grande presença de elementos tensoativos na composição do petróleo, o que reduz a quantidade de energia total a ser empregada na geração de emulsões suficientemente estáveis. Por outro lado, a energia fornecida ao sistema pelo homogenizador ULTRA-TURRAX (® na região localizada entre seu rotor e estator (Figura 3.6) é bastante superior a necessária, acarretando na geração de gotas de tamanho bastante inferior quando se comparado a um mesmo corte de água em emulsões reais. 


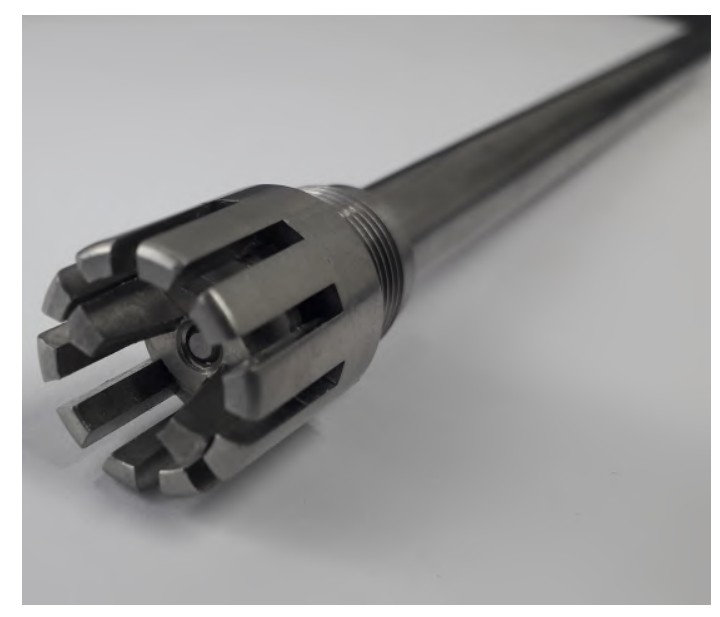

Figura 3.6: Foto representativa do rotor (interno) e estator (externo) contidos no ULTRA-TURRAX ®.

Como forma de adaptar o processo de emulsificação para as emulsões modelo foi projetado um novo elemento dispersor com o objetivo de se obter gotas de emulsão com tamanhos semelhantes àquelas encontradas em emulsões reais de uma forma mais eficiente e homogênea. Sendo assim, os elementos transversais posicionados ao longo da haste principal garantem que o cisalhamento não seja local. Somado a isso, uma hélice contida na última haste assegura uma mistura mais homogênea do sistema, conforme visto na Figura (3.7). Portanto, de acordo com essas modificações, diferentes rotações e tempos são utilizados para a síntese das emulsões modelo, conforme serão explicitados ao longo deste trabalho.

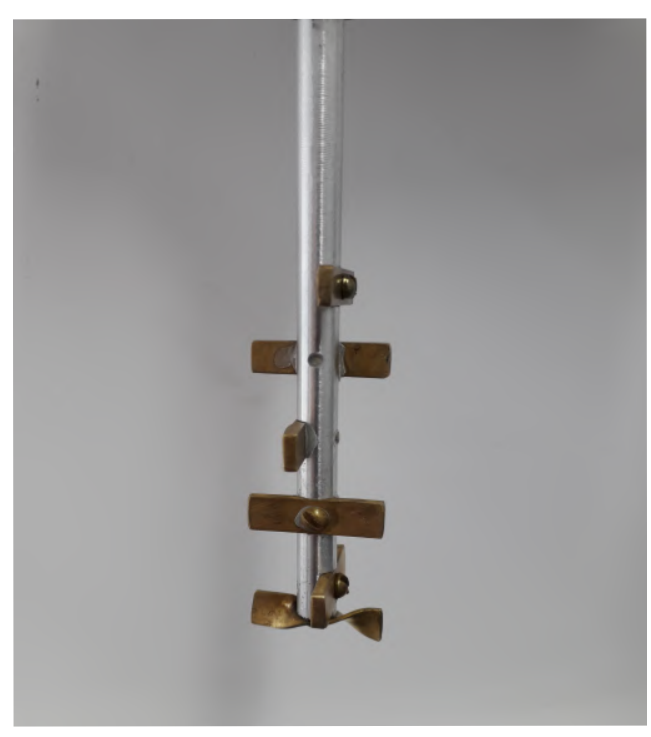

Figura 3.7: Foto representativa do novo elemento dispersor projetado para o processo de emulsificação das emulsões modelo. 
Além da geometria do misturador, estudou-se também métodos para que a eficiência do processo de emulsificação fosse ainda maior. Por isso, três técnicas bastante difundidas na indústria foram analisadas a fim de que misturas ineficientes não ocorressem [57], dentre elas:

- Instalação de defletores ao longo do recipiente contendo a amostra;

- Montagem vertical de misturadores deslocados do centro;

- Montagem dos misturadores em ângulo de offset;

A primeira delas foi utilizada mas não gerou uma diferença significativa nos resultados quando se comparado àqueles obtidos com o método de mistura mais simplificado, no qual o misturador fica descentralizado no frasco, conforme visto na Figura (3.8). Contudo, ao aplicar a segunda técnica, verificou-se a possibilidade de uma eficiência do processo de emulsificação ainda maior, o que possibilitaria o emprego desta ao longo dos testes experimentais. A explicação para isso se baseia no fato de que quando o misturador é posicionado de forma centralizada ao frasco, a massa de fluido giraria de maneira única devido as velocidades tangenciais provocadas pelos elementos transversais, o que não acontece quando uma descentralização axial do frasco é feita. Por fim, a terceira técnica exposta apresenta a dificuldade de garantir a repetibilidade do ângulo offset o que fez com que tal técnica não fosse empregada ao longo dos testes.
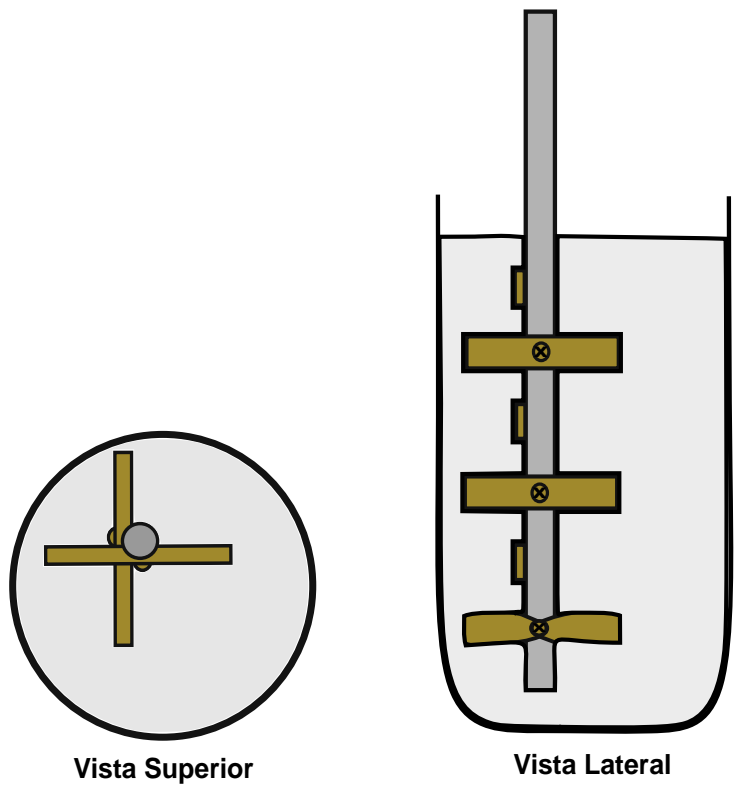

Figura 3.8: Desenho representativo da descentralização do misturador com relação ao frasco que contém a emulsão.

Com todos esses fatores já pré-estabelecidos, definiu-se, então, um volume de emulsão de $80 \mathrm{~mL}$, como acontecia nas emulsões de petróleo. Sendo assim, 
após a pesagem dos fluidos, tendo por base as massas específicas de todos os constituintes, esses são despejados em um béquer com dimensões de diâmetro $\mathrm{D}=42 \mathrm{~mm}$ e altura $\mathrm{h}=150 \mathrm{~mm}$, que é utilizado como frasco de mistura.

Para cada um dos petróleos estudados desenvolveu-se um protocolo experimental de emulsificação visando uma melhor adequação dos resultados experimentais obtidos com as emulsões de petróleo. Cabe frisar que o procedimento experimental para a síntese dos dois óleos modelos desenvolvidos apresentou uma divergência, uma vez que a composição dos mesmos possuía algumas mudanças. Tais procedimentos podem ser vistos abaixo:

Protocolo de emulsificação - Emulsão Modelo A $\mathrm{O}$ protocolo de emulsificação das emulsões modelo do petróleo A pode ser divido em três etapas, dentre elas:

\section{Emulsões até 32\%}

- Pesagem de Primol, Span 85 e água sintética.

- Mistura a 1800 RPM por 15 minutos com a haste descentralizada.

- Adição de Tween 85 e vaselina.

- Mistura a 1800 RPM por 15 minutos com a haste descentralizada.

\section{Emulsões de $40 \%$}

- Pesagem de Primol, Span 85 e água sintética.

- Mistura a 1800 RPM por 2 minutos com a haste agitadora descentralizada. Em sequência, com a mesma rotação, 3 minutos com a haste centralizada.

- Adição de Tween 85 e vaselina.

- Mistura a 300 RPM por 2 minutos com a haste centralizada.

\section{Emulsões de 50\%}

- Pesagem de Primol, Span 85 e água sintética.

- Mistura a 1800 RPM por 2 minutos com a haste descentralizada. Em sequência, com a mesma rotação, 6 minutos com a haste centralizada.

- Adição de Tween 85 e vaselina.

- Mistura a 300 RPM por 2 minutos com a haste centralizada. 
Protocolo de emulsificação - Emulsão Modelo B Para o caso das emulsões modelo do petróleo $\mathrm{B}$, tem-se o seguinte protocolo:

\section{Emulsões até 15\%}

- Pesagem de Primol, Span 85 e água sintética.

- Mistura a 1200 RPM por 15 minutos com a haste descentralizada.

- Adição de Tween 85 e vaselina.

- Mistura a 1200 RPM por 15 minutos com a haste descentralizada.

\section{Emulsões de $30 \%$}

- Pesagem de Primol, Span 85 e água sintética.

- Mistura a 1200 RPM por 2 minutos com a haste agitadora descentralizada.

- Adição de Tween 85 e vaselina.

- Mistura a 300 RPM por 2 minutos com a haste centralizada.

\section{Emulsões de 50\%}

- Pesagem de Primol, Span 85 e água sintética.

- Mistura a 1200 RPM por 4 minutos com a haste descentralizada.

- Adição de Tween 85 e vaselina.

- Mistura a 300 RPM por 2 minutos com a haste centralizada.

É importante ressaltar que a flexibilidade entre os protocolos utilizados pelas emulsões reais e as modelo representam apenas meio diferentes para realizar a síntese das emulsões que chegariam a entrada do separador gravitacional. Sendo assim, as diferentes formas de se chegar a essas emulsões não são um empecilho para que o objetivo geral deste trabalho pudesse ser obtido, uma vez que, para um certo corte de água na entrada do separador gravitacional as duas emulsões (reais e modelo) devem possuir similaridade nas suas propriedades reológicas $(\eta)$, de distribuição de tamanho de gota (Dmedio e PDI) e de estabilidade $\left(\phi_{e f f}\right)$. Portanto, as modificações realizadas entre os dois protocolos utilizados puderam ser efetuadas uma vez que o objetivo final fosse alcançado. 


\subsection{4}

\section{Caracterização das emulsões}

\subsubsection{1}

\section{Caracterização Reológica}

As curvas de escoamento de ambas as emulsões foram realizadas baseadas através do uso dos procedimentos descritos na seção (3.2.2.1). É importante notar que a temperatura escolhida $\left(40{ }^{\circ} \mathrm{C}\right)$ teve por base uma série de fatores que já foram citados anteriormente ao longo deste trabalho.

Por outro lado, algumas modificações foram realizadas para a otimização dos testes experimentais das emulsões. Primeiramente, reduziu-se para 15 minutos o tempo de repouso do fluido na temperatura de interesse, uma vez que verificou-se que o equilíbrio térmico já havia sido atingido. É importante notar também que, nesse caso, tais curvas de escoamento foram realizados a partir de $\dot{\gamma}$ mais altos para as taxas mais baixas, pois esse procedimento é comumente utilizado na literatura para esses tipos de sistemas.

\subsubsection{2}

\section{Concentração efetiva}

Como uma forma de avaliar a estabilização das emulsões formadas, é importante salientar que após a emulsificação ocorrer, verifica-se a ocorrência ou não da separação de fases. Após o processo de emulsificação, o fluido é transferido para um funil de separação, no qual permanece por cerca de 30 minutos. Cabe ressaltar que esse tempo de espera foi definido tendo como base uma extrapolação do tempo de residência médio de emulsões em separadores gravitacionais industriais em plataformas, que é de cerca de 10 minutos. Assim, ao final destes 30 minutos, caso haja separação de fases, a água livre é retirada da emulsão e seu volume é medido com uma proveta. A emulsão formada, nesse caso, não possui uma concentração de água igual ao corte de água estabelecido antes da realização do processo de emulsificação já que não há uma incorporação total da água adicionada. Assim, há o surgimento de um conceito denominado de concentração efetiva de água na emulsão que pode ser calculada de acordo com a Equação (3-1).

$$
\phi_{e f f}=\frac{V_{a i}-V_{a l}}{V_{t}-V_{a l}}
$$

no qual $V_{a i}$ é o volume de água inicial, $V_{a l}$ é o volume de água livre que não foi incorporada na emulsificação e $V_{t}$ é o volume total da emulsão.

Tal procedimento acontece tanto para as emulsões reais quanto para as modelo, sendo bastante representativo ao processo que ocorre ao longo do 
separador gravitacional. A principal divergência se deve ao fato que o separador gravitacional opera de forma contínua, diferentemente do processo em batelada no funil de separação. Contudo, esse procedimento é de extrema importância para o processo de mimetização das emulsões.

\subsubsection{3}

\section{Distribuição do Tamanho de Gotas (DTG)}

Conforme já explicitado, um dos fatores fundamentais para o estudo das emulsões é verificar a distribuição do tamanho de gotas da emulsão gerada. Para isso, utilizou-se o microscópio Nikon Eclipse LV100n polarizado (Figura 3.9) para a captação de fotos microscópicas das amostras. Primeiramente, trata-se uma placa de Petri com um produto hidrofóbico denominado de Glass Shield Cristalizador de vidros Autoshine durante 15 minutos com o objetivo de não haver interação entre a superfície do vidro e as gotas de emulsão formadas, evitando-se que gotas de água se espalhem quando em contato com o fundo da placa. Após esse tempo, lava-se a mesma placa de Petri com detergente para que seja retirado o excesso do produto utilizado.

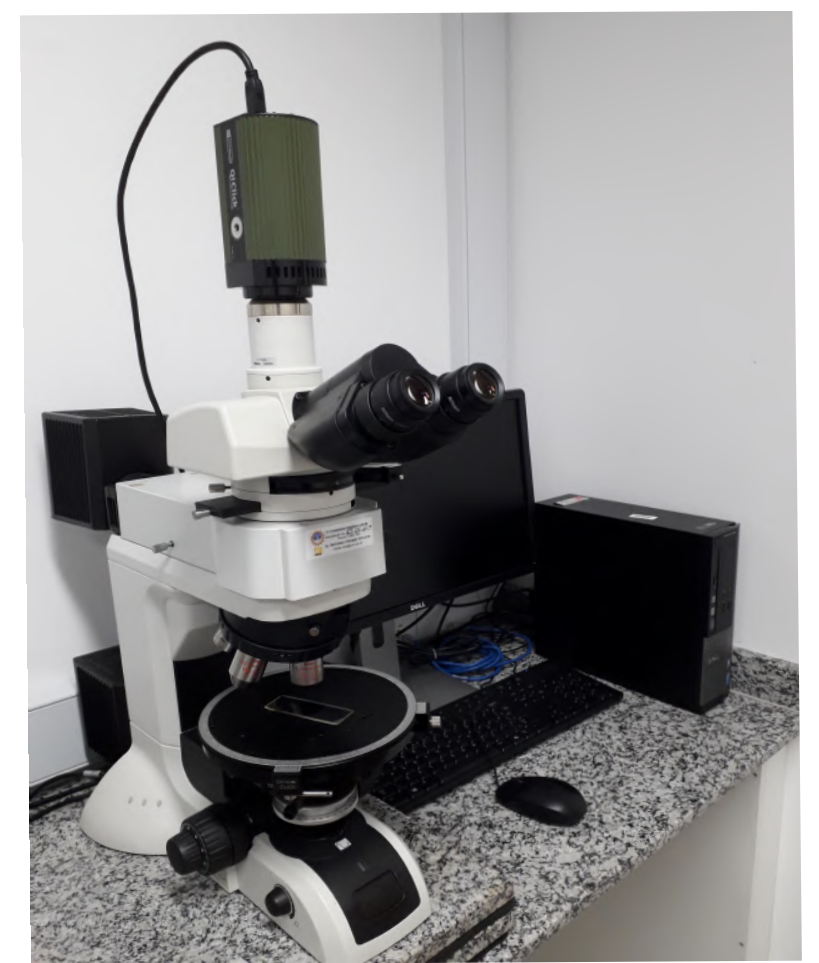

Figura 3.9: Foto do microscópio Nikon Eclipse LV100n polarizado.

O passo posterior é o de diluição das emulsões em uma fase oleosa de menor viscosidade EXXSOL D60 puro, para o caso de emulsões de petróleo ou com saturação de Span 85, para emulsões modelo. Isso é devido às dificuldades 
encontradas na obtenção das imagens de microscópio, levando em consideração a coloração do óleo e a alta concentração de gotas de água nas amostras. Cabe ressaltar também que o diluente formado, para o caso modelo, necessita de uma determinada concentração de surfactante uma vez que a ausência deste gera uma difusão de moléculas de surfactante da interface água/óleo para o óleo puro, o que acarreta num enfraquecimento da rigidez da mesma. Por isso, ao saturar o óleo diluente com uma concentração determinada de surfactante, essa difusão é diminuída e gotas possuem uma interface mais bem definida e rígida, o que propicia a obtenção das imagens microscópicas.

Como último passo, a emulsão diluída é colocada na placa de Petri pré tratada e, em seguida, posicionada no microscópio. Sendo assim, gravam-se cerca de 30 imagens de cada amostra de emulsão e, com estas, utiliza-se um código escrito no MATLAB® em que é possível a determinação da distribuição do tamanho de gotas.

Esse programa se baseia, sobretudo em identificar, nas imagens fornecidas, os contornos das gotas da emulsão conforme pode ser visto na Figura (3.10). Para tal, a imagem é interpretada através de uma função que destaca partículas circulares. Isso é feito com o uso de um parâmetro de sensibilidade que serve como um controlador do nível aceitabilidade para que uma partícula seja considerada esférica. É importante destacar que, de acordo com o grau de sensibilidade utilizado, pode acontecer do programa detectar gotas sobrepostas umas as outras. Contudo, isso foi contornado através do uso de uma função que possui um limite de tolerância entre a distância dos centros e os raios calculados.

Além disso, gotas muito grandes ou pequenas são capturadas a partir de uma função contida na rotina que aumenta ou reduz o tamanho da imagem, o que facilita a detecção das mesmas. 


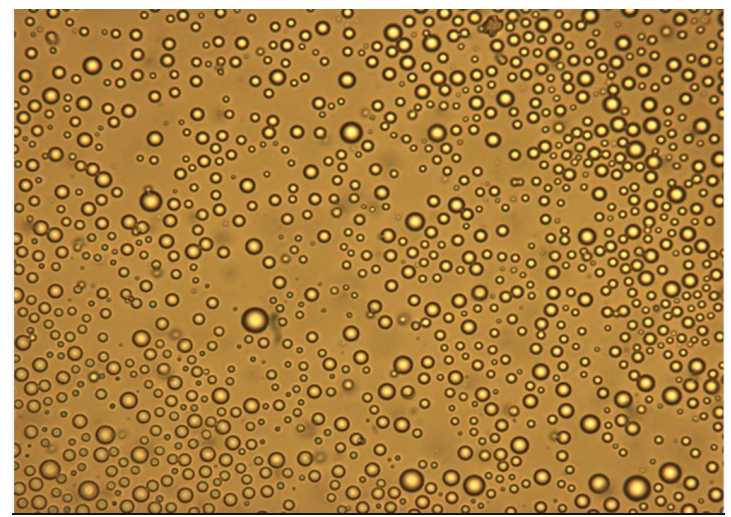

Antes do tratamento de imagem

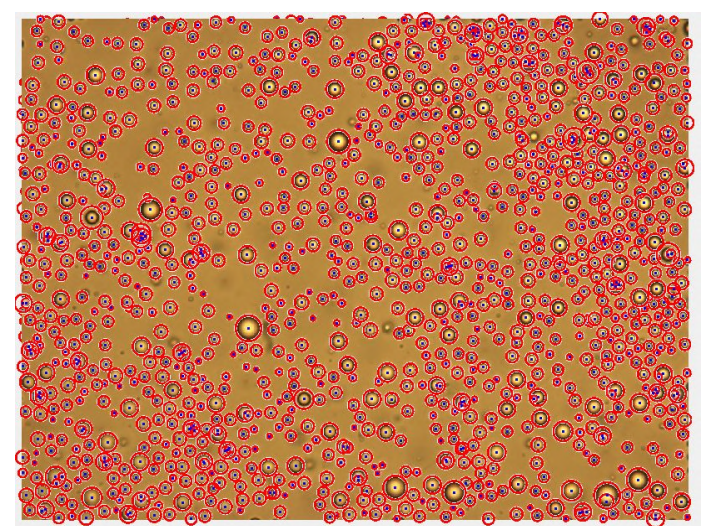

Após o tratamento de imagem

Figura 3.10: Fotos de antes e depois da análise feita pelo programa MATLAB®.

A partir disso, o programa determina a distribuição do tamanho de gotas da emulsão (Figura 3.11) e calcula o tamanho médio do raio das mesmas gerando dados estatísticos como o índice de polidispersidade e o diâmetro médio das gotas. É importante notar que esse índice é expresso em termos de uma razão entre o desvio padrão pela média dos diâmetros obtidos.

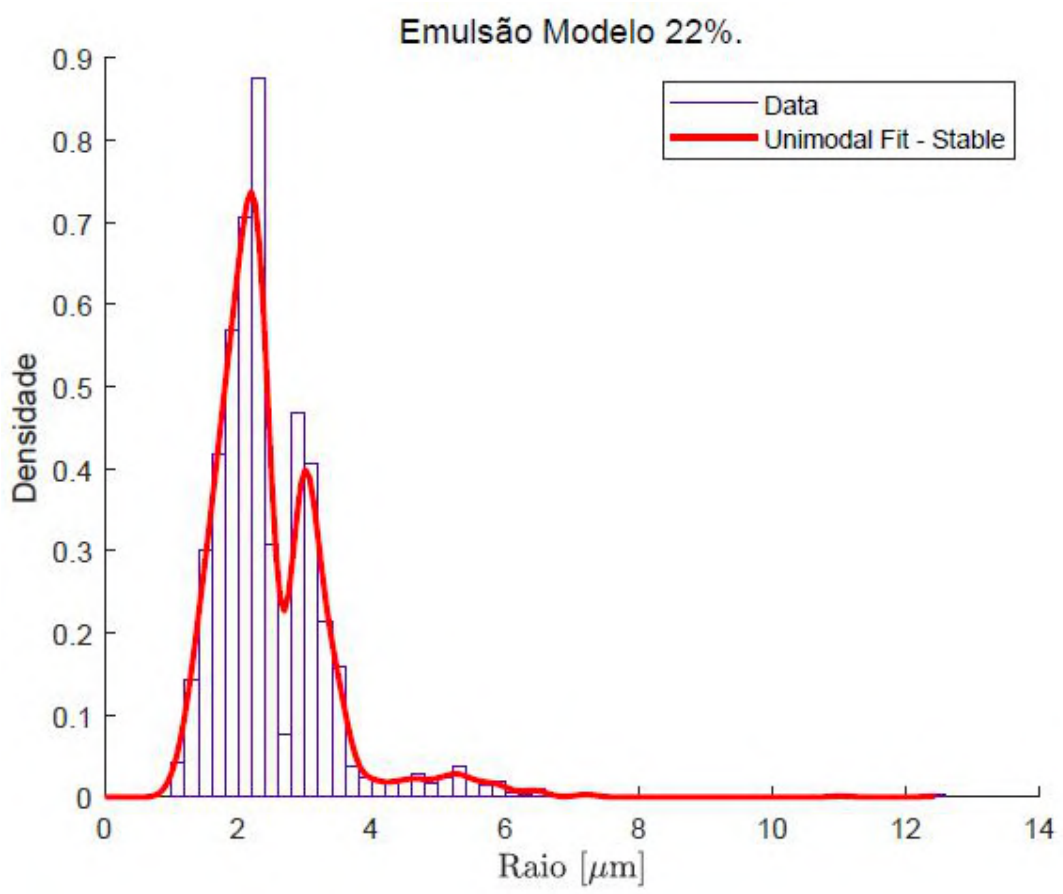

Figura 3.11: Gráfico gerado da distribuição de tamanho de gotas de uma emulsão. 


\section{4}

\section{Resultados e discussão}

4.1

Caracterização físico-química dos petróleos

\subsection{1}

\section{Composição dos petróleos}

Através de uma análise dos principais componentes do petróleo A (análise SARA) é possível verificar a presença de componentes saturados de maneira majoritária. Cabe ressaltar que tal análise foi realizada pela Petrobrás e que tais informações não foram fornecidas para o petróleo B.

\begin{tabular}{cc} 
Componentes & Concentração $(\% \mathrm{~m} / \mathrm{m})$ \\
\hline Saturados & 59.40 \\
Aromáticos & 21.00 \\
Resinas & 19.60 \\
Asfaltenos & 0.50 \\
\hline
\end{tabular}

Tabela 4.1: Análise SARA do petróleo A. 


\subsection{2}

\section{Massa específica}

A partir da medição das massas específicas, conforme descrito na seção (3.2.1), os seguintes resultados puderam ser obtidos.

Temperatura Densidade Densidade após tratamento

\begin{tabular}{lccc} 
& $\left({ }^{\circ} \mathrm{C}\right)$ & $\left(\mathrm{g} / \mathrm{cm}^{3}\right)$ & $\left(\mathrm{g} / \mathrm{cm}^{3}\right)$ \\
\hline \multirow{2}{*}{ Petróleo A } & 20 & 0.9010 & 0.8981 \\
& 25 & 0.8975 & 0.8946 \\
& 40 & 0.8872 & 0.8842 \\
\hline \multirow{2}{*}{ Petróleo B } & 20 & 0.9143 & 0.9198 \\
& 25 & 0.9110 & 0.9163 \\
& 40 & 0.9008 & 0.9064 \\
\hline
\end{tabular}

Tabela 4.2: Massa específica dos petróleos em diferentes temperaturas.

Observando-se a Tabela 4.2 anterior, é possível perceber que a densidade de ambos os petróleos não é modificada consideravelmente ao longo das temperaturas testadas após a etapa de tratamento.

\subsection{3}

\section{Caracterização reológica}

Conforme explicitado anteriormente, curvas de escoamento foram realizadas a $40^{\circ} \mathrm{C}$ a fim de que fosse possível observar o valor da viscosidade dos fluidos a essa temperatura. Para esse valor, os fluidos apresentaram comportamento praticamente Newtoniano com suas viscosidades expressas na Tabela 4.3.

\begin{tabular}{cc} 
Petróleo & Viscosidade (mPa.s) \\
\hline Petróleo A & 34 \\
Petróleo B & 49
\end{tabular}

Tabela 4.3: Média da viscosidade dos petróleos a $40^{\circ} \mathrm{C}$. 


\subsection{4}

\section{Tensão interfacial}

A tensão interfacial dos sistemas petróleo A ou B e água sintética foram determinadas a $25^{\circ} \mathrm{C}$ e a $40^{\circ}$ Catravés do protocolo experimental contido na seção (4.1.4). Seus valores estão expressos na Tabela 4.4.

\section{Temperatura Tensão Interfacial}

\begin{tabular}{llc} 
& $\left({ }^{\circ} \mathrm{C}\right)$ & $(\mu \mathrm{N} / \mathrm{m})$ \\
\hline Petróleo A & 25 & 5.71 \\
& 40 & 8.03 \\
\hline \multirow{2}{*}{ Petróleo B } & 25 & 10.44 \\
& 40 & 9.49 \\
\hline
\end{tabular}

Tabela 4.4: Valores de tensão interfacial do sistema petróleo A ou B e água sintética em duas diferentes temperaturas: $25^{\circ} \mathrm{C}$ e $40^{\circ} \mathrm{C}$.

Através da análise da Tabela anterior, é possível perceber que as tensões interfaciais de ambos os petróleos apresentaram valores pequenos. Além disso, nota-se também que o petróleo B possui uma tensão interfacial superior ao petróleo A em ambas as temperaturas estudadas.

\section{2}

\section{Caracterização das emulsões de petróleo}

\subsection{1}

\section{Concentração efetiva}

Com a síntese das emulsões reais realizada pela utilização do protocolo evidente na seção (3.2.3.2) e sua caracterização reológica, foi possível a geração de gráficos representativos sobre o comportamento das mesmas. Primeiramente, gráficos do corte de água versus a concentração efetiva das emulsões mostram a presença de um corte de água crítico a partir do qual acima deste valor o sistema apresenta água livre. Para as emulsões do petróleo A esse ponto é aproximadamente $32 \%$ enquanto para as emulsões com o petróleo B gira em torno de 15\%. Tal comportamento pode ser visto tanto no gráfico das emulsões de petróleo A (Figura 4.1) quanto para as emulsões do petróleo B (Figura 4.2) abaixo. 


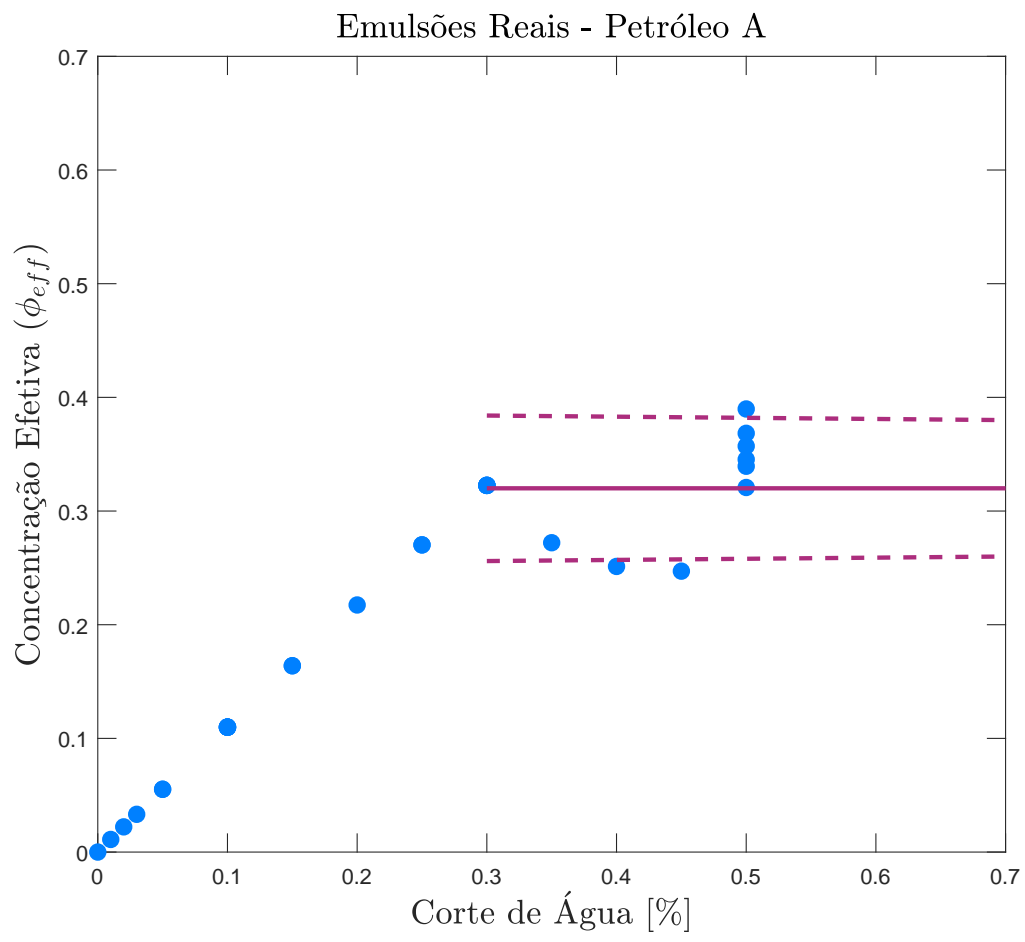

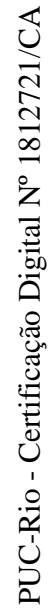

Figura 4.1: O corte de água crítico para as emulsões do petróleo A se estabelece entre 32 e $37 \%$ de concentração com o protocolo utilizado.

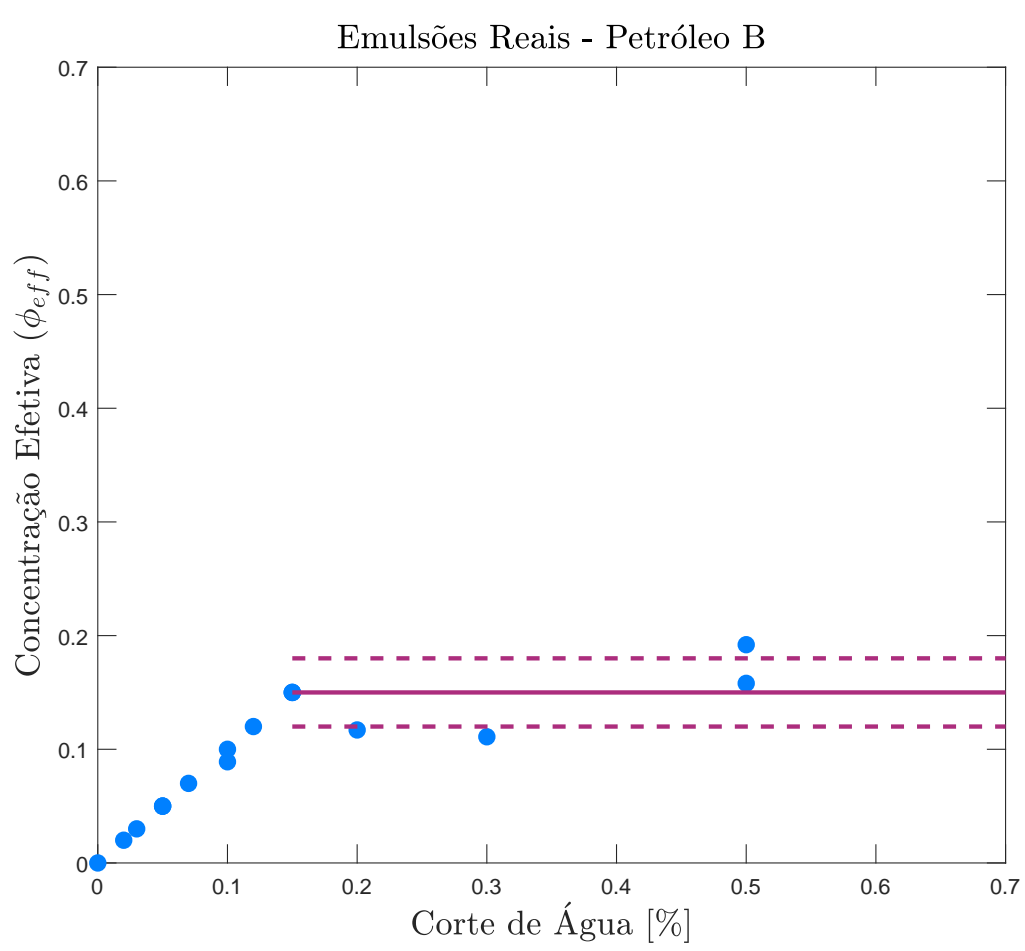

Figura 4.2: O corte de água crítico para as emulsões do petróleo B se estabelece entre 15 e $20 \%$ de concentração com o protocolo utilizado. 
Com esses resultados, pode-se supor que, em emulsões do petróleo A com cortes de água menores que $32 \%$, o uso de separadores gravitacionais não seria eficaz, uma vez que essas emulsões se comportam de maneira estável. Da mesma forma, em emulsões do petróleo B com cortes menores que 15\%, a separação gravitacional não seria uma operação eficiente a ser realizada. Contudo, tais resultados podem ser diferentes na prática uma vez que o processo de emulsificação das emulsões em campo é bastante distante daquele realizado em laboratório.

É importante frisar também que, para cortes de água acima do valor crítico, há uma enorme dispersão dos dados experimentais. Um exemplo disso pode ser visto em cortes em torno de $50 \%$ para emulsões do petróleo A, apresentando diferentes valores de concentração efetiva. Lamentavelmente, a realização de uma quantidade maior de testes experimentais para esses cortes não pode ser feita devido a falta de amostra dos petróleos estudados.

Cabe salientar que a baixa repetibilidade de experimentos com petróleo em altas concentrações é descrita em diversos campos de pesquisa, sendo inclusive uma das motivações mencionadas para o desenvolvimento de um óleo modelo. Por causa disso e da distribuição dos dados experimentais observada ao longo dos testes determinou-se uma faixa de variação da concentração efetiva para os cortes de água acima do crítico, conforme visto nos gráficos anteriores. Para isso, estabeleceu-se um patamar no último ponto em que não acontecia separação de fases das emulsões, determinando-se uma faixa de variação como critério de avaliação baseada no desvio padrão dos dados ao redor deste valor. Tal faixa de variação pode ser considerada razoável devido a complexidade dos componentes envolvidos no sistema.

\subsection{2}

\section{Propriedades}

\subsubsection{1}

\section{Viscosidade}

Conforme exposto na seção (4.1.3), o comportamento praticamente Newtoniano das emulsões de petróleo possibilita a definição de um valor médio das viscosidade para cada corte de água. Sendo assim, a aplicação dos dados experimentais na equação de Krieger-Dougherty (2-29), apresentada na seção (2.5.1), pode ser realizada. Através dela, parâmetros do modelo são ajustados com uma rotina de MATLAB® de forma com que houvesse uma minimização do erro com relação aos dados experimentais, sendo possível a definição de uma relação entre a viscosidade e a concentração efetiva das emulsões presente 
no modelo.

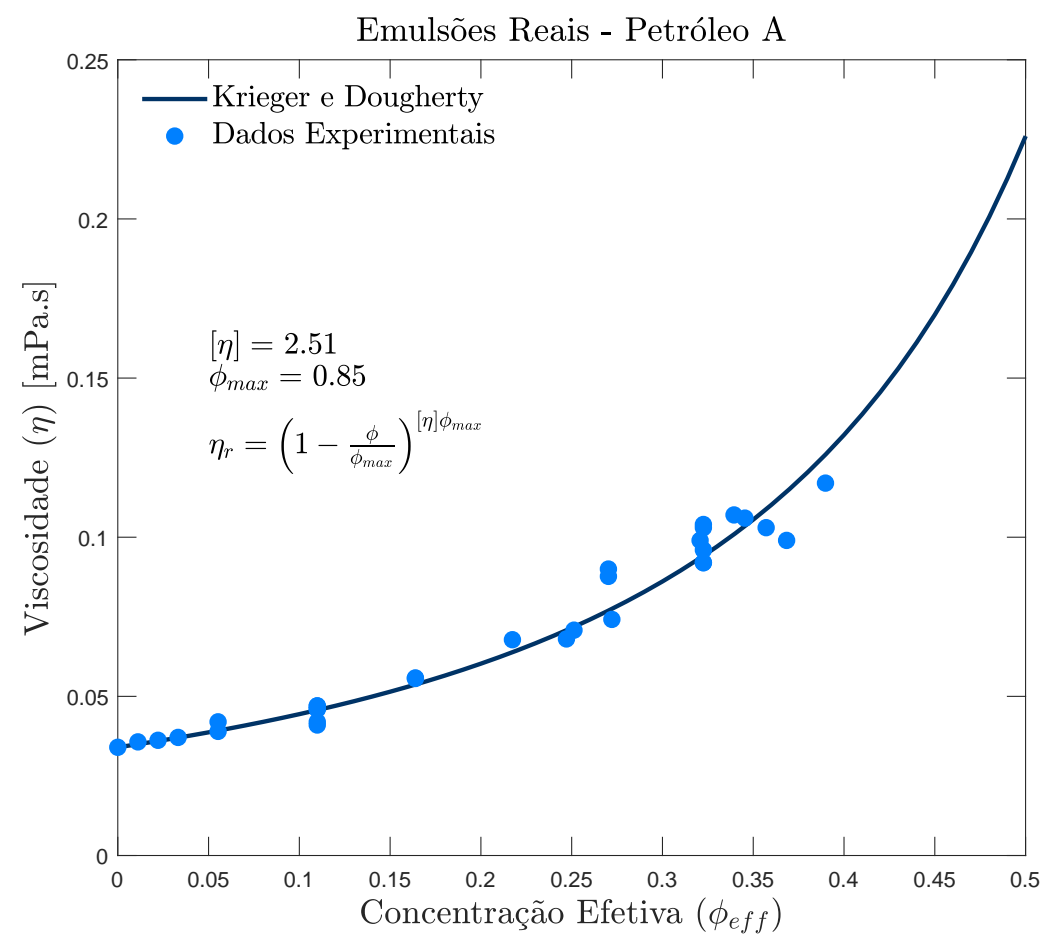

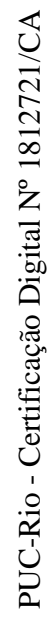

Figura 4.3: Gráfico da equação viscosidade de Krieger-Dougherty baseado nos dados experimentais das emulsões do petróleo A.

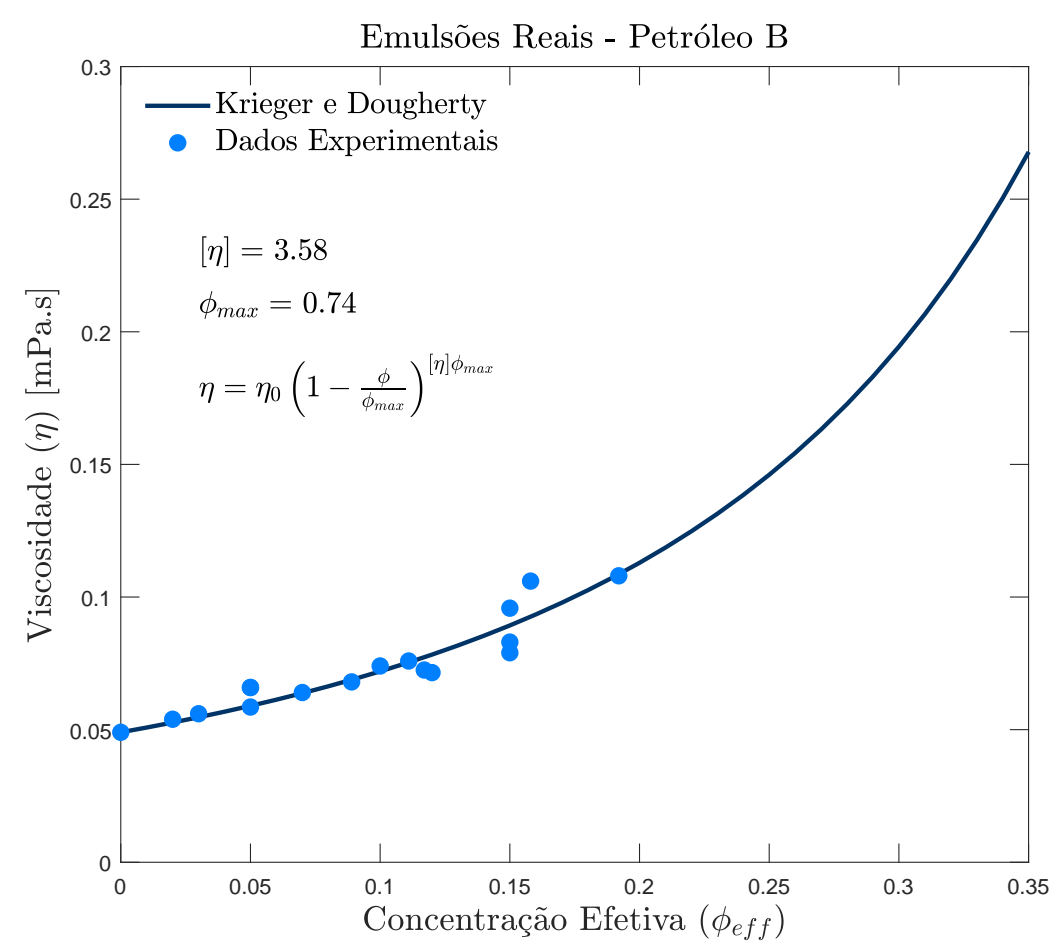

Figura 4.4: Gráfico da equação viscosidade de Krieger-Dougherty baseado nos dados experimentais das emulsões do petróleo B. 
Com a análise dos gráficos anteriores, é notório perceber que as emulsões do petróleo A apresentam uma fração máxima de empacotamento $\left(\phi_{m}\right)$ superior àquela encontrada nas emulsões do petróleo B. Conforme visto na seção (2.2), essa propriedade é regida por dois fatores principais: a polidispersidade e a deformabilidade das gotas. Para o primeiro fator, tem-se que, a medida que as gotas apresentam tamanhos variados dentro de um sistema, a ocupação de gotas menores nos espaços livres entre as maiores, aumentam a capacidade de empacotamento. Com relação ao segundo fator citado anteriormente, pode-se considerar que o valor de $\phi_{m}$ aumenta com a capacidade de deformação das gotas, uma vez que essas conseguem abandonar o formato esférico tradicional e assumir formas que possibilitem uma organização mais eficiente da rede.

Paralelamente ao valor de $\phi_{m}$, o modelo exposto anteriormente ajusta também uma propriedade denominada de viscosidade intrínseca $([\eta])$, que pode ser relacionada com o formato das gotas. Para o caso das emulsões do petróleo A, verificou-se que o valor encontrado está bastante próximo à constante de Einstein para esferas rígidas em regimes diluídos. Por outro lado, o valor obtido na curva relativa às emulsões do petróleo $\mathrm{B}$ diverge consideravelmente desse número, o que induz a presença de agregados não esféricos na emulsão sintetizada com este petróleo.

\subsubsection{2}

\section{Distribuição de tamanho de gotas}

Através do método experimental expresso na seção (3.2.4.3), foi possível a obtenção do diâmetro médio das gotas das emulsões dos petróleos. Sendo assim, gráficos do diâmetro médio das emulsões dos petróleos A (Figura 4.5) e B (Figura 4.6) em função da concentração efetiva foram gerados. 


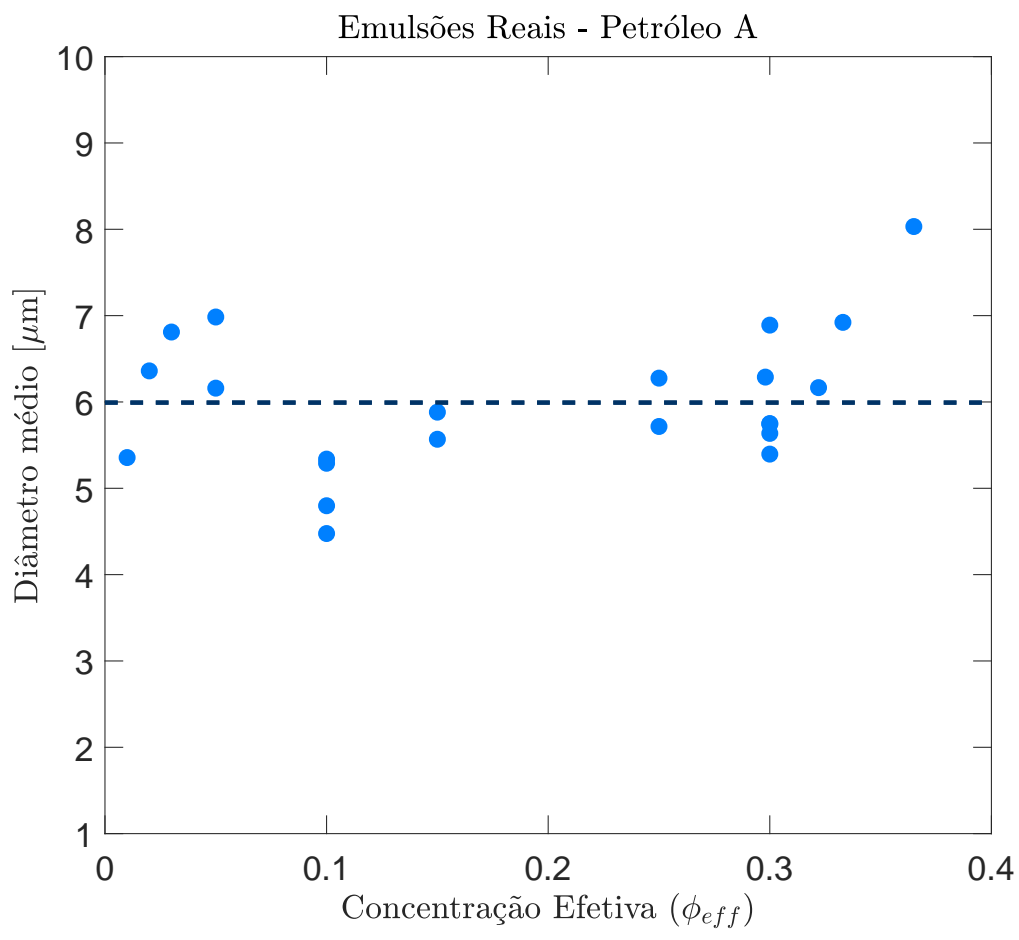

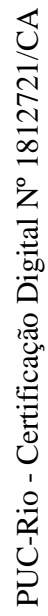

Figura 4.5: Diâmetro médio das gotas das emulsões do petróleo A em diferentes concentrações efetivas.

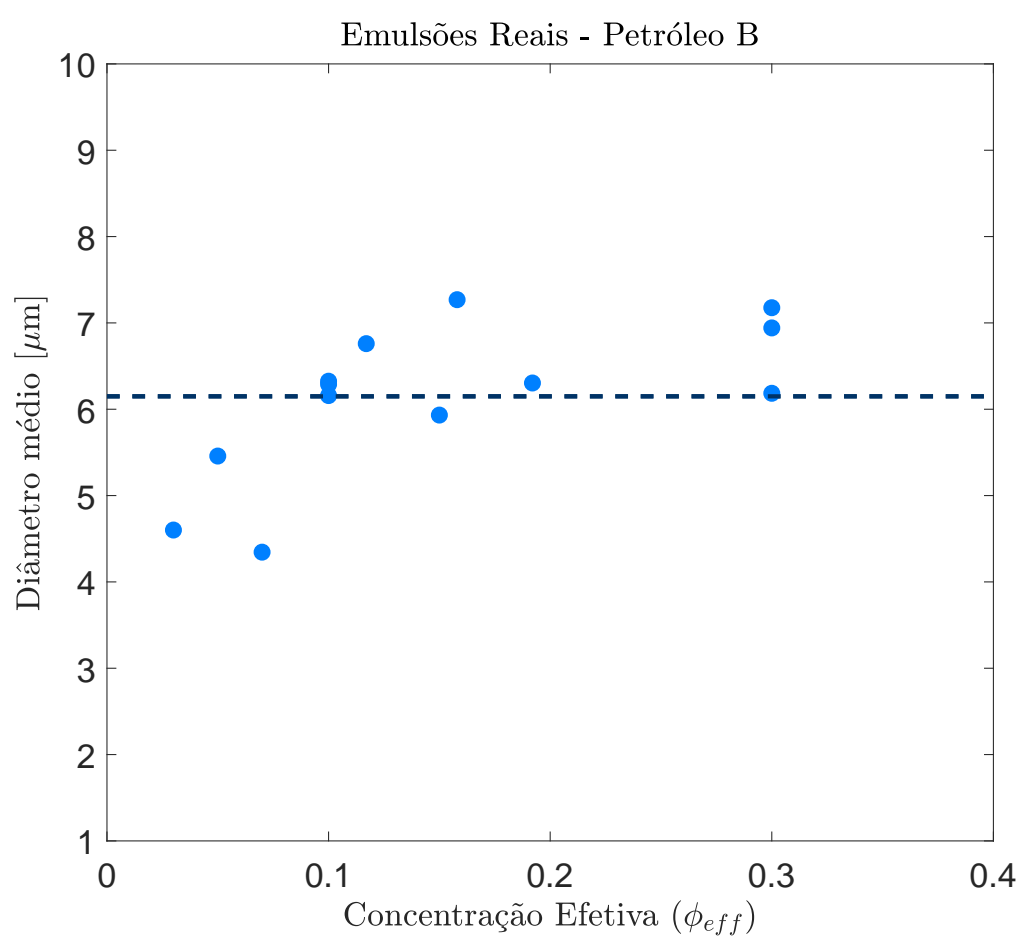

Figura 4.6: Diâmetro médio das gotas das emulsões do petróleo B em diferentes concentrações efetivas.

Analisando-se os dados anteriores, foi plausível o cálculo do diâmetro 
médio das gotas das emulsões: para as emulsões do petróleo A esse valor foi de

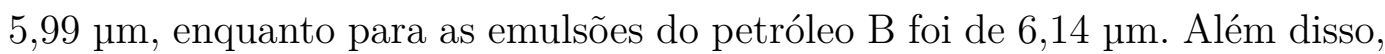
concluiu-se também que há uma grande distribuição dos dados experimentais em torno do valor médio apresentado anteriormente. Por isso, não foi capaz a observação de uma tendência clara entre o diâmetro médio das gotas e o aumento da concentração efetiva.

Com relação ao índice de polidispersidade (Figuras 4.7 e 4.8) o mesmo comportamento foi observado. Sendo assim, calculou-se também um valor de PDI médio para as gotas das emulsões sendo de 0,48 para as emulsões do petróleo A e 0,55 para emulsões do óleo B. Na posse desses dados, conclui-se, portanto, que a hipótese de que fração máxima de empacotamento da emulsão A é superior devido a um índice de polidispersidade maior pode ser descartada.

Portanto, a divergência na fração máxima de empacotamento entre as emulsões dos dois petróleos deve ser baseada no parâmetro de deformabilidade das gotas. É bastante plausível que a diferença de composição química entre os petróleos acarrete em emulsões cujas gotas possuam superfícies com tensoativos diferentes, sendo admissível uma maior deformabilidade das gotas das emulsões do petróleo B, por exemplo.

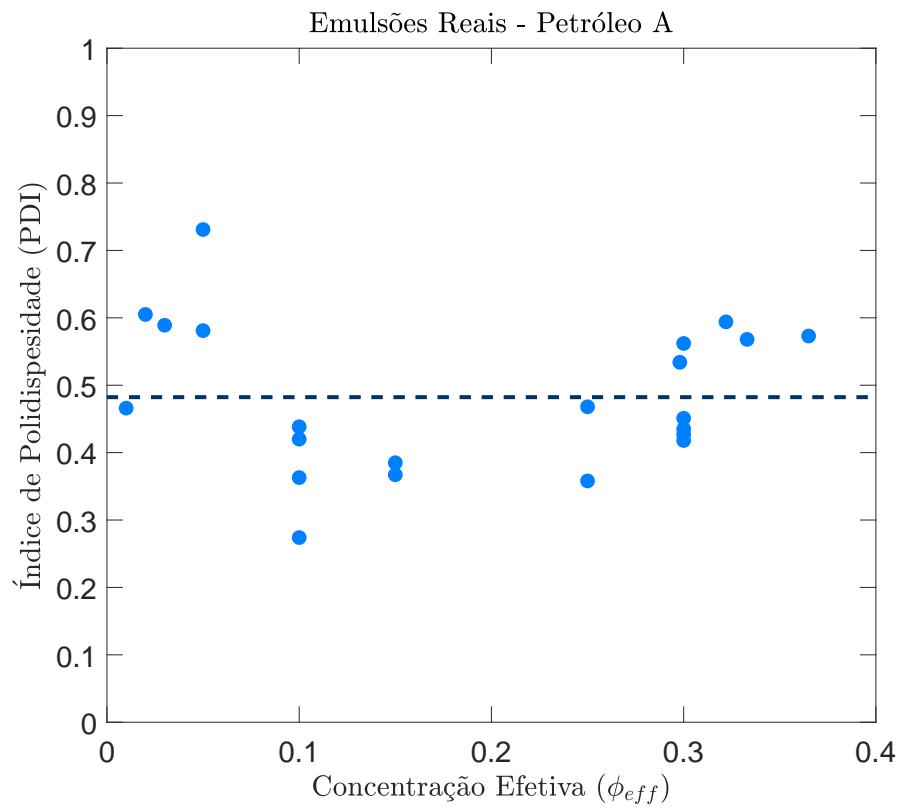

Figura 4.7: Índice de polidispersidade das emulsões do petróleo A em diferentes concentrações efetivas. 


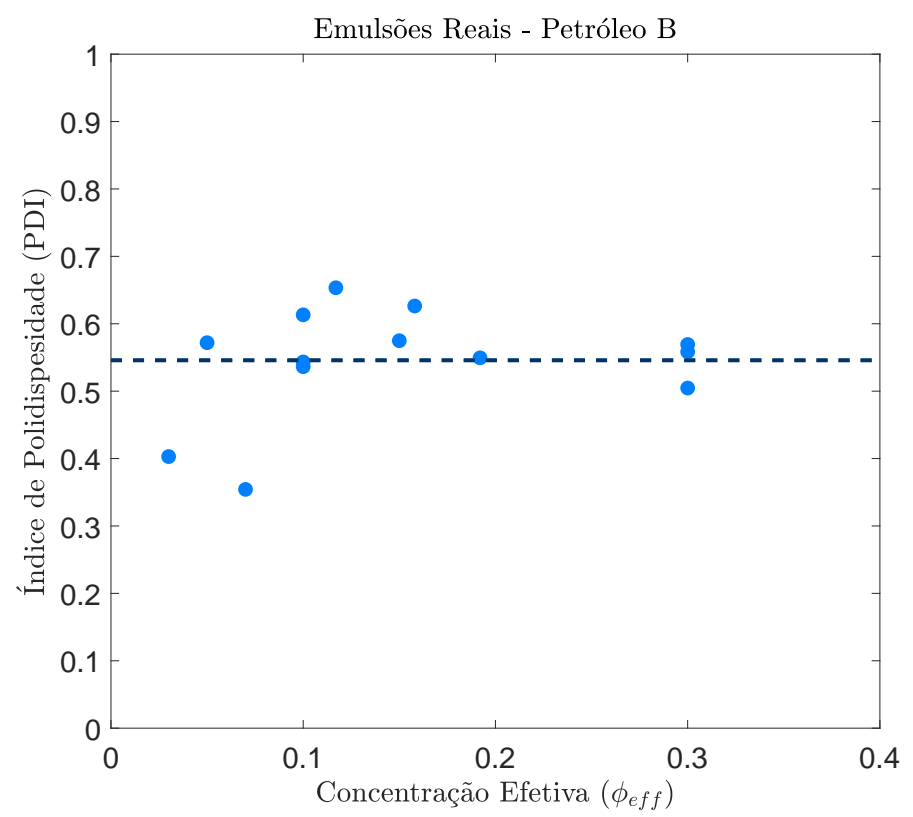

Figura 4.8: Índice de polidispersidade das emulsões do petróleo B em diferentes concentrações efetivas.

\section{3}

\section{Caracterização de óleos modelo}

A escolha da composição do óleo modelo é crucial para o sucesso na mimetização das emulsões modelo. Primeiramente, deve-se escolher um óleo base cuja principal característica seja a solubilização dos surfactantes que serão utilizados para a formação das emulsões. Para um melhor controle químico, usualmente óleos minerais com alto grau de pureza são utilizados, uma vez que outros tipos de óleos podem ter diferenças na sua composição entre um lote e outro do produto.

Além disso, óleos minerais são inodores, quimicamente inertes e transparentes, características essas que os tornam apropriados para o uso em fluidos modelo. Cabe ressaltar que, a fim de que a viscosidade final do fluido modelo seja similar a do petróleo mimetizado, pode ser necessário a combinação de dois óleos minerais distintos. Óleos mais ou menos viscosos são sintetizados com o ajuste na fração volumétrica de cada um desses componentes, possibilitando assim o desenvolvimento tanto petróleos leves quanto pesados.

Uma série de testes foi realizada com o objetivo de se encontrar a melhor combinação possível entre os óleos minerais. A viscosidade e a densidade dos mesmos à $40^{\circ} \mathrm{C}$ foram medidas e estão dispostas na Tabela 4.5. Sendo assim, o óleo base escolhido foi definido com a utilização de uma mistura de Primol 352, 
produzido pela Exxson Mobil, e vaselina líquida, sintetizada pela LabSynth.

\begin{tabular}{cccc} 
Nome do óleo & Código & Viscosidade $[\mathrm{mPa} . \mathrm{s}]$ & Densidade $[\mathrm{g} / \mathrm{L}]$ \\
\hline Vaselina Líquida & $\mathrm{Va}$ & 11.47 & 853.9 \\
Óleo Mineral UQ & OM & 57.86 & 869.4 \\
Polialfaolefina & PAO & 39.38 & 826.0 \\
Primol 352 & $\mathrm{Pr}$ & 57.76 & 851.1
\end{tabular}

Tabela 4.5: Viscosidade e densidade de diferentes óleos utilizados para a formação do óleo modelo.

Outros componentes importantes do óleo modelo são os surfactantes. A escolha destes é extremamente fundamental para a síntese de emulsões e deve tentar representar o mais fielmente possível a ação dos tensoativos do petróleo. Sendo assim, é usual a combinação de dois ou mais tipos desses componentes, conforme já explicitado na seção (2.4). Através disso, parâmetros como viscosidade, densidade e tensão interfacial do óleo modelo podem ser similares às do petróleo a ser mimetizado.

Conforme visto na seção (2.1), o petróleo possui uma grande quantidade de moléculas que podem ocupar a interface das emulsões. Dentre elas, se encontram macromoléculas como asfaltenos e resinas que se ancoram fortemente à interface e criam uma barreira estérica extensa entre as gotas. Por causa desse fator, escolheu-se utilizar surfactantes não-iônicos para a síntese das emulsões modelo, uma vez que é possível uma estabilização estérica com os mesmos. Para a escolha da melhor mistura possível entre dois diferentes surfactantes, testou-se uma série de tensoativos, conforme visto na lista abaixo:

- Ácido Abiético (AA)

- Ácido Esteárico (AE)

- Ácido Naftênico (AN)

- Span 80 (Sp80)

- Span 85 (Sp85)

- Tween 80 (Tw80)

- Tween 85 (Tw85)

Primeiramente, testou-se ácidos abiéticos, esteáricos e naftênicos como surfactantes para estabilização das emulsões. Contudo, essas emulsões não obtiveram resultados satisfatórios já que a emulsificação se fez de forma 
ineficiente. Isso pode ser explicado uma vez que esses componentes são estruturas utilizadas como elementos estabilizantes, usualmente dispostas na interface de emulsões de petróleo.

Sendo assim, supôs-se que essas moléculas apresentavam elevada solubilidade no óleo modelo e pouca afinidade com a interface das gotas. Assim, para a utilização dessas moléculas no sistema de emulsões é imprescindível a combinação com moléculas que apresentem forte afinidade com a interface, como é o caso de polímeros de ancoragem. Esse processo pode ser realizado com a síntese de surfactantes através de reações químicas que acarretem na geração de moléculas que possuam uma parte estabilizadora e outra responsável por essa ancoragem na interface.

Através de um levantamento da literatura, verificou-se que usualmente os surfactantes dos tipos de Span e Tween são mais utilizados. A molécula de Span possui maior solubilidade no óleo e tende a formar emulsões do tipo água-em-óleo, apresentando valores menores de HLB. Por outro lado, as moléculas do Tween apresentam uma solubilidade maior na água, o que faz com que haja uma maior facilidade na formação de emulsões do tipo óleo-em-água. Cabe ressaltar que o numeral no nome desses surfactantes se deve ao tamanho da cadeia linear: quanto maior a cadeia linear, maior será o sufixo numérico e a repulsão estérica.

Com a utilização de uma série desses surfactantes, definiu-se que uma mistura de moléculas de Span $85($ HLB $=1,8)$ e de Tween $85($ HLB $=11)$ em uma proporção que acarretaria em um HLB de mistura de 4,5 resultaria em condições mais propícias para que o objetivo do trabalho fosse alcançado.

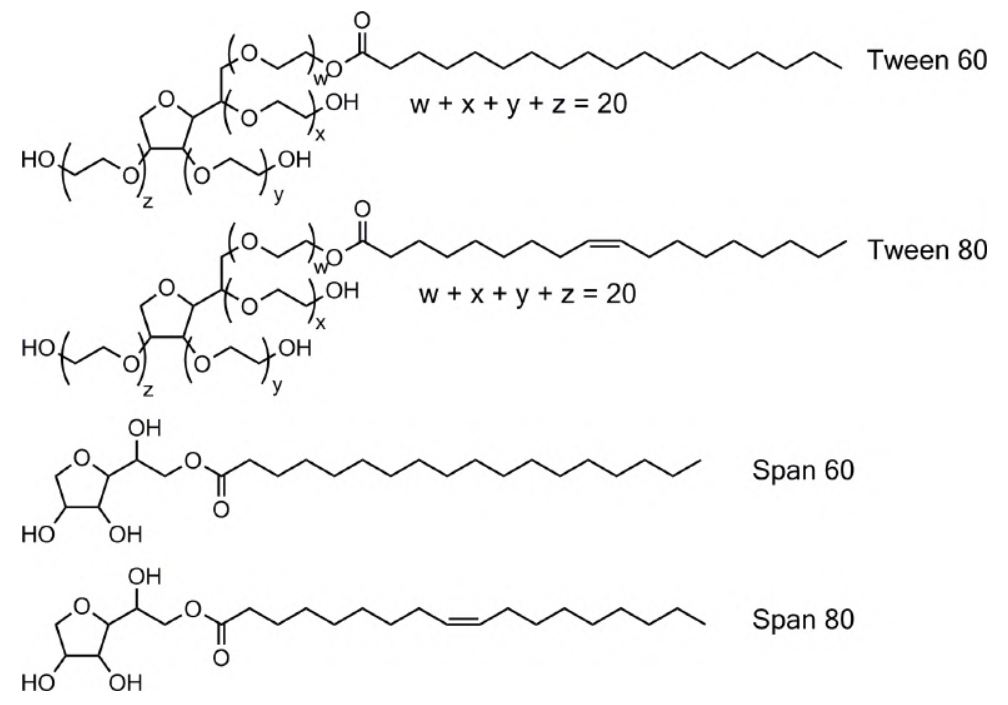

Figura 4.9: Comparação da estrutura química de moléculas de Span e Tween, com variação de sufixo numérico [58]. 
Finalmente, as composições dos óleos modelo para cada um dos petróleos foi definida, conforme vista na Tabela 4.6 abaixo.

\begin{tabular}{ccc} 
& Modelo - A & Modelo - B \\
\hline Primol 352 & 72.5 & 92.5 \\
Vaselina & 26 & 6 \\
Span 85 & 1.06 & 1.06 \\
Tween 85 & 0.44 & 0.44
\end{tabular}

Tabela 4.6: Composições percentuais dos componentes em cada um dos óleos modelo.

A seguir, é possível ver um quadro comparativo (Tabela 4.7) dos resultados obtidos dos petróleos nas seções (4.1) e (4.1.4), comparados com as propriedades dos óleos modelo:

\begin{tabular}{ccccc} 
& Petróleo A & Modelo - A & Petróleo B & Modelo - B \\
\hline$\eta(\mathrm{mPa} . \mathrm{s})$ & 34 & 35.9 & 49 & 51.5 \\
$\rho\left(\mathrm{kg} / \mathrm{m}^{3}\right)$ & 884.2 & 852.1 & 906.4 & 852.7 \\
$\gamma(\mathrm{mN} / \mathrm{m})$ & 8.03 & 10.20 & 9.49 & 15.88
\end{tabular}

Tabela 4.7: Viscosidade, densidade e tensão interfacial (com a água sintética) dos petróleos e seus respectivos óleos modelos a $40^{\circ} \mathrm{C}$.

É possível notar, portanto, que os valores das propriedades dos petróleos e óleos modelos apresentaram resultados satisfatórios apesar de uma pequena divergência entre eles. Esses resultados podem ser consideráveis uma vez que a mimetização simplificada de uma interface tão complexa quanto a de emulsões de petróleo é um desafio relevante. Por isso, a dificuldade de simulação exata das forças de interação entre gotas interfere de uma maneira maior nos resultados das emulsões modelo do que nas propriedades macroscópicas expressas anteriormente. 


\section{4}

\section{Caracterização das emulsões modelo - A}

\subsection{1}

\section{Concentração efetiva}

A síntese da emulsão modelo A é baseada no procedimento descrito na seção (3.2.3.3). Para a geração de uma gama extensa de testes, escolheram-se previamente cortes de água que representassem valores similares aos obtidos com as emulsões de petróleo. Para cada corte de água, foi possível obter uma concentração efetiva da emulsão, parâmetro este que não leva em consideração a água livre do sistema. Sendo assim, as emulsões modelo geradas poderiam ser comparadas com aquelas formadas a partir do petróleo.

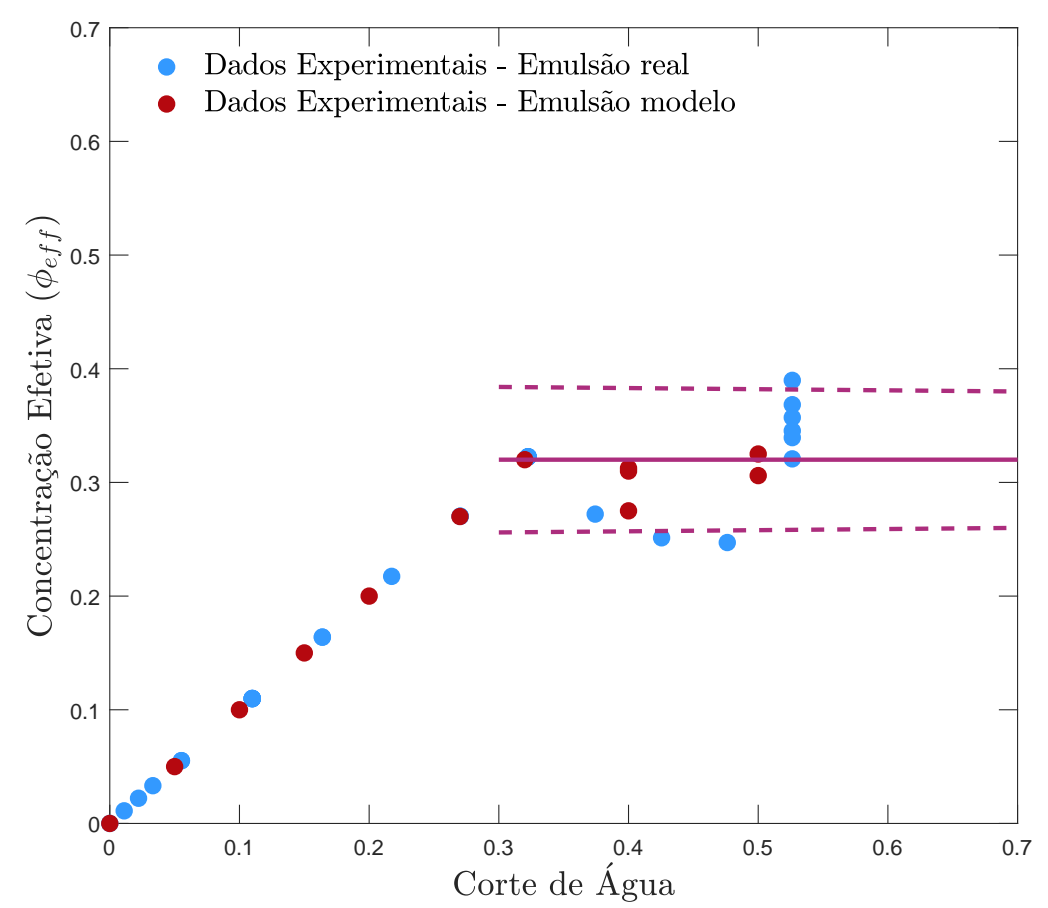

Figura 4.10: Gráfico representativo das emulsões modelo do petróleo A.

Analisando-se a Figura (4.10), é possível observar que o corte de água crítico de ambas as emulsões é $32 \%$. A partir desse valor, os cortes de água escolhidos não representam a mesma concentração efetiva final após a observação da separação de fases, havendo a presença de água livre no sistema. Esse processo de separação de fases pode ser diferente para um mesmo corte de água, o que impossibilita uma repetibilidade exata dos testes. Por causa disso, realizou-se a projeção de uma linha que representasse a dispersão dos dados nos cortes acima do valor crítico, conforme explicado anteriormente. É possível 
perceber, portanto, que os resultados dessas emulsões se mantém dentro da faixa de dispersão dos dados da emulsão real, o que é bastante representativo.

\subsection{2}

\section{Propriedades}

\subsubsection{1}

Viscosidade

Devido a diversos fatores já citados na seção (2.5.1), sabe-se que a reologia das emulsões pode ser influenciada por uma série de fatores. Um comportamento bastante comum nesses sistemas é o chamado shear thinning que pode ser gerado a partir da deformabilidade das gotas, floculação de diferentes magnitudes, entre outros fatores. Cabe notar que esses fatores são dependentes da maneira com que as gotas interagem e, consequentemente, da composição de sua interface.

Conforme explicitado na seção (4.2), a maioria dos resultados experimentais apresentaram comportamento praticamente Newtoniano para grande parte dos cortes de água escolhidos. Por outro lado, emulsões modelo apresentaram o fenômeno de shear-thinning com a taxa de cisalhamento no regime semi-diluído em determinados cortes de água. Tais resultados podem ser observados para dois casos específicos de $5 \%$ e $32 \%$. Em emulsões pouco diluídas, como é o caso de 5\%, foi possível observar que o comportamento Newtoniano permanece mesmo para as emulsões modelo. Já para emulsões mais concentradas, o efeito reológico começa a aparecer gradativamente a medida que há um aumento da fração volumétrica da fase dispersa. 

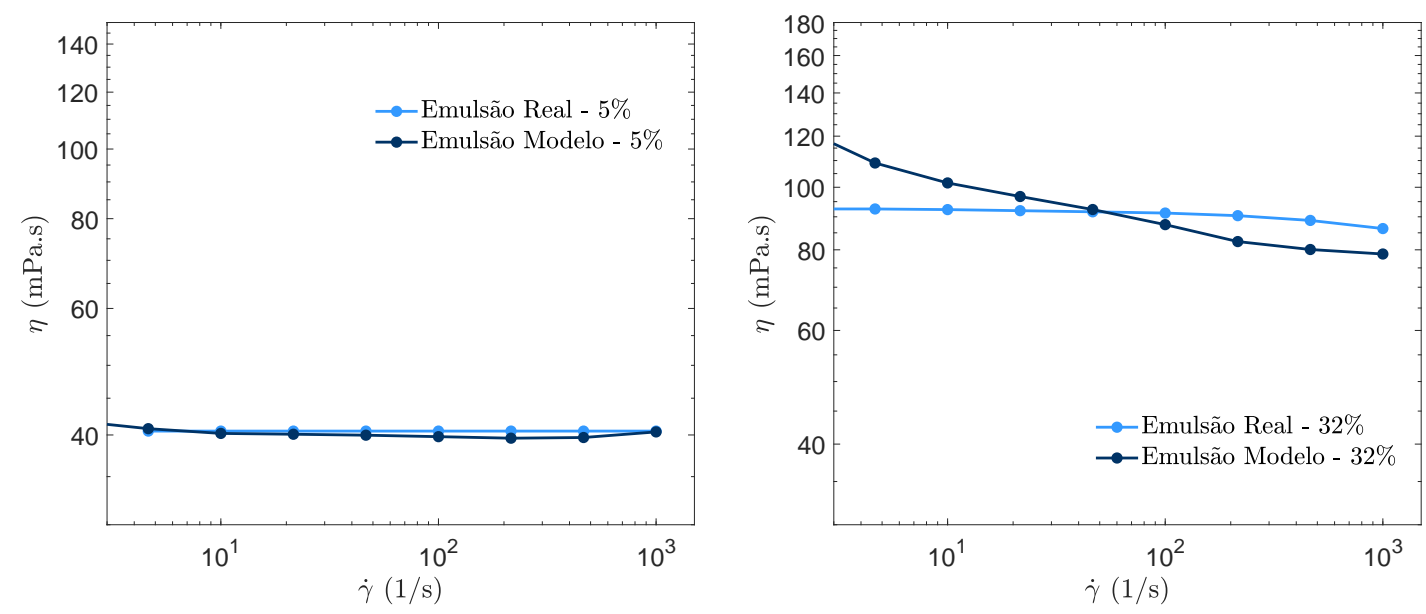

Figura 4.11: (a) Curva de escoamento de emulsões de petróleo A reais e modelo com $5 \%$ de concentração efetiva (b) Curva de escoamento de emulsões de petróleo A reais e modelo com $32 \%$ de concentração efetiva. Para este caso, o comportamento shear-thinning pode ser observado.

Posteriormente a isso, baseando-se em uma análise das interfaces entre as duas emulsões (real e modelo), concluiu-se que o comportamento não-Newtoniano pode ser derivado da diferença de complexidade entre as interfaces presentes em cada uma das emulsões. Conforme já descrito, a interface das emulsões de petróleo é extremamente complexa com a presença de diferentes tipos de macromoléculas, enquanto a interface das emulsões modelo é bem mais simplória e reduzida em alguns poucos componentes.

De acordo com o que foi expresso anteriormente, a camada estabilizante contida nas emulsões terá discrepâncias de espessura $\left(\delta_{\text {real }} \neq \delta_{\text {modelo }}\right)$ devido a diferença estrutural das moléculas constituintes da interface. Essa defasagem na espessura da camada estabilizante influencia as interações entre as gotas, uma vez que a repulsão estérica derivada das estruturas moleculares é diferente para cada um dos casos [59,60]. Dado que as emulsões modelo possuem moléculas que ocasionam uma menor repulsão estérica, a tendência de ocorrência do fenômeno da floculação e, consequentemente, formação de agregados é maior nesse caso. Com isso, se essas floculações forem fracas, forças hidrodinâmicas serão responsáveis pelo quebra desses agregados acarretando no comportamento de shear-thinning observado.

É importante constatar também que em altas taxas de cisalhamento $(\dot{\gamma}>$ $\dot{\gamma}_{c}$ ), a estrutura floculada é quebrada totalmente e a viscosidade das emulsões finalmente atinge um patamar $\left(\eta_{\infty}\right)$. Através desse valor de viscosidade e das concentrações efetivas referentes a cada um dos cortes de água escolhidos, propõe-se uma correlação com o uso da equação de Krieger-Dougherty, aplicada 
anteriormente para a emulsão de petróleo. Para isso, escolheu-se utilizar o resultado da viscosidade em $\dot{\gamma}_{c}=100[1 / s]$ uma vez que esse é um valor intermediário da curva de escoamento realizada.

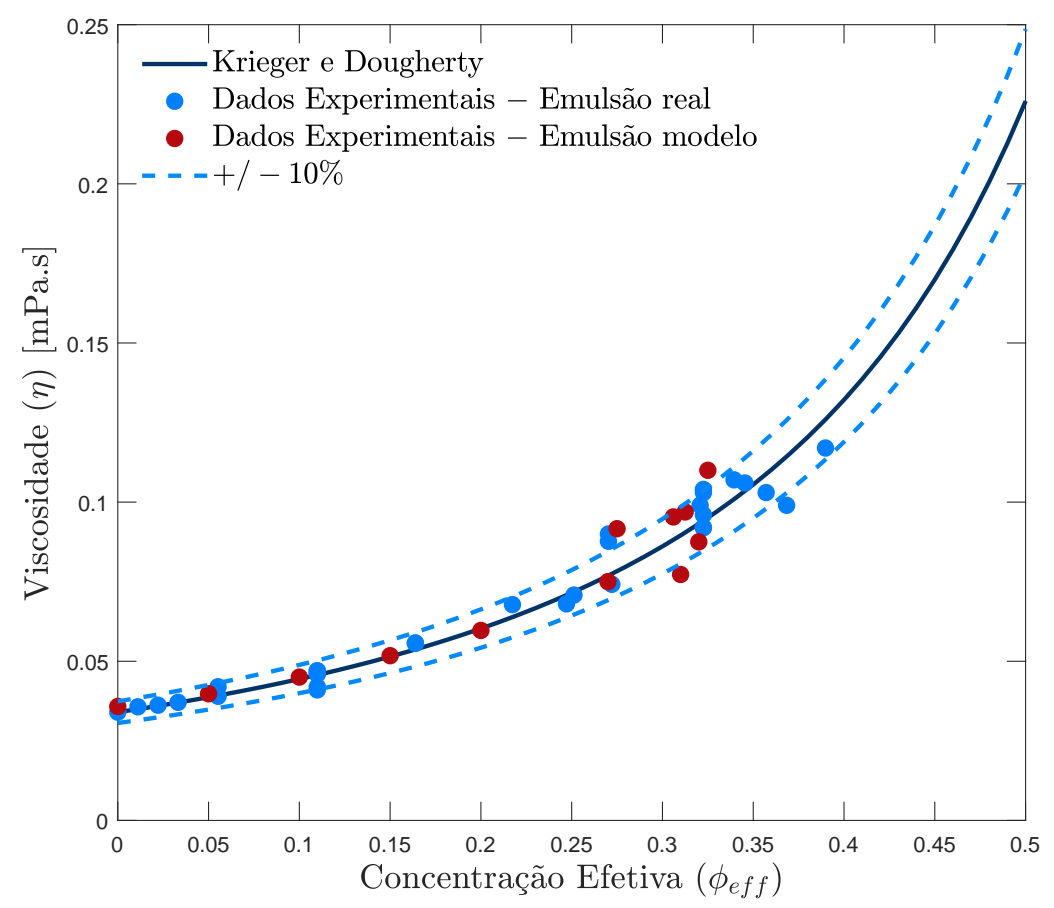

Figura 4.12: Comparação dos dados experimentais das emulsões do petróleo A com a Equação de viscosidade de Krieger-Dougherty.

A comparação entre a curva obtida para as emulsões de petróleo e a emulsão modelo mostra que esses pontos apresentam uma boa correspondência com a curva de Krieger até o valor de corte crítico de 32\%. Para valores acima do corte crítico, conforme já explicitado anteriormente, há uma grande dispersão dos dados experimentais sobretudo devido a diferença de concentração efetiva de água entre um teste e outro.

\subsubsection{2}

\section{Distribuição de tamanho de gotas}

Conforme já visto previamente, parâmetros como diâmetro médio das gotas $\left(D_{\text {medio }}\right)$ e o índice de polidispersidade (PDI) puderam ser obtidos para as emulsões do petróleo A. Uma vez que ambas as propriedades não apresentam uma tendência clara, estabeleceram-se valores médios para cada uma delas: $D_{\text {medio }}=5,99 \mu \mathrm{m}$ e PDI $=0$, 48. Sendo assim, realizou-se o mesmo procedimento para emulsões modelo e valores próximos puderam ser obtidos: $D_{\text {medio }}=6,58 \mu \mathrm{m}$ e PDI $=0,49$. 

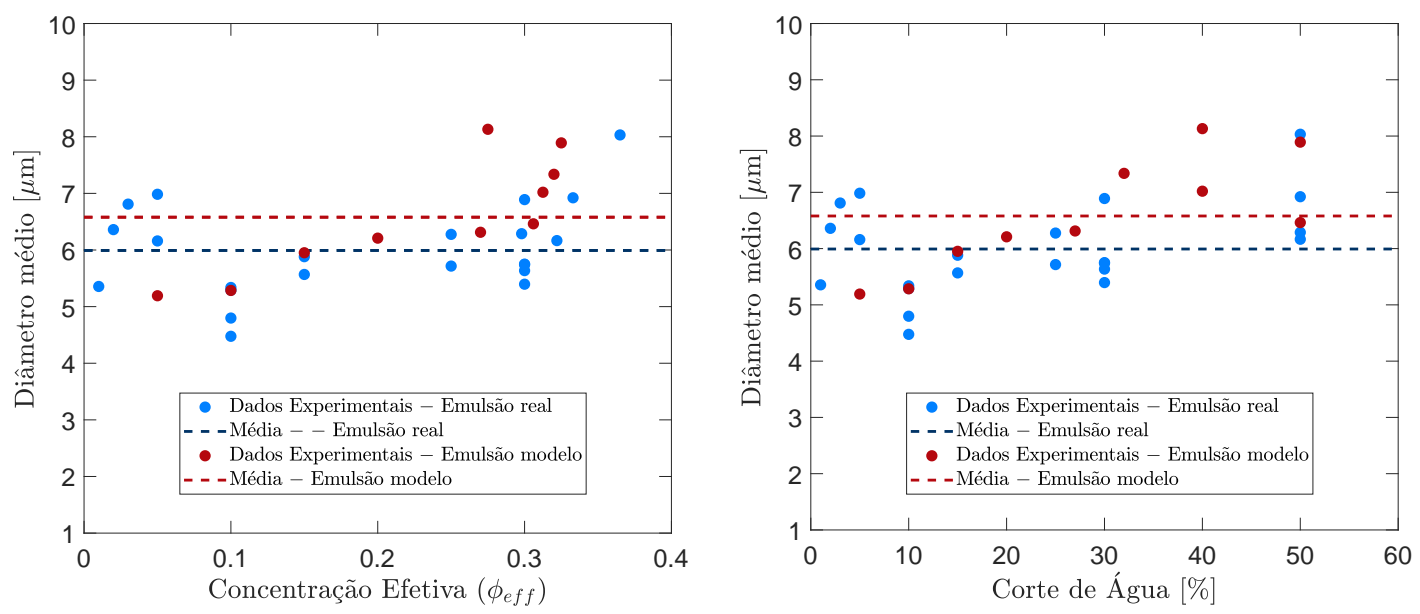

Figura 4.13: Comparação dos diâmetros médios das emulsões reais e modelo do petróleo A com relação (a) à concentração efetiva e (b) ao corte de água.

Com relação as emulsões modelo, é possível perceber que há uma relação entre o diâmetro médio e a concentração efetiva. Através da análise da Figura (4.13), percebe-se que, com o aumento da concentração efetiva, o diâmetro médio encontrado foi maior. Essa característica qualitativa pode ser baseada nas diferenças no processo de emulsificação entre as emulsões de petróleo e modelo.

Conforme visto na seção (3.2.3.2), o cisalhamento realizado pelo ULTRA-TURRAX ${ }^{\circledR}$ ocorre com uma grande transferência de energia para o sistema, na qual a maior parte desta é perdida na forma de calor. Devido a esse excesso de energia fornecida, a emulsão é submetida a maiores esforços mecânicos, gerando gotas menores na emulsão sintetizada. É importante constatar também que devido a natureza do cisalhamento ocorrer de forma localizada no espaço anular entre o rotor e o estator, muitas gotas não são submetidas a esses esforços, o que faz com que o índice de polidispersidade seja maior.

Por outro lado, o procedimento para a síntese das emulsões modelo é extremamente mais eficiente e homogêneo. Como o cisalhamento ocorre ao longo de toda a massa de fluido e não somente em uma região localizada, este é muito mais uniforme quando se comparado ao caso das emulsões de petróleo. Por causa disso, o índice de polidispersidade é ligeiramente inferior para emulsões com corte de água inferiores ao crítico, conforme pode ser visto na Figura (4.14).

Ainda, para valores acima do valor crítico, o PDI aumenta consideravelmente devido às mudanças no procedimento, como visto ao 
longo da seção (3.2.3.3). Dentre essas mudanças, pode-se citar o fato de que parte da emulsificação ocorre com o misturador centralizado ao frasco, o que diminui a eficiência do cisalhamento. Devido à essa centralização do elemento emulsificador, a agitação da amostra pode causar colisões de gotas, que podem coalescer e, assim, o diâmetro médio e o índice de polidispersidade dessas amostras são alterados.
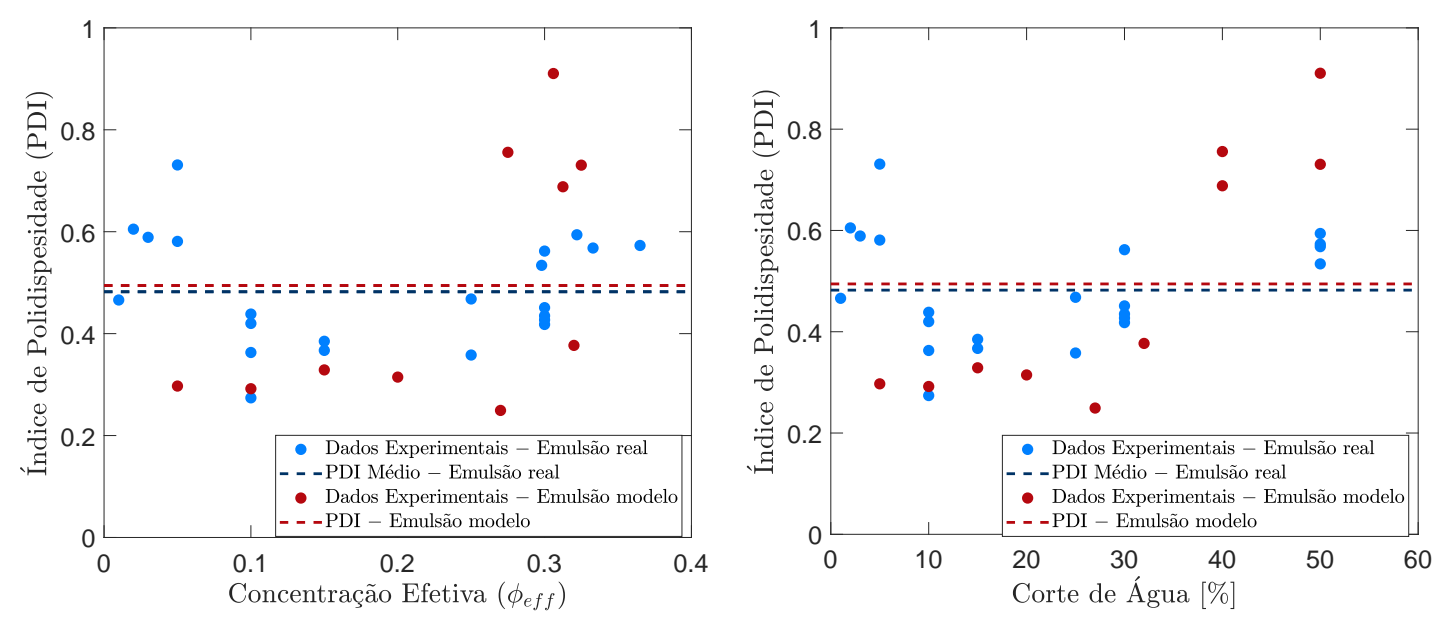

Figura 4.14: Comparação dos índices de polidispersidade das emulsões reais e modelo do petróleo A com relação (a) à concentração efetiva e (b) ao corte de água.

Por fim, valores menores do diâmetro médio com relação à concentração efetiva nos cortes de água abaixo do crítico também podem ser justificados pelo fato de que a energia total transferida para as gotas é constante pois o protocolo de emulsificação é idêntico até este valor. Por isso, a medida que há um aumento na concentração da fase dispersa, a energia é mais bem distribuída, sendo o diâmetro médio das gotas maior. Para o caso das emulsões reais, não é possível perceber tal fenômeno, uma vez que quanto menor a concentração da fase dispersa, uma maior quantidade de energia é dissipada termicamente.

\section{5}

\section{Caracterização das emulsões modelo - B}

\subsection{1}

\section{Concentração efetiva}

De acordo com a utilização do óleo modelo estabelecido na seção (4.3) e o protocolo experimental proposto na seção (3.2.3.3), emulsões modelo do 
petróleo B puderam ser obtidas. Sendo assim, um gráfico representativo da concentração efetiva em função do corte de água pode ser obtido abaixo.

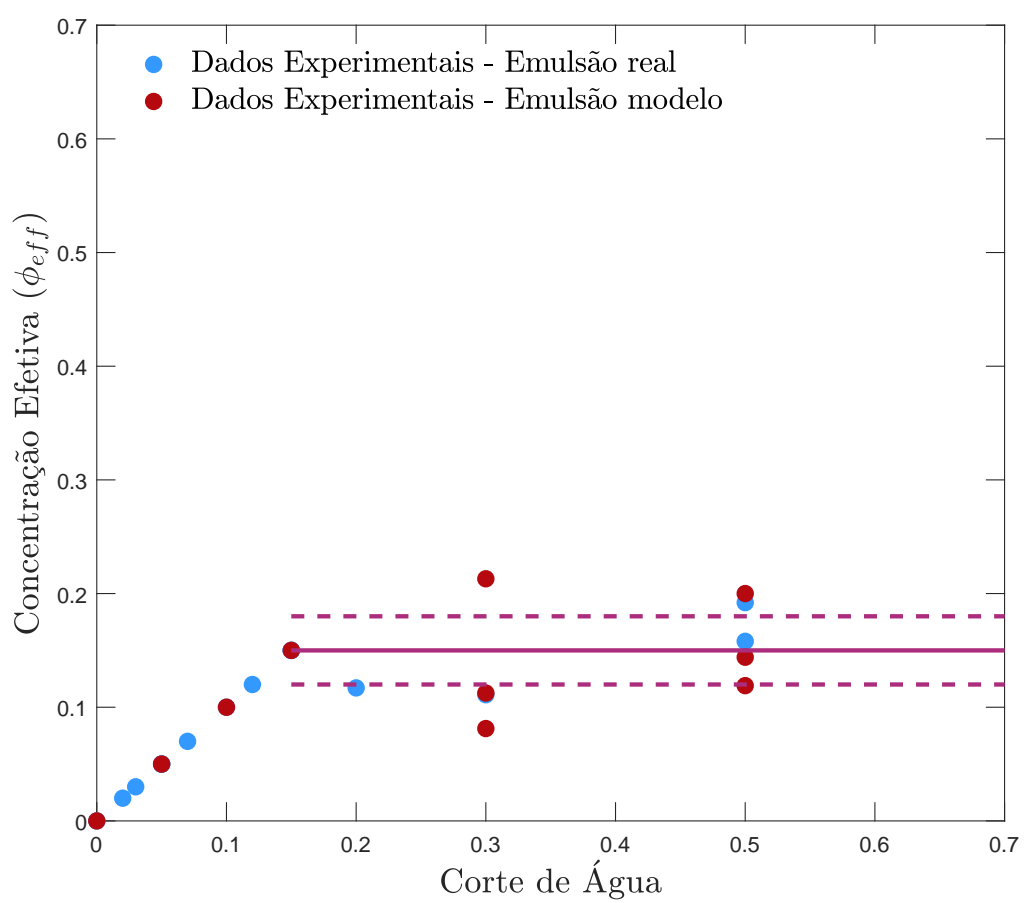

Figura 4.15: Gráfico representativo das emulsões modelo do petróleo B.

Através da observação da Figura 4.15, é possível constatar que o corte de água crítico de ambas as emulsões é 15\%. A partir desse valor, a concentração efetiva das emulsões com cortes de água superiores apresenta grande dispersão. Infelizmente, os dados obtidos não se mantém dentro da faixa limite obtida com os dados da emulsão real, principalmente devido a falta de amostra suficiente de petróleo para que fosse possível a síntese de um número maior de emulsões. Isso possibilitaria uma maior representatividade desta região e a geração de dados mais precisos para a mesma. 


\subsection{2}

\section{Propriedades}

\subsubsection{1}

\section{Viscosidade}

Assim como para as emulsões modelo do petróleo A, foi possível perceber também comportamento shear-thinning para as emulsões modelo do petróleo B, sobretudo em cortes de água próximos ao crítico. Assim, conforme já explicitado na seção (4.4), isso acontece, principalmente, por causa da ocorrência do fenômeno de floculação no sistema, posto que a repulsão estérica entre as gotas é insuficiente.

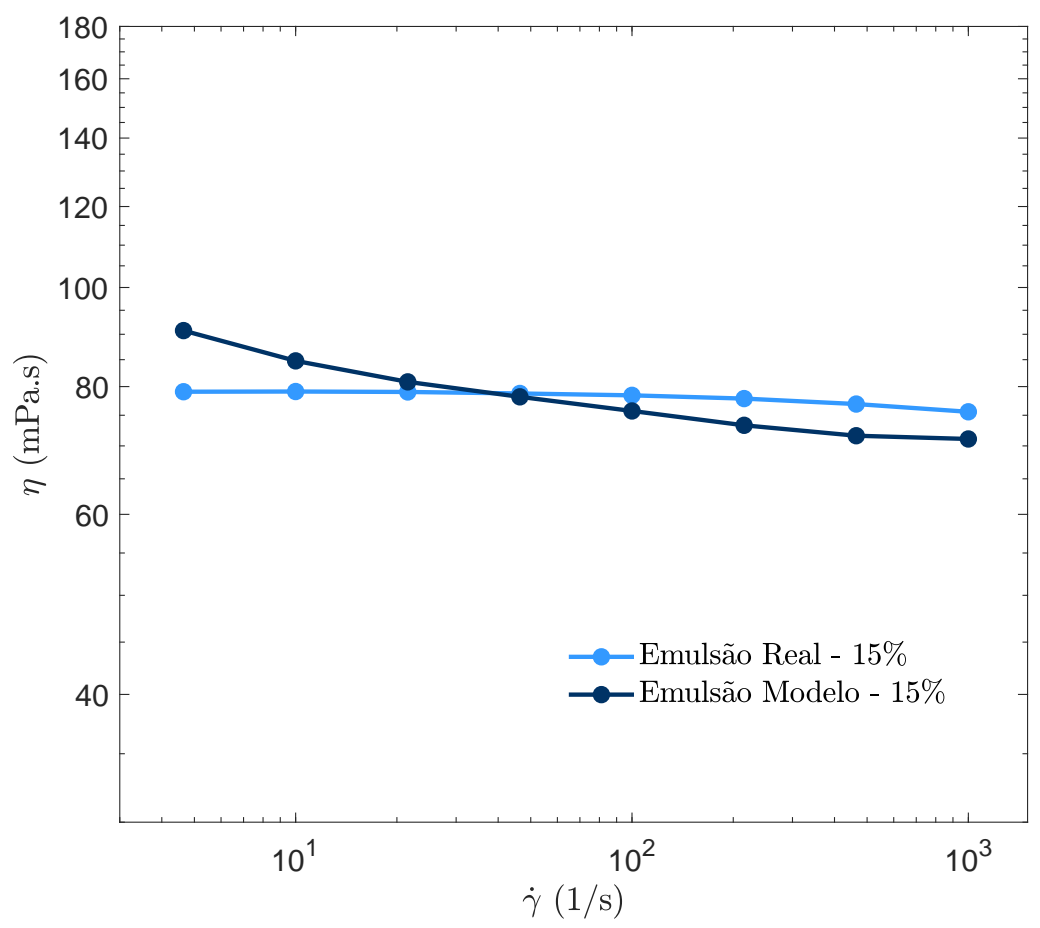

Figura 4.16: Curvas de escoamento de emulsões reais (B) e modelo com $15 \%$ de concentração efetiva.

Através da observação do gráfico anterior, é possível perceber que a viscosidade das emulsões atinge um determinado patamar em taxas de cisalhamentos maiores. Assim como foi feito anteriormente, para as emulsões modelo B, a taxa de cisalhamento escolhida visando a comparação com a emulsão real foi de $\dot{\gamma}_{c}=100[1 / s]$.

Sendo assim, para o caso das emulsões modelo B, a correspondência entre os dados experimentais das duas emulsões apresenta um maior desvio quando se comparada aos das emulsões modelo A. Para este petróleo, é possível 
perceber que emulsões com concentração efetiva abaixo do valor crítico já apresentam viscosidades inferiores as emulsões reais, como é o caso de $\phi_{\text {eff }}=$ 0,1, conforme expresso na Figura (4.17).

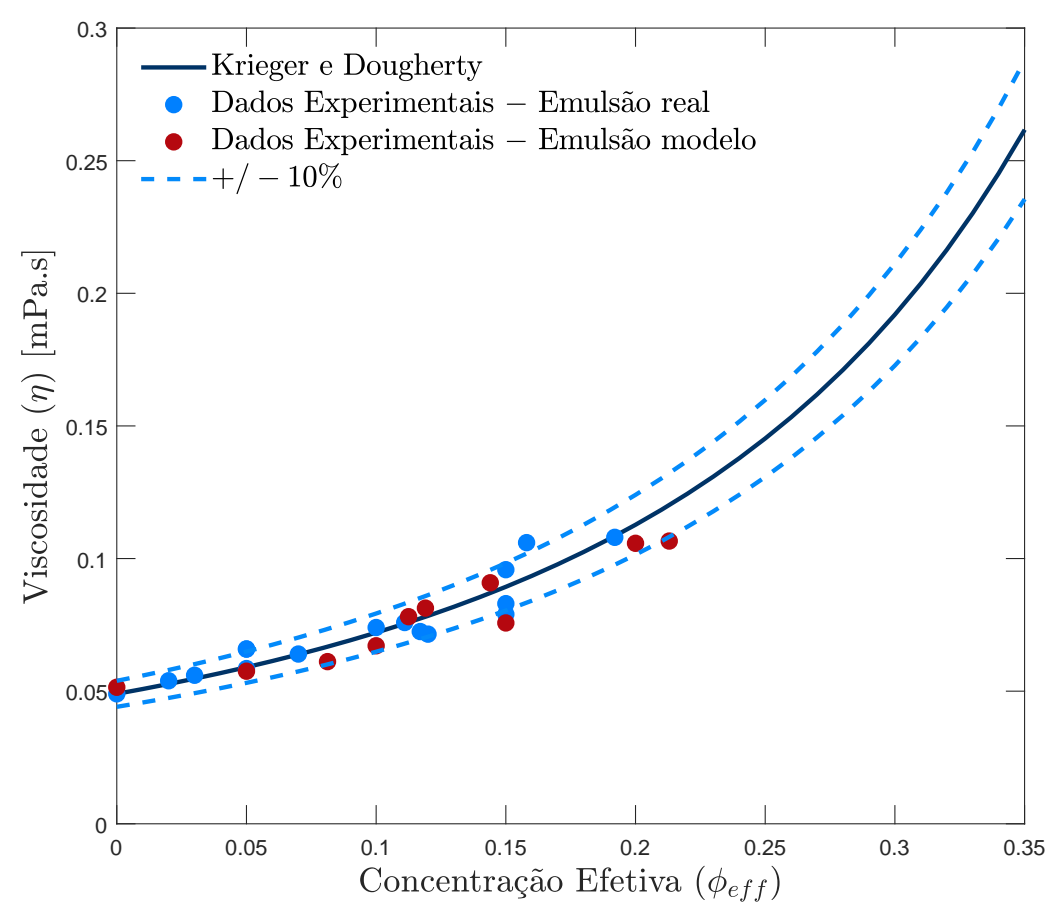

Figura 4.17: Comparação dos dados experimentais das emulsões modelo B com a Equação de viscosidade de Krieger-Dougherty.

Como uma forma de avaliação do gráfico anterior, é importante salientar primeiramente que, em concordância com o que foi visto na seção (4.2.2.1), a viscosidade intrínseca $([\eta]=3,58)$ obtida pelo ajuste de Krieger-Dougherty para a emulsão real do petróleo B explicita que há a formação de agregados com formatos não esféricos. Por isso, é plausível que esses agregados sejam gerados a partir de floculações fortes, fazendo com que o comportamento shear-thinning nessas emulsões não pudesse ser notado.

Somado a isso, é possível frisar que emulsões sintetizadas a partir do óleo modelo A possuíram ajuste satisfatório com as emulsões do petróleo A, que apresentam gotas e agregados esféricos $([\eta]=2,5)$. É importante notar que a composição do óleo modelo $\mathrm{B}$ é feita de forma bastante similar àquela do óleo modelo A, sendo as diferenças baseadas no fato de que o petróleo A possui viscosidade maior do que o B. Por causa disso, um novo equilíbrio entre os dois óleos base usados na confecção do óleo modelo torna-se necessário.

Por outro lado, a escolha dos surfactantes utilizados nas duas emulsões modelo foi a mesma, fazendo com que a interação entre as gotas dificilmente fosse alterada. Consequentemente, devido a falta de conformidade dos dados 
experimentais para as emulsões modelo $B$, seria preciso uma mudança na composição interfacial desse sistema visando a formação de agregados não esféricos, conforme visto nas emulsões de petróleo. Assim, com um arranjo alternativo de surfactantes a viscosidade das emulsões modelo poderia ser mimetizada com uma maior precisão.

\subsubsection{2}

\section{Distribuição de tamanho de gotas}

Assim como visto para as emulsões do petróleo A, analisando-se o diâmetro médio das gotas e o índice de polidispersidade das emulsões reais do petróleo B foi possível observar que, em ambos os casos, os resultados experimentais apresentaram uma distribuição aleatória. Sendo assim, valores médios puderam ser obtidos para os dois parâmetros sendo estes $D_{\text {medio }}=$ $6,15 \mu \mathrm{m}$ e PDI $=0,55$. Com relação a emulsão modelo $\mathrm{B}$, observou-se uma similaridade desses valores médios: $D_{\text {medio }}=6,09 \mu \mathrm{m}$ e PDI $=0,57$.
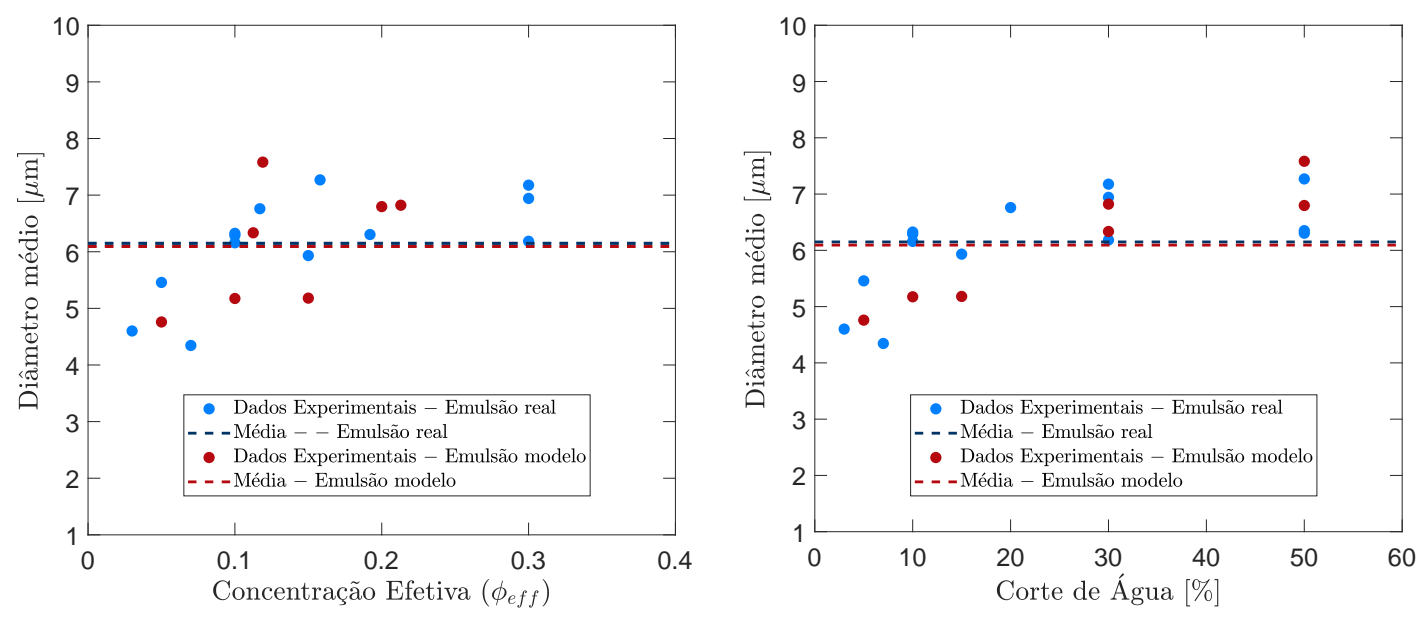

Figura 4.18: Comparação dos diâmetros médios das emulsões reais e modelo do petróleo $\mathrm{B}$ com relação (a) à concentração efetiva e (b) ao corte de água.

Da mesma forma, como nas emulsões modelo A, foi possível observar um aumento do diâmetro médio das gotas e do índice de polidispersidade em cortes de água acima do crítico para as emulsões modelo B. Isso pode ser explicado devido às modificações no protocolo de emulsificação nesses cortes de água através da centralização do misturador ao longo do frasco, tornando o processo menos eficaz e fazendo com que as gotas tenham um maior diâmetro. 

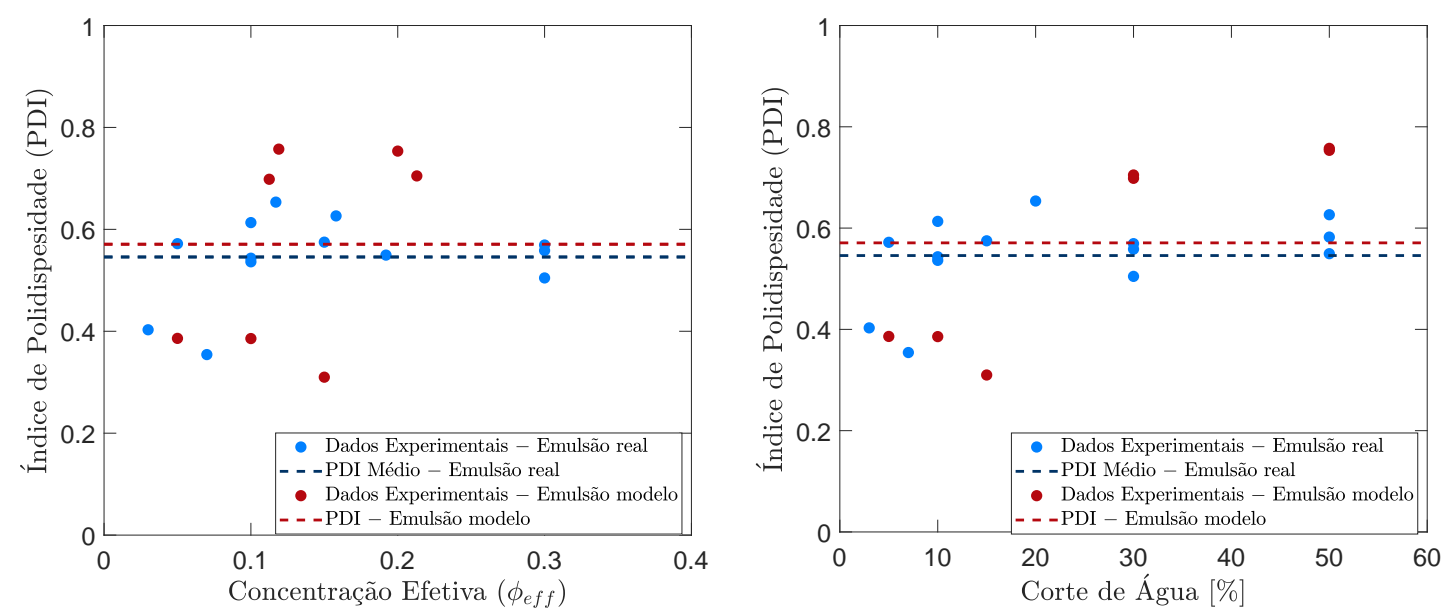

Figura 4.19: Comparação dos índices de polidispersidade das emulsões reais e modelo do petróleo $\mathrm{B}$ com relação (a) à concentração efetiva e (b) ao corte de água.

Portanto, levando-se em conta as diferenças relatadas acima, é notório que, em média, há uma correlação entre os resultados obtidos para a distribuição de tamanho de gotas das emulsões reais e modelo. 


\section{5}

\section{Conclusão}

Ao longo do desenrolar deste trabalho foi possível um desenvolvimento técnico e prático com relação ao estudo de emulsões. Sendo assim, foi proposto a síntese de um modelo que possibilitaria em uma avaliação para uma possível transição gradual do uso de emulsões modelo em substituição com as de petróleo. Isso seria feito nos testes que proporcionam a verificação da eficiência de equipamentos de separação gravitacional em processos industriais.

Como meio de comparação entre os sistemas, parâmetros como viscosidade $(\eta)$ e relativos ao tamanho de gotas $\left(D_{\text {medio }}\right.$ e PDI) devem possuir resultados similares entre emulsões de petróleo e as modelo. Primeiramente, isso é alcançado através do uso de um óleo modelo que possua propriedades macroscópicas relevantes $\left(\eta_{0}, \rho, \gamma\right)$ próximas à do petróleo correspondente.

Com esse objetivo estabelecido, inicialmente, óleos modelo com características macroscópicas muito próximas às dos petróleos A e B puderam ser obtidos. Posteriormente, utilizando-se tais óleos, emulsões modelo foram sintetizadas, apresentando boa correspondência àquelas emulsões reais provenientes do petróleo A. Além disso, a relação entre o corte de água que entraria no separador gravitacional de fases e a concentração efetiva da emulsão que sairia do mesmo foi reproduzida com bastante precisão. Torna-se importante notar que a flexibilidade entre os protocolos utilizados pelas emulsões reais e as modelo representam apenas meios diferentes para realização da síntese dos fluidos que alcançariam a entrada do separador gravitacional. Sendo assim, as diferentes formas de se chegar a essas emulsões não são um empecilho para que o objetivo geral deste trabalho pudesse ser obtido.

Por outro lado, divergências na reologia puderam ser obtidas, uma vez que enquanto emulsões de petróleo possuíam comportamento praticamente Newtoniano para a maioria dos cortes de água escolhidos, emulsões modelo apresentavam um fenômeno de shear-thinning ao longo dos testes experimentais. Acredita-se que isso se deve, principalmente, por diferenças estruturais na espessura da camada estabilizante $\left(\delta_{\text {real }} \neq \delta_{\text {modelo }}\right)$. Conforme já descrito ao longo deste trabalho, isso pode ser explicado com o fato de que a interface em emulsões de petróleo é composta por macromoléculas 
variadas enquanto a de emulsões modelo é baseada em moléculas menores que constituem os surfactantes comerciais. Além disso, pequenas diferenças foram observadas no tamanho médio das gotas acima do corte de água crítico, justamente devido à mudanças no protocolo de emulsificação das emulsões reais e modelo.

Finalmente, emulsões modelo do petróleo B apresentaram resultados com uma correspondência menor quando se comparado às do petróleo A. Todavia, para o caso do das emulsões reais do petróleo B, a comparação dos dados experimentais foi prejudicada pela falta de quantidade do mesmo para a síntese de emulsões reais em cortes de água mais elevados. Cabe ressaltar que, em ambos os sistemas, utilizou-se o mesmo conjunto de surfactantes. Assim, conclui-se que a mimetização de emulsões com viscosidades intrínsecas distintas, como pode ser visto na análise das emulsões de petróleo, deve ser feita com o emprego de agentes tensoativos qualitativamente diferentes, uma vez que esses são responsáveis pela interação entre as gotas e, consequentemente, a formação de agregados.

\section{1 \\ Trabalhos futuros}

Conforme dito anteriormente, foi possível notar que, devido a complexidade do problema proposto, a mimetização de emulsões modelo que representassem as de petróleo pôde ser realizada de maneira satisfatória. Contudo, para que o processo seja fielmente evidenciado, um aprimoramento de alguns fatores ainda pode ser executado visando uma maior similaridade entre as emulsões modelo e real.

Primeiramente, uma análise de toda a termodinâmica envolvida no balanço de forças de interação entre as gotas com os surfactantes utilizados pode ser realizado aspirando entender maneiras que minimizem o efeito de floculação. Assim, será possível também a síntese de uma camada estabilizadora mais espessa de acordo com o grau de adsorção de cada molécula na interface. Além disso, há a possibilidade também de uma representação mais próxima da realidade, em emulsões modelo, da formação de gotas/agregados com formatos diferentes de esféricos, como foi o caso de emulsões do petróleo B.

Portanto, com o total domínio de todos esses fatores, será possível uma síntese mais complexa da interface das emulsões modelo, objetivando-se uma maior semelhança com aquela das emulsões reais. Uma forma para tal pode ser feita através da síntese de surfactantes sintéticos produzidos a partir de reações químicas de moléculas diferentes. Um exemplo é a combinação entre uma 
molécula que apresenta forte ancoragem na superfície e outra mais compatível com o meio de dispersão, fazendo com que a camada estabilizadora seja maior e possibilite uma repulsão estérica entre as gotas que impeça a floculação entre elas. Esse processo pode ser feito através do uso de polímeros de grandes cadeias, por exemplo.

Por fim, seria possível ainda uma modelagem do processo de separação gravitacional tendo por base trabalhos contidos em $[52,53,61]$. Isso possibilitaria simular o processo de separação de fases nos equipamentos com um grau razoável de confiabilidade utilizando-se os modelos encontrados. 


\section{Referências bibliográficas}

[1] RODIONOVA, G. et al. Preparation and characterization of reference fluid mimicking behavior of North Sea heavy crude oil. Fuel, Elsevier BV, v. 135, p. 308-314, nov 2014.

[2] KABALNOV, A. Thermodynamic and theoretical aspects of emulsions and their stability. Current Opinion in Colloid \& Interface Science, Elsevier BV, v. 3, n. 3, p. 270-275, jun 1998.

[3] ZHANG, Z.; MCCLEMENTS, D. J. Overview of nanoemulsion properties: stability, rheology and appearance. In: Nanoemulsions. Elsevier, 2018. p. 21-49.

[4] ADAMS, F. et al. Modern aspects of emulsion science. Royal Society of Chemistry, 2007.

[5] TADROS, T. F. Emulsion formation, stability, and rheology. Emulsion formation and stability, Wiley Online Library, v. 1, p. 1-75, 2013.

[6] BORTOLOTI, G. B. et al. Injeção de emulsões e seu impacto na produção de petróleo. Lajer - Latin American Journal of Energy Research, Latin American Journal of Energy Research, v. 2, n. 1, p. 8, aug 2015.

[7] LANGEVIN, D. et al. Crude oil emulsion properties and their application to heavy oil transportation. Oil \& Gas Science and Technology, EDP Sciences, v. 59, n. 5, p. 511-521, sep 2004.

[8] FONSECA, M. B. et al. Geração de emulsões de petróleo A/O e O/A sem a adição de surfactante. Lajer - Latin American Journal of Energy Research, Latin American Journal of Energy Research, v. 3, n. 1, p. 10, sep 2016.

[9] KELEȘOĞLU, S. et al. Preparation and characterization of reference fluids to mimic flow properties of crude oil emulsions (W/O). Journal of Dispersion Science and Technology, Taylor \& Francis, v. 36, n. 10, p. 1458-1464, 2015.

[10] JING, J. et al. Rheological and emulsification behavior of Xinjiang heavy oil and model oils. The Open Fuels \& Energy Science Journal, v. 9, n. 1, 2016.

[11] SOARES, I. F. Reologia de ácidos orgânicos na interface água/óleo. Dissertação (Mestrado) — Universidade Federal do Rio de Janeiro, 2017.

[12] SILVA, R. L. da. Remoção de ácidos naftênicos presentes na mistura modelo de querosene de aviação utilizando adsorventes tipo perovsquitas modificadas. Dissertação (Mestrado) - Universidade Federal de Pernambuco, 2009. 
[13] RAMALHO, J. B. V. S. Emulsão água-em-óleo no Processamento Primário de Petróleo. CENPES/Petrobrás, 2019.

[14] TAVARES, M. E. E. Análise do Refino no Brasil: estado e perspectivas-uma análise “cross-section”. Tese (Doutorado) — Universidade Federal do Rio de Janeiro, 2005.

[15] ADAMS, J. M.; OLMSTED, P. D. Nonmonotonic models are not necessary to obtain shear banding phenomena in entangled polymer solutions. Physical Review Letters, American Physical Society (APS), v. 102, n. 6, feb 2009.

[16] SJÖBLOM, J. et al. Our current understanding of water-in-crude oil emulsions.: recent characterization techniques and high pressure performance. Advances in Colloid and Interface Science, Elsevier, v. 100, p. 399-473, 2003.

[17] PRADILLA, D. Asphaltenes and Asphaltene model compounds: Adsorption, Desorption and Interfacial Rheology. Tese (Doutorado) Norwegian University of Science and Technology, 2016.

[18] POTEAU, S. et al. Influence of $\mathrm{pH}$ on stability and dynamic properties of asphaltenes and other amphiphilic molecules at the oil-water interface. Energy \& Fuels, ACS Publications, v. 19, n. 4, p. 1337-1341, 2005.

[19] SHAW, D. J. Introduction to colloid and surface chemistry. Butterworths, 1980.

[20] MORAN, M. J. et al. Fundamentals of engineering thermodynamics. John Wiley \& Sons, 2010.

[21] WALSTRA, P. Principles of emulsion formation. In: The Preparation of Dispersions. Veldhofen, 1991. p. 77-92.

[22] CLAESSON, P. M.; BLOMBERG, E.; POPTOSHEV, E. Surface forces and emulsion stability. Marcel Dekker, New York, 2001.

[23] HAMAKER, H. The London —van der Waals attraction between spherical particles. Physica, Elsevier BV, v. 4, n. 10, p. 1058-1072, oct 1937.

[24] SJÖBLOM, J. Emulsions and emulsion stability. CRC Press, 2005.

[25] TADROS, T. F. Emulsion science and technology: a general introduction. Wiley Online Library, 2009.

[26] VERWEY, E. J. W. Theory of the stability of lyophobic colloids. The Journal of Physical Chemistry, ACS Publications, v. 51, n. 3, p. 631-636, 1947.

[27] DERJAGUIN, B. Acta physicochimica. USSR, v. 14, 1941.

[28] HENRIQUEZ, C. J. M. W/O emulsions: formulation, characterization and destabilization. Technischen Universität Cottbus zur Erlangung, 2009.

[29] ZECHA, H. Stabilization of colloidal dispersions by polymer adsorption. Acta Polymerica, Wiley Online Library, v. 32, n. 9, p. 582-582, 1981. 
[30] PETSEV, D. Theory of emulsion flocculation. In: Interface Science and Technology. Elsevier, 2004. p. 313-350.

[31] OOSAWA, F.; ASAKURA, S. Surface tension of high-polymer solutions. The Journal of Chemical Physics, AIP, v. 22, n. 7, p. 1255-1255, 1954.

[32] VRIJ, A. Polymers at interfaces and the interactions in colloidal dispersions. Pure and Applied Chemistry, De Gruyter, v. 48, n. 4, p. 471-483, 1976.

[33] DIMITROVA, T. D. et al. Kinetics of cream formation by the mechanism of consolidation in flocculating emulsions. Journal of Colloid and Interface Science, Elsevier, v. 230, n. 2, p. 254-267, 2000.

[34] PINFIELD, V. J.; DICKINSON, E.; POVEY, M. J. Modeling of combined creaming and flocculation in emulsions. Journal of Colloid and Interface Science, Elsevier, v. 186, n. 1, p. 80-89, 1997.

[35] SALAGER, J.-L. Surfactants types and uses. FIRP booklet, v. 300, 2002.

[36] BIOLINSCIENTIFIC. Interfacial Tension. 2020. Disponível em: $<$ https://www.biolinscientific.com/measurements/interfacial-tension\# lets-find-the-best-tensiometer-for-your-measurements $>$.

[37] GUERTECHIN, L. O. de. Classification of surfactants. Handbook of Cosmetic Science and Technology, CRC Press, p. 431, 2001.

[38] RUCKENSTEIN, E. Microemulsions, macroemulsions and the Bancroft rule. Langmuir, ACS Publications, v. 12, n. 26, p. 6351-6353, 1996.

[39] MEDINA, D. A. V. et al. Solventes supramoleculares: Uma alternativa na microextração em fase líquida para análises cromatográficas. Scientia Chromatographica, v. 9, n. 2, p. 83-100, 2017.

[40] BUTT, H.-J.; GRAF, K.; KAPPL, M. Physics and chemistry of interfaces. John Wiley \& Sons, 2013.

[41] BANCROFT, W. D. The theory of emulsification. The Journal of Physical Chemistry, ACS Publications, v. 17, n. 6, p. 501-519, 2002.

[42] TAKAMURA, A. et al. Effects of Tween and Span group emulsifiers on the stability of $O / W$ emulsions. Chemical and Pharmaceutical Bulletin, The Pharmaceutical Society of Japan, v. 27, n. 12, p. 2921-2926, 1979.

[43] GURKOV, T. et al. Composition of mixed adsorption layers of non-ionic surfactants an oil/water interfaces. Colloids and Surfaces A: Physicochemical and Engineering Aspects, Elsevier, v. 87, n. 2, p. 81-92, 1994.

[44] ANTONPARR. The influence of particles on suspension rheology. 2019. Disponível em: <https://wiki.anton-paar.com/br-pt/ a-influencia-de-particulas-na-reologia-de-suspensao/ $>$.

[45] MARCHESSAULT, R. H.; SKAAR, C. Surfaces and Coatings Related to Paper and Wood: A Symposium. Syracuse University Press, 1967. 
[46] DERKACH, S. Rheology on the way from dilute to concentrated emulsions. International Review of Chemical Engineering, Praise Worthy Prize, v. 2, n. 3, p. 465-472, 2010.

[47] SAIKI, Y.; PRESTIDGE, C. A.; HORN, R. G. Effects of droplet deformability on emulsion rheology. Colloids and Surfaces A: Physicochemical and Engineering Aspects, Elsevier, v. 299, n. 1-3, p. 65-72, 2007.

[48] TADROS, T. Fundamental principles of emulsion rheology and their applications. Colloids and Surfaces A: Physicochemical and Engineering Aspects, Elsevier BV, v. 91, p. 39-55, nov 1994.

[49] BICERANO, J.; DOUGLAS, J. F.; BRUNE, D. A. Model for the viscosity of particle dispersions. Journal of Macromolecular Science, Part C, Taylor \& Francis, v. 39, n. 4, p. 561-642, 1999.

[50] PAL, R.; RHODES, E. Viscosity/concentration relationships for emulsions. Journal of Rheology, Society of Rheology, v. 33, n. 7, p. 1021-1045, oct 1989.

[51] RODRIGUEZ, B.; KALER, E.; WOLFE, M. Binary mixtures of monodisperse latex dispersions. 2. Viscosity. Langmuir, ACS Publications, v. 8, n. 10, p. 2382-2389, 1992.

[52] ALEEM, W.; MELLON, N. Model for the prediction of separation profile of oil-in-water emulsion. Journal of Dispersion Science and Technology, Taylor \& Francis, v. 39, n. 1, p. 8-17, 2018.

[53] GRIMES, B. Population balance model for batch gravity separation of crude oil and water emulsions. Part I: model formulation. Journal of Dispersion Science and Technology, Taylor \& Francis, v. 33, n. 4, p. 578-590, 2012.

[54] MANNING, F. S.; THOMPSON, R. E. Oilfield processing of petroleum: Crude oil. Pennwell books, 1995. v. 2.

[55] STEWART, M.; ARNOLD, K. E. Surface Production Operations: Design of Oil Handling Systems and Facilities. Elsevier, 2011. v. 1.

[56] D'ALOIA, F. A. Análise exergética de sistemas de compressão de gás em plataformas offshore de produção de petróleo. Tese (Doutorado) Universidade de São Paulo, 2017.

[57] PAUL, E. L.; ATIEMO-OBENG, V. A.; KRESTA, S. M. Handbook of industrial mixing: science and practice. John Wiley \& Sons, 2004.

[58] BARTELDS, R. et al. Niosomes, an alternative for liposomal delivery. PloS one, Public Library of Science, v. 13, n. 4, 2018.

[59] WU, X.; VEN, T. Van de; CZARNECKI, J. Colloidal forces between emulsified water droplets in toluene-diluted bitumen. Colloids and Surfaces A: Physicochemical and Engineering Aspects, Elsevier, v. 149, n. 1-3, p. 577-583, 1999.

[60] TCHOUKOV, P. et al. Role of asphaltenes in stabilizing thin liquid emulsion films. Langmuir, ACS Publications, v. 30, n. 11, p. 3024-3033, 2014. 
[61] GRIMES, B. et al. Population balance model for batch gravity separation of crude oil and water emulsions. Part II: Comparison to experimental crude oil separation data. Journal of dispersion science and technology, Taylor \& Francis, v. 33, n. 4, p. 591-598, 2012. 